YATIONAL, SEREAT OF. ETANUL TIDE
LIBRABT

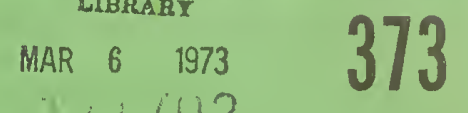

\title{
Radio-Frequency Measurements
} in the NBS Institute for Basic Standards

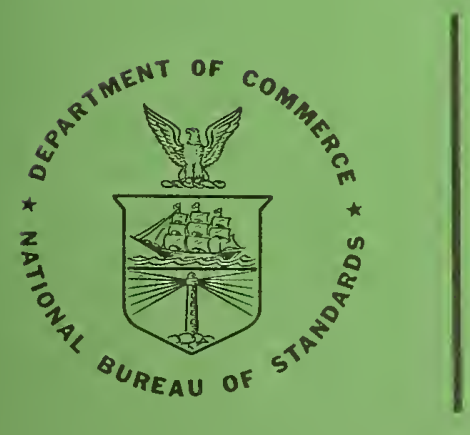

U.S. DEPARTMENT OF COMMERCE National Bureau of Standards 


\section{NATIONAL BUREAU OF STANDARDS}

The National Bureau of Standards was established by an act of Congress March 3. 1901. Teday, in addition to serving as the Nation's central measurement laboratory, the Bureau is a principal focal point in the Federal Government for assuring maximum application of the physical and engineering sciences to the advancement of technology in industry and commerce. To this end the Bureau conducts research and provides central national services in four broad program areas. These are: (1) basic measurcments and standards. (2) materials measurements and standards. (3) technological measurements and standards, and (4) transfer of technology.

The Bureau comprises the Institute for Basic Standards, the Institute for Materials Research, the Institute for Applied Technology, the Center for Radiation Research, the Center for Computer Sciences and Technology, and the Office for Information Programs.

THE INSTITLTE FOR BASIC STANDARDS provides the central basis within the United States of a complete and consistent system of physical measurement; coordinates that system with measurement systems of other nations; and furnishes essential services leading to accurate and uniform physical measurements throughout the Nation's scientific community, industry, and commerce. The Iristitute consists of an Office of Measurement Services and the following technical divisions:

Applied Mathematics-Electricity--Metrology-Mechanics-Heat-Atomic and Molecular Physics-Radio Physics "-Radio Engineering "- Time and Frequency "-Astrophysics "-Cryogenics."

THE INSTITUTE FOR MATERIALS RESEARCH conducts materials research leading to improved methods of measurement standards, and data on the properties of well-characterized materials needed by industry, commerce, educational institutions, and Government; develops. produces, and distributes standard reference materials; relates the physical and chemical properties of materials to their behavior and their interaction with their environments; and provides advisory and research services to other Government agencies. The Institute consists of an Office of Standard Reference Materials and the following divisions:

Analytical Chemistry-Polymers-Metallurgy-Inorganic Materials_Physical Chemistry: THE INSTITUTE FOR APPLIED TECHNOLOGY provides technical services to promote the use of available technology and to facilitate technological innovation in industry and Government; cooperates with public and private organizations in the development of technological standards, and test methodologies; and provides advisory and research services for Federal, state, and local government agencies. The Institute consists of the following technical divisions and offices:

Engineering Standards-Weights and Measures - Invention and Innovation - Vehicle Systems Research-Product Evaluation-Building Research-Instrument Shops-Measurement Engineering-Electronic Technology-Technical Analy'sis.

THE CENTER FOR RADIATION RESEARCH engages in research, measurement, and application of radiation to the solution of Bureau mission problems and the problems of other agencies and institutions. The Center consists of the following divisions:

Reactor Radiation-Linac Radiation-Nuclear Radiation-Applied Radiation.

THE CENTER FOR COMPUTER SCIENCES AND TECHNOLOGY conducts research and provides technical services designed to aid Government agencies in the selection, acquisition, and effective use of automatic data processing equipment; and scrves as the principal focus for the development of Federal standards for automatic data processing equipment, techniques, and computer languages. The Center consists of the following offices and divisions:

Information Processing Standards-Computer Information - Computer Services - Systems Development-Information Processing Technology.

THE OFFICE FOR INFORMATION PROGRAMS promotes optimum dissemination and accessibility of scientific information generated within NBS and other agencies of the Federal government: promotes the development of the National Standard Reference Data System and a system of information analysis centers dealing with the broader aspects of the National Measurement System, and provides appropriate services to ensure that the NBS staff has optimun accessibility to the scientific information of the world. The Office consists of the following organizational units:

Office of Standard Reference Data-Clearinghouse for Federal Scientific and Technical Information -Office of Technical Information and Publications-Library-Office of Public Information-Office of International Relations.

Headquariers and Laboratories at Caithersburg. Maryland, unless otherwise noted: mailing address Washington. D.C. 20234. Located at Boulder. Colorado 80302 . 
UNITED STATES DEPARTMENT OF COMMERCE

Maurice H. Stans, Secretary

NATIONAL BUREAU OF STANDARDS - A. V. Astin, Director

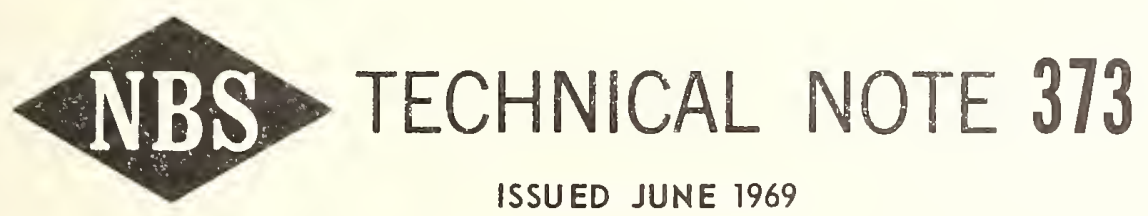

Nat. Bur. Stand. (U.S.), Tech. Note 373, 116 pages (June 1969)

CODEN: NBTNA

\title{
RADIO - FREQUENCY MEASUREMENTS IN THE NBS INSTITUTE FOR BASIC STANDARDS
}

\author{
EDITED BY ROBERT S. POWERS \\ AND WILBERT F. SNYDER \\ Institute for Bosic Standards \\ Notional Bureau of Standards \\ Boulder, Colorodo 80302
}

\begin{abstract}
NBS Technical Notes are designed to supplement the Bureau's regular publications program. They provide a means for making availabie scientific data that are of transient or limited interest. Technical Notes may be listed or referred to in the open literature.
\end{abstract}




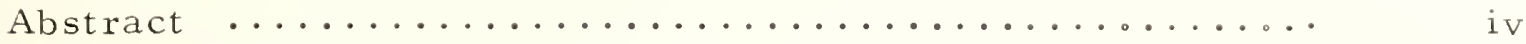

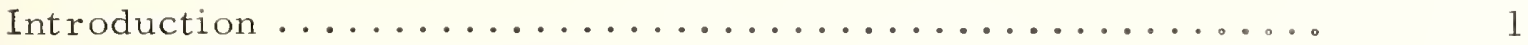

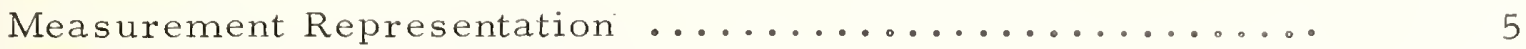

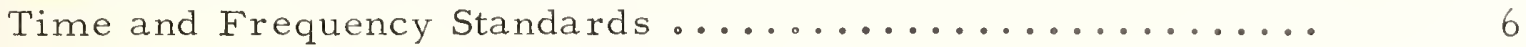

Time and Frequency Dissemination ................. 7, 8,9,10

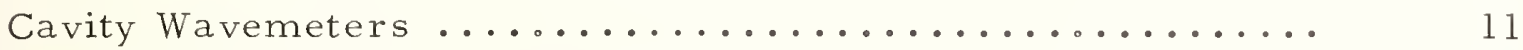

Stability of Stable Oscillators and Other Signal Sources ...... 12

RF Power in Coaxial Systems: ................... 13, 14

Dry Load Calorimetric Measurement and Coaxial

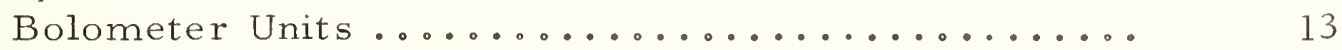

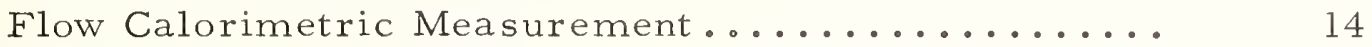

Microwave Power: ..........................15, 16, 17

Coaxial Bolometer Units, Adapter Method .......... 15

Waveguide Bolometer Units: ................ 16, 17

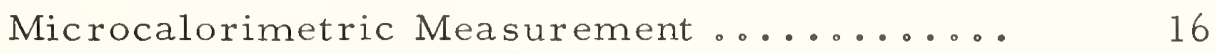

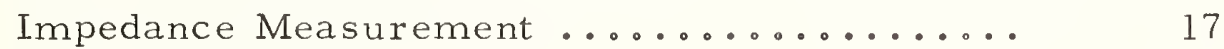

RF Peak-Pulse Power in Coaxial Systems ................ 18

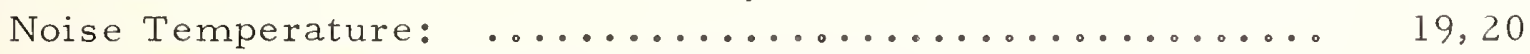

Noise Temperature, Coaxial Systems .............. 19

Effective Noise Temperature, Waveguide Systems .... 20

RF Voltage, Coaxial Systems ..................... 21

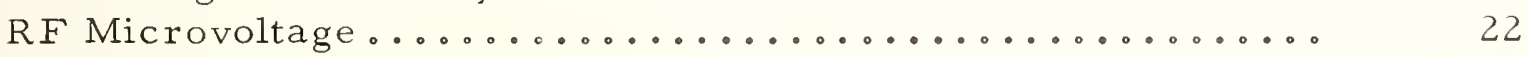

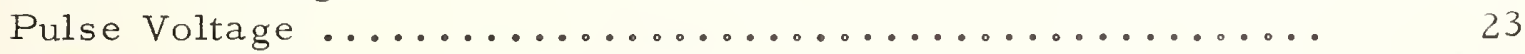

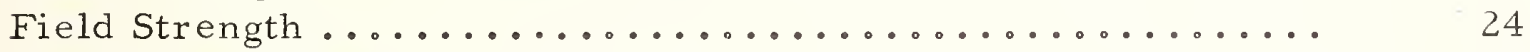

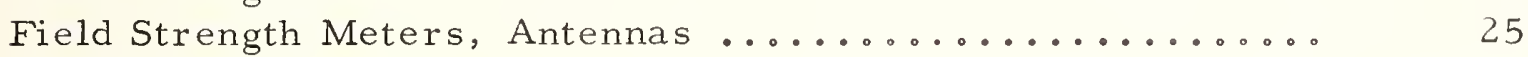

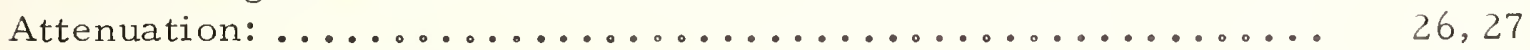

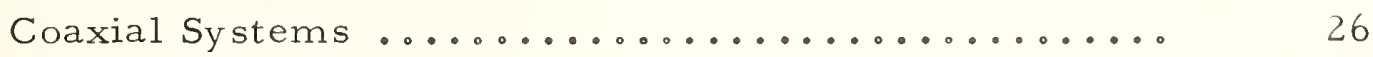

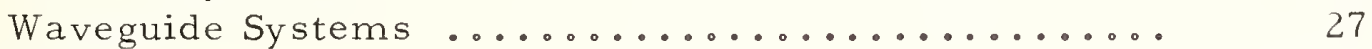

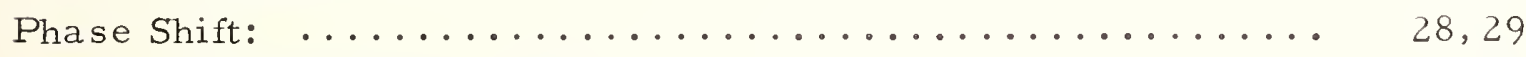

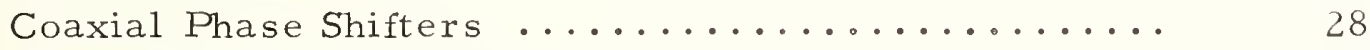

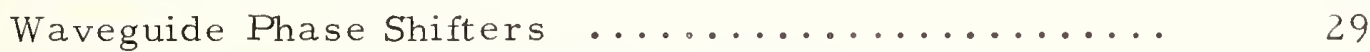

Reflection Coefficient Magnitude of Waveguide Devices ...... 30

Distributed Parameters in Coaxial Systems .............. 31

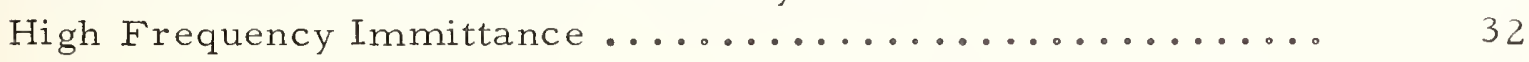

Large Complex Relative Dielectric Permittivity .......... 33

High Frequency Relative Dielectric Permittivity ........... 34

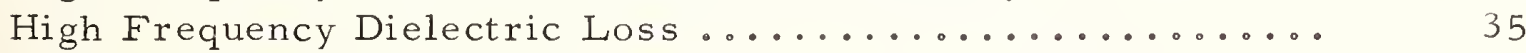

Microwave Complex Relative Dielectric Permittivity: .... 36,37

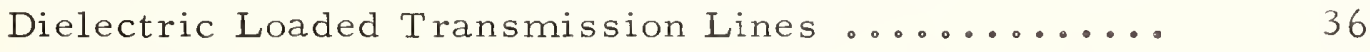

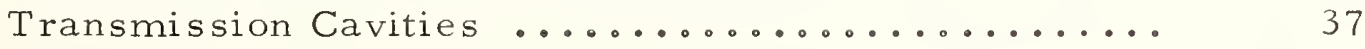




\section{ABSTRACT}

This volume is a collection of diagrams, tables, and text material, which has been assembled to show the interrelationships between various radio frequency measurements made by the Institute for Basic Standards (IBS). In particular, the measurements are those which lead to services provided to the public or to other government agencies. These services include not only calibrations made for fees, but the broadcast services of the four NBS radio stations. Measurements made as part of the IBS research and development program are not included.

The information included is designed to give the users and potential users of the radio frequency services a clearer understanding of the origins of the measurement output of IBS in this field.

Key words: accuracy; calibration services; measurements; measurement techniques; radio frequency; uncertainties of measurement. 


\title{
RADIO-FREQUENCY MEASUREMENTS IN THE NBS INSTITUTE FOR BASIC STANDARDS
}

\author{
Edited by Robert S. Powers \\ and Wilbert F. Snyder
}

\section{INTRODUCTION}

This volume is being published to give users of the National Bureau of Standards calibration services at radio frequencies a collection of information about the uncertainties given in Report of Calibration. It is a collection of diagrams, tables, and text material which shows the interrelationships among various radio frequency measurements made by the Institute for Basic Standards (IBS). In particular, the measurements are those which lead to services provided to the public or to other government agencies. These services include not only calibrations made for fees, but also the broadcast services of the four NBS radio stations. Measurements made as part of the IBS research and development program are not included.

It is hoped that this information will give the users and potential users of the radiowfequency services a clearer understanding of the origins of the measurement output of IBS in this field.

Generally, the sequence of measurements which leads to an output calibration or other service is shown by measurement flow charts. The notations of these charts are explained on page 5.

Each measurement may have errors arising from many sources. Typical values of these errors are given in one of two ways. In most cases, known or suspected sources of bias error are listed along with typical values of the random errors (or imprecision). In addition, in many instances, Error Flow Diagrams have been included to show more explicitly the way the various sources of uncertainty enter the measurement chain.

The study that led to these charts and tables was initiated to provide the management of the Institute and its divisions with a fairly detailed analysis of how the elements of the NBS part of the national system of radio measurements relate to each other. This was to help identify those parts of the "NBS subsystem of radio measurement" which could make the greatest contributions to improving the output of 
the subsystem as a whole, if given the limited funds that are available. The principal suggestion arising from the study was that significant gains in the overall performance of the IBS system could result from improvement in the treatment and reporting of the known error sources. At this time, a program to improve the reporting of uncertainties is under way.

This information is current as of approximately January, 1969. It serves to update, and present in a different form, some of the information in NBS Technical Note 262.*

The term "error" means the difference between the value actually measured and some "true value" which would have been obtained from a hypothetical "perfect" experiment. ** The term "uncertainty" refers to the range within which the metrologist believes the actual error, as defined above, does fall. Thus, an error does have a particular value, although the metrologist does not know that value; the uncertainty is a range of values specified by the metrologist to indicate his best knowledge about the likely value of the error.

The phrase "bias uncertainties" has been used rather than the more commonly used "systematic errors" to express the uncertainty about the sources of error listed. If the error itself could be evaluated, a correction would be made. The phrase "random error" is us ed to represent observed deviations of measurements from the mean of a set of measurements.

In perusing these pages, the reader will observe that the values for errors are sometimes shown with plus and minus signs ( \pm ) and sometimes without the signs. There is no significant difference between the two designations, it being mostly a matter of personal choice. Prepared material for this volume came from a number of sources, and no particular effort was made to bring the use of plus and minus signs into uniformity. To do so would have required extensive redrafting and retyping.

* NBS Technical Note 262, Accuracy in measurements and calibrations, 1965, edited by W. A. Wildhack, R. C. Powell, and H. L. Mason, issued June 15, 1965.

** The concept of "true value" is discussed in some detail by Churchill Eisenhart in his paper, Realistic evaluation of the precision and accuracy of instrument calibrating systems, J. Res. NBS 67C, 161 (1963). 


\section{Bias Uncertainties:}

The uncertainties shown in these tables are typical values and in general may vary somewhat, depending on the range of frequency, the magnitude of the measurand (the quantity being measured), or the nature of the particular device being calibrated. Sometimes the magnitude is given as a single typical value and sometimes as a range of values. More details can be obtained from the person(s) listed under Personnel.

Where error flow diagrams were available, they were used in place of tables.

\section{Random Errors:}

In general, the number given for the random error represents approximately three times the estimated standard deviation ( $3 \sigma$ ) for a representative set of measurements.

\section{Total Uncertainty:}

The total uncertainty figure represents the sum of the estimated bias uncertainties and the $3 \sigma$ random errors. Note that in a rather large number of the radio frequency measurements the random errors are quite negligible with respect to the bias uncertainties. The terms "limits of uncertainty" and "limits of error" are often used interchangeably with "total uncertainty."

\section{Uncertainty quoted customer:}

The uncertainty quoted to the customer is not always equal to the total uncertainty as described above. It is sometimes larger due to round-off, and sometimes larger to include an additional margin of safety in the estimate of possible error. Reporting practice is tending more and more toward quoting the actual number obtained as above, rather than the larger figures.

\section{Notes:}

The notes include information and comments which are intended to clarify the diagrams and charts or otherwise, help the reader to understand some aspect of the measurement. 


\section{References:}

The lists of references are not intended to be complete, but rather to supply the reader with at least one source of published information concerning the measurement, as made by NBS. Sometimes no such sources are available. Where references are given, they often include extensive bibliographies on the subject measurement. Unpublished information can often be obtained from the personnel whose names are listed.

\section{Personnel:}

The name of the person(s) responsible for each measurement is given. Anyone requiring more detailed information about any of the reasurements is invited to write to the appropriate person at

$$
\begin{aligned}
& \text { National Bureau of Standards } \\
& \text { Institute for Basic Standards } \\
& \text { Boulder, Colorado } 80302
\end{aligned}
$$

or telephone (303) 447-1000 and ask for the person named.

These names are also listed to give credit to those who helped to prepare the charts and other information on the various measurements. 


\section{MEASUREMENT REPRESENTATION}

The Symbol:

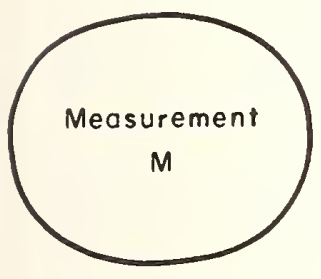

u

Meter
Represents:

A meosurement technique or device

The output of one meosurement and input to other measurements; e.g., a calibroted meter hoving uncertainty $u$. The uncertainty is expressed either os a percentoge, as a fraction, or as a

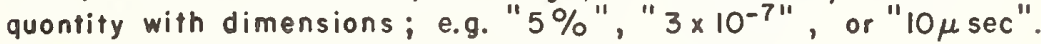
These outputs are usually availoble to NBS customers.

A measurement output ovailable to NBS customers. 


\section{TIME AND FREQUENCY STANDARDS}

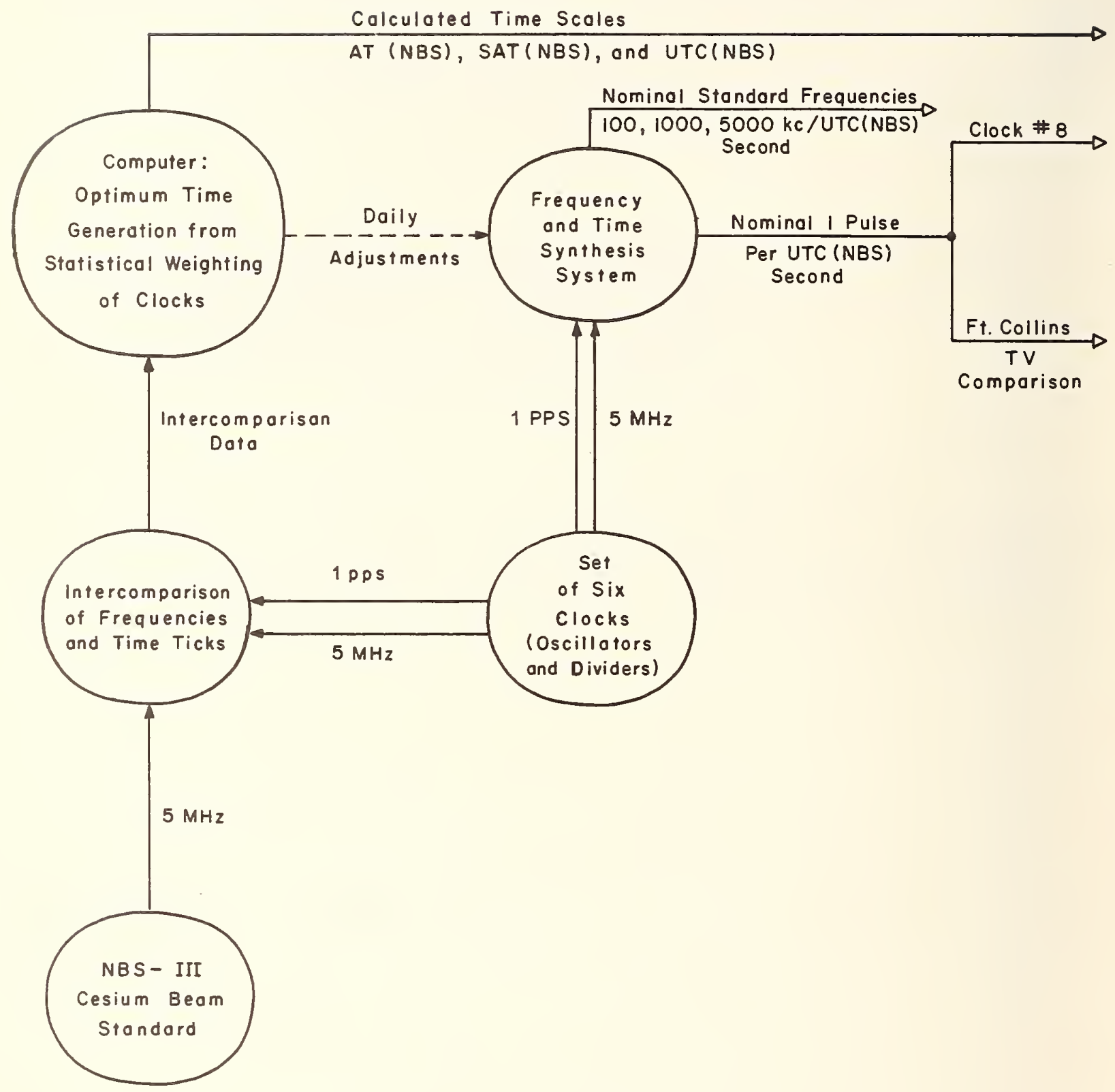


Bias Uncertainties:

Source of Uncertainty

Magnitude of $\overline{\mathrm{H}(\mathrm{x})} \quad(3 \sigma$ limits $)$

Overlap of neighboring transitions

Use of $\mathrm{H}(\mathrm{x})^{2}$ for $\mathrm{H}^{2}(\mathrm{x})$

Distortion arising from $\mathrm{C}$-field nonuniformity

Cavity mistuning

Uncertainty in magnitude of cavity phase shift

Doppler shifts

Microwave power level

Spectral purity of excitation

Second harmonic distortion of servo modulation

Miscellaneous servo system effects

Multiplier chain transient phase shifts
Fractional Uncertainty

0.3

1. 0

0,1

0.5

0.1

3. 0

1. 0

1. 0

2. 0

0.5

2. 0

1.0

$\underline{\text { Random Errors }}$ (one hour averaging, $3 \sigma$ ): 0.5

Total Uncertainty (square root of sum of squares): 
used to adjust the frequencies of the five working sources, when necessary, as shown on page 6 .

The standard signals used to control the NBS broadcast stations are generated from one of the working oscillators. The AT (NBS) time scale is derived directly from the frequency of the cesium atom, as realized by NBS-III. The UTC (NBS) scale is generated from a signal having a frequency offset which has been promulgated by the Bureau International de l'Heure to make the time scale correspond approximately to the UT2 time scale.

\section{USNO and NBS Time Coordination}

On 1 October 1968 the epochs of the UTC (NBS) and the UTC (USNO) time scales were within one microsecond of each other. Since there was a slight rate difference between the master clocks at these two institutions, this time coincidence would not have continued. Hence, the USNO and the NBS agreed to each change their rates by nominally half the difference on 1 October 1968, and from thenceforth coordinate the rates so that the master clock at the USNO and the master clock at the NBS would remain near synchronous. It was initially felt and agreed upon that the time difference could be kept less than $5 \mu \mathrm{s}$.

In the figure (page 6), the abbreviation "pps" means "pulses per second."

Reference: R. E. Beehler and D. J. Glaze, The performance and capability of cesium beam frequency standards at the National Bureau of Standards, IEEE Trans. Instr. Meas., IM-15, 48 (1966).

Personnel: D. Halford

D. W. All an 


\section{TIME AND FREQUENCY \\ DISSEMINATION - WWVL}

19.9 or 20.5 and $20.0 \mathrm{kc} /(\mathrm{sec}-$ UTC)

UTC (NBS) Time Scole

AT BOULDER :

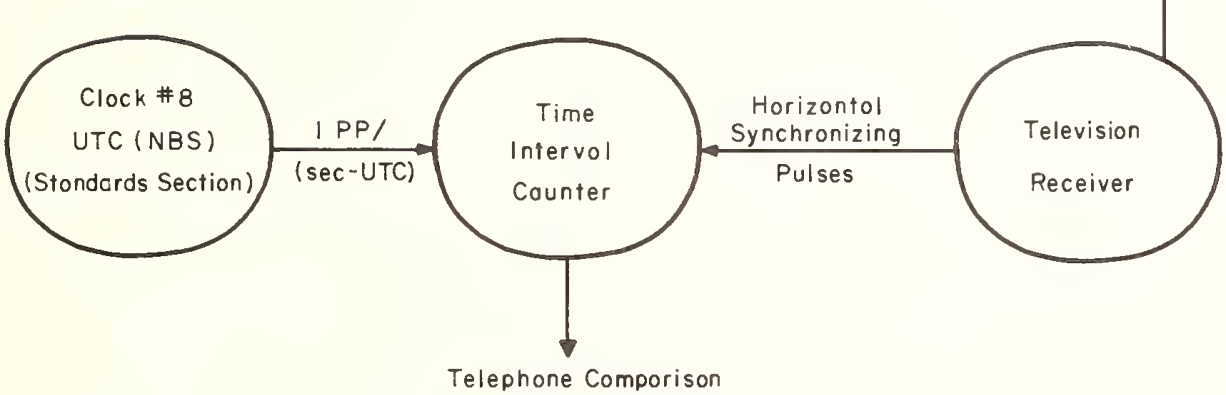

with $\mathrm{F} \uparrow$. Collins Counter

AT FT. COLLINS :

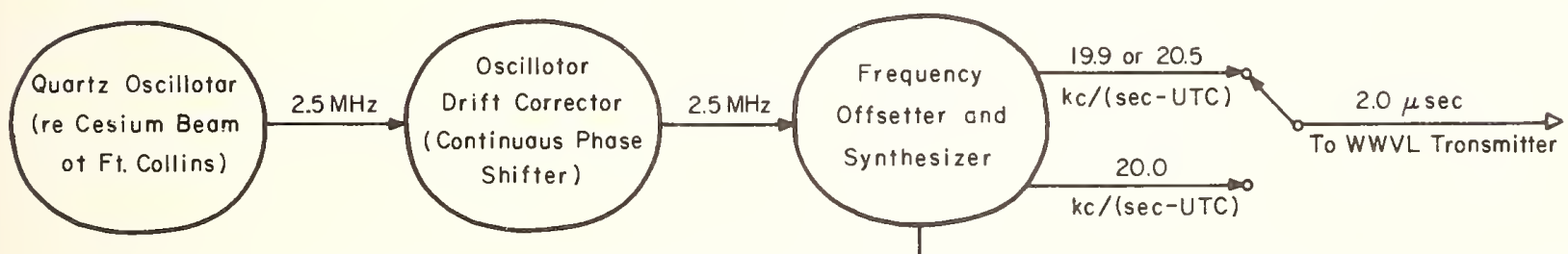

$100 \mathrm{kc} /(\mathrm{sec}-U T C)$

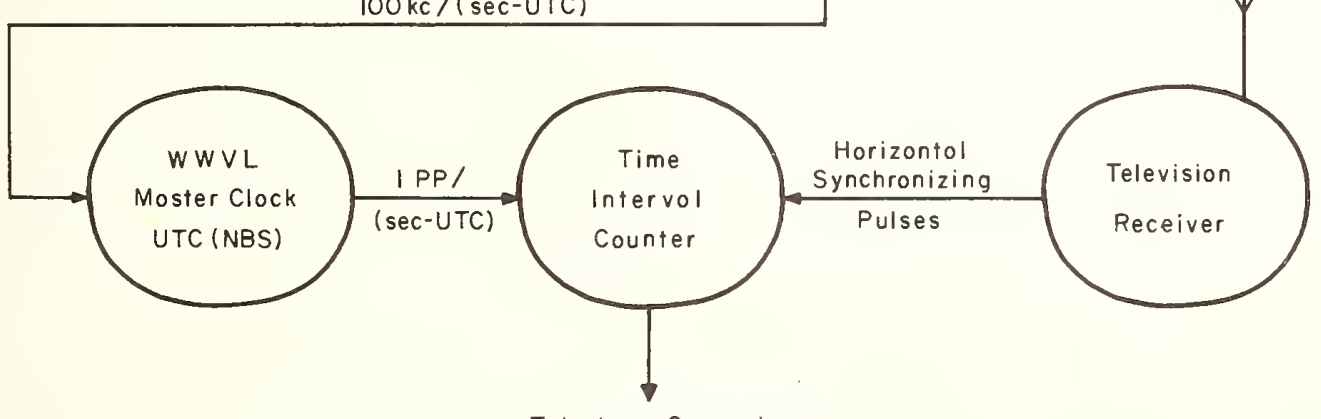

Telephone Camporison

with Boulder Counter 


\section{TIME AND FREQUENCY DISSEMINATION - WWVB}
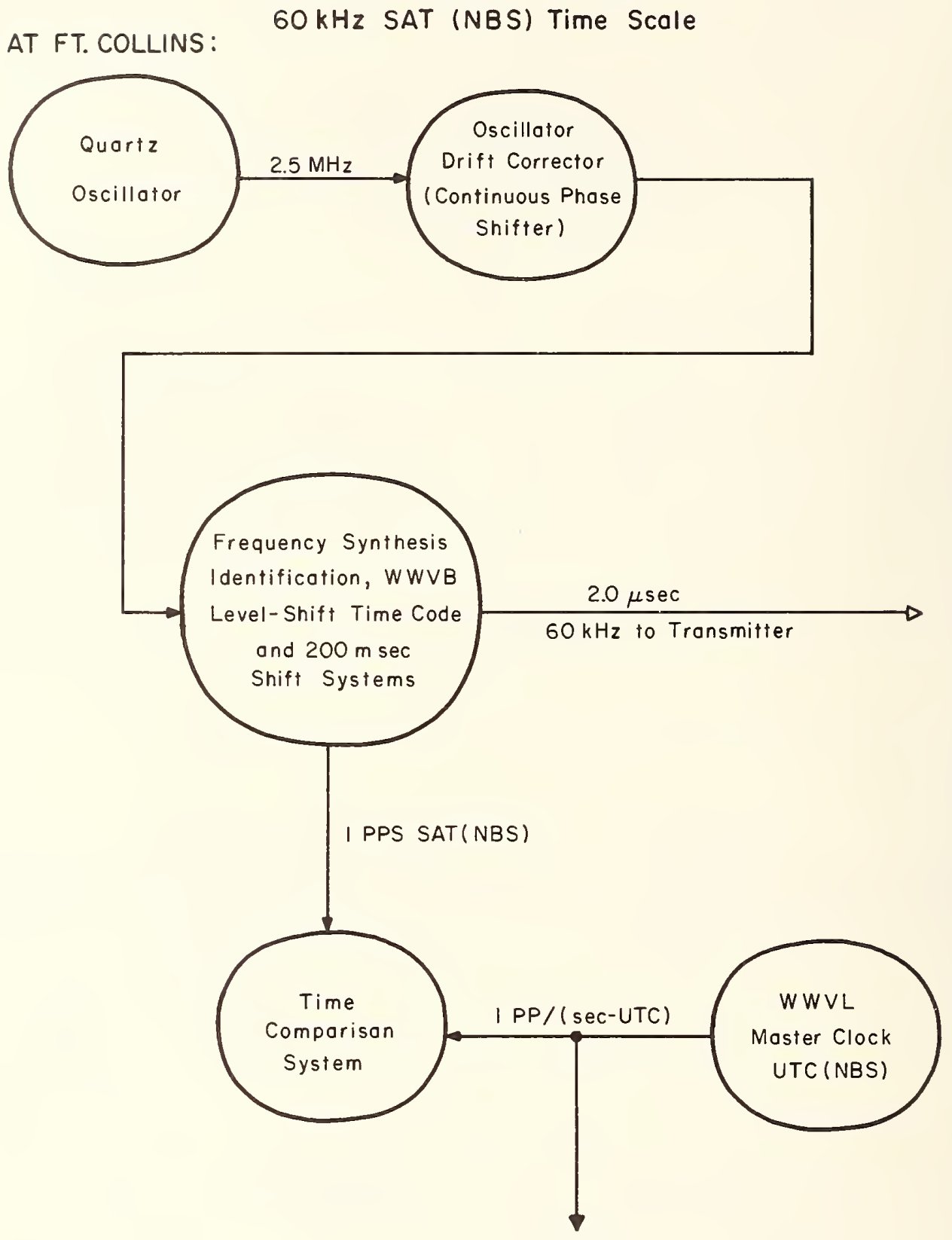

To WWV 
TIME AND FREQUENCY

DISSEMINATION - WW V

$2.5,5,10,15,20 \& 25 \mathrm{Mc} /(\mathrm{sec}$-UTC)

UTC (NBS) Time Scale

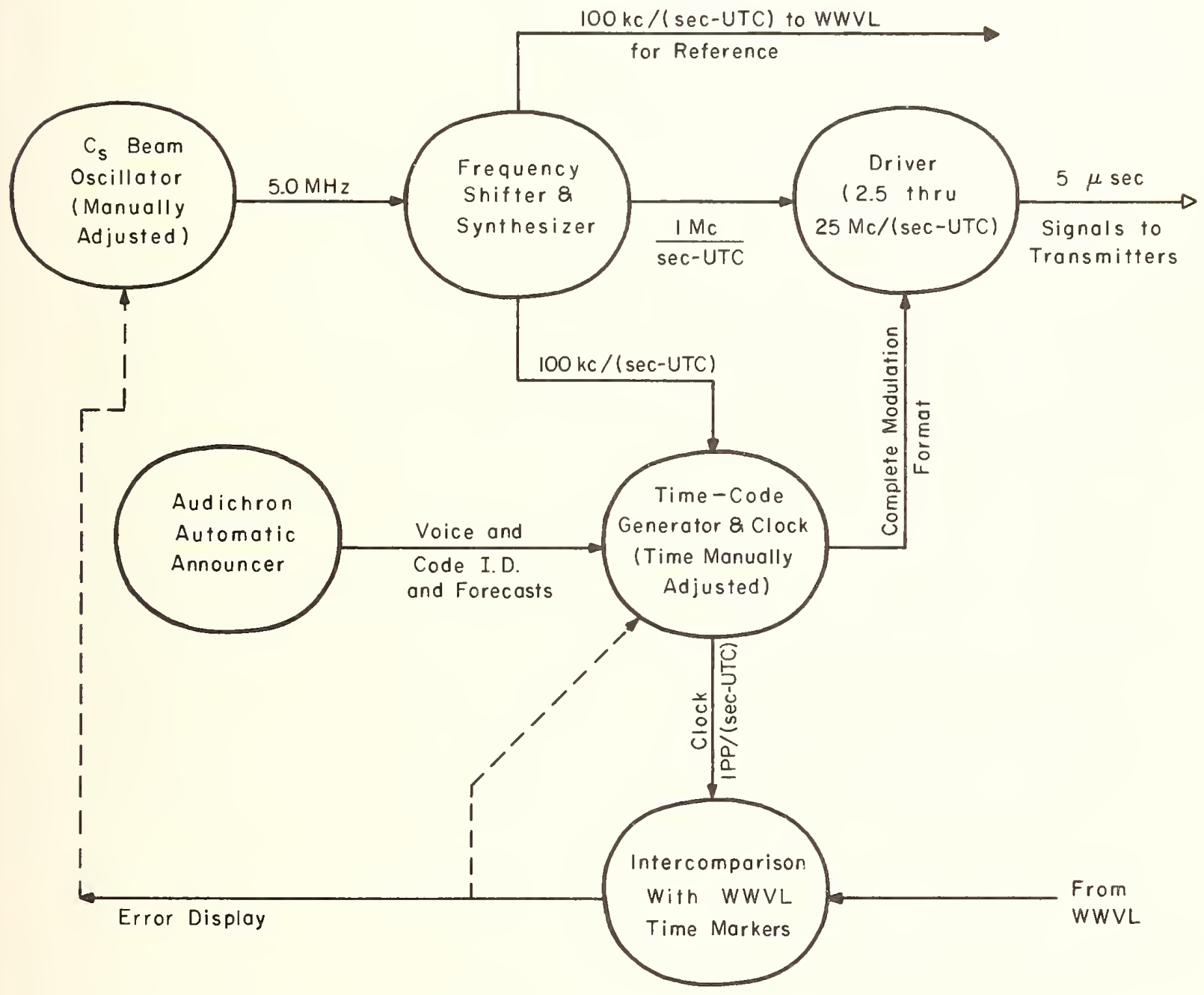




\section{TIME AND FREQUENCY \\ DISSEMINATION - WWVH}

$2.5,5,10 \& 15 \mathrm{Mc} /(\mathrm{sec}-U T C)$

UTC (NBS) Time Scale

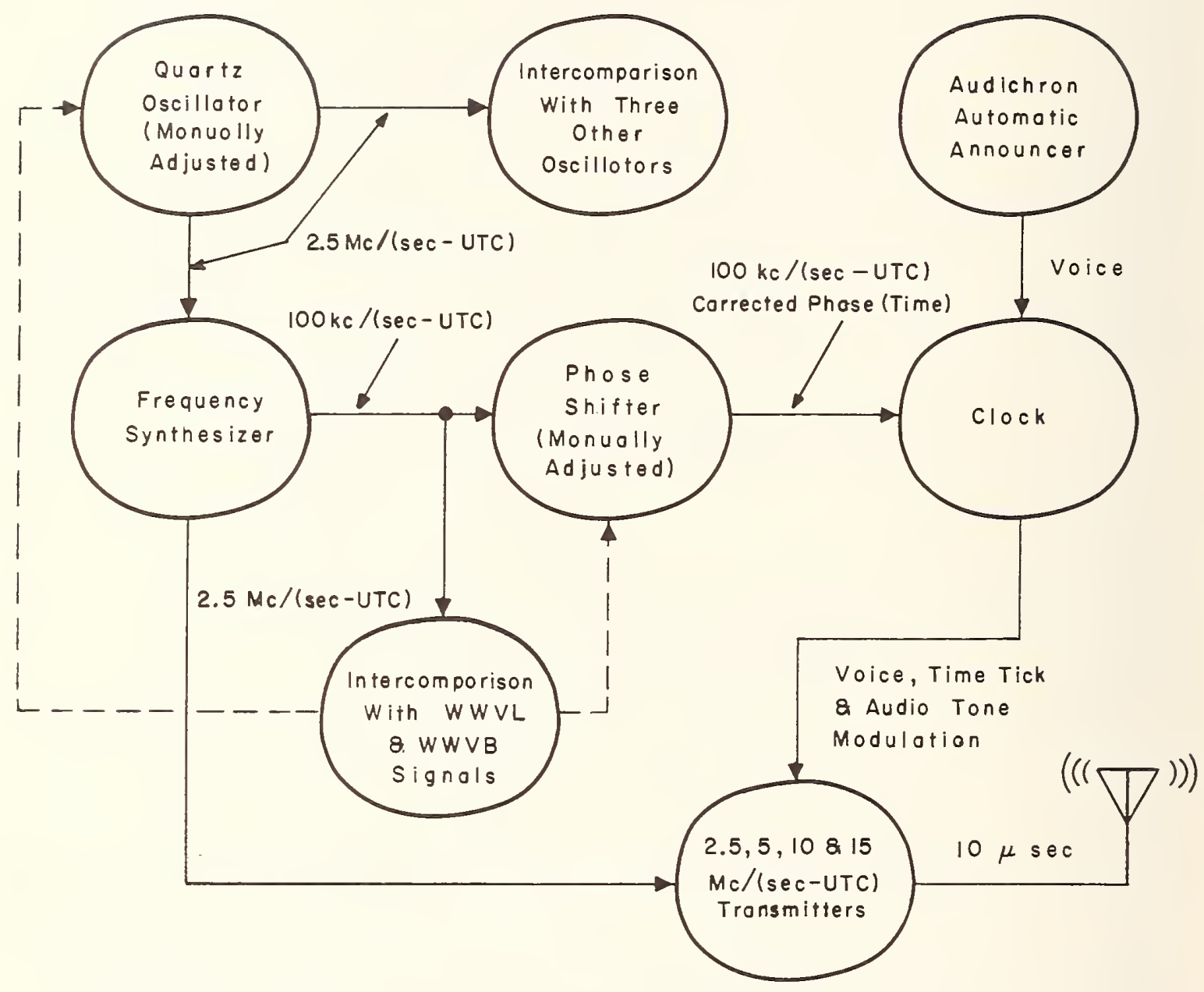


WWVL, WWVB, WWV, and WWVH:

Bias Uncertainties: Since the signals from all the stations are controlled by the standards in Boulder, as shown on pages 7-10, there is no significant long-term bias in the phase of the broadcast signals relative to the

NBS time scales.

Random Errors: The phase (time) uncertainties given below are random fluctuations due to weather-caused changes in antenna impedance and to operator and equipment limitations.

Station

Maximum Phase Error [re SAT(NBS) or UTC(NBS)] (microseconds)

WWVL,

WWVB

WWV

WWVH
2. 0

2. 0

5.0

10.0

Total Uncertainty: Same as Random Errors

Notes: Standard time and frequency signals are broadcast from fou r radio stations operated by the National Bureau of Standards. WWVL, WWVB, and WWV are located near Ft. Collins, Colorado; WWVH is on the island of Maui, Hawaii. For detailed description of the information available on each signal, see the reference below.

The unit of frequency, $\mathrm{Hz}$, is used to denote one cycle per second, where the second is that defined internationally in terms of a transition in cesium. The unit, c/(sec -UTC), denotes one cycle per second where the second is derived from the UTC(NBS) time scale.

The frequency offset from the internationally defined atomic frequency required to generate the UTC(NBS) time scale is determined annually by the Bureau International de $1^{\prime}$ Heure (BIH) in Paris. At present the offset is -300 parts in $10^{10}$.

$\mathrm{SAT}(\mathrm{NBS})$ is a Stepped Atomic Time scale based on the atomic frequency with periodic retardations to approximate UT-2.

Time synchronization between the NBS coordinated time scale UTC(NBS) and the clocks at the Ft. Collins transmitter sites is checked daily. 
Reference: NBS Standard Frequency and Time Services, Special Pub. 236 (1968). (Revised annually).

Personnel: P. Viezbicke 


\section{DIRECT COMPARISON:}

In addition to obtaining time information from the broadcast signals, one can also make direct comparisons between the NBS clocks at Boulder and a portable clock.

\section{Bias Uncertainties: See Notes}

Random Errors: See Notes

Total Uncertainty: See Notes

Uncertainty quoted customer: See Notes

Notes: Comparison between $A T(N B S)$ and the customer clock can be made with a precision of about $1 \mathrm{n} \mathrm{sec}$. and an accuracy of about $100 \mathrm{n} \mathrm{sec}$.

Reference: D. W. Allan, R. L. Fey, H. E. Machlan, J. A. Barnes, An ultraprecise time synchronization system designed by computer simulation, Frequency 6 , \#1, 11 (1968).

Personnel: D. W. Allan 


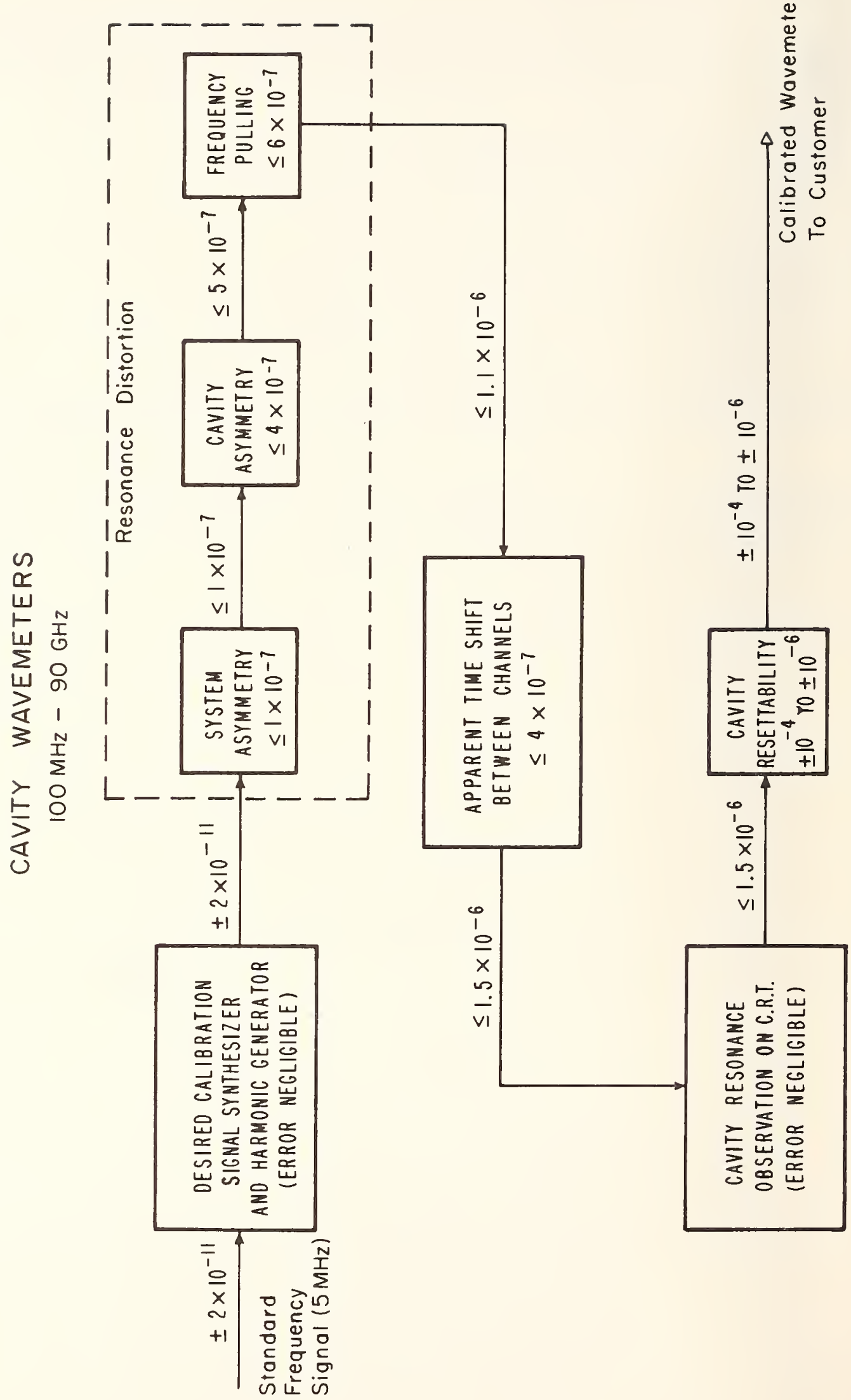




$$
\begin{aligned}
& \text { Cavity Wavemeters } \\
& 100 \mathrm{MHz}-90 \mathrm{GHz}
\end{aligned}
$$

Bias Uncertainties:

Random Errors:

Total Uncertainty:

See Error Flow Diagram, page 11

Uncertainty quoted customer:

Notes: None

Reference: C. G. Montgomery, Techniques of microwave measurements, Radiation Laboratory Series, No. 11, pp. 291-293 (1947).

Personnel: R. E. Larson

C. K. S. Miller 

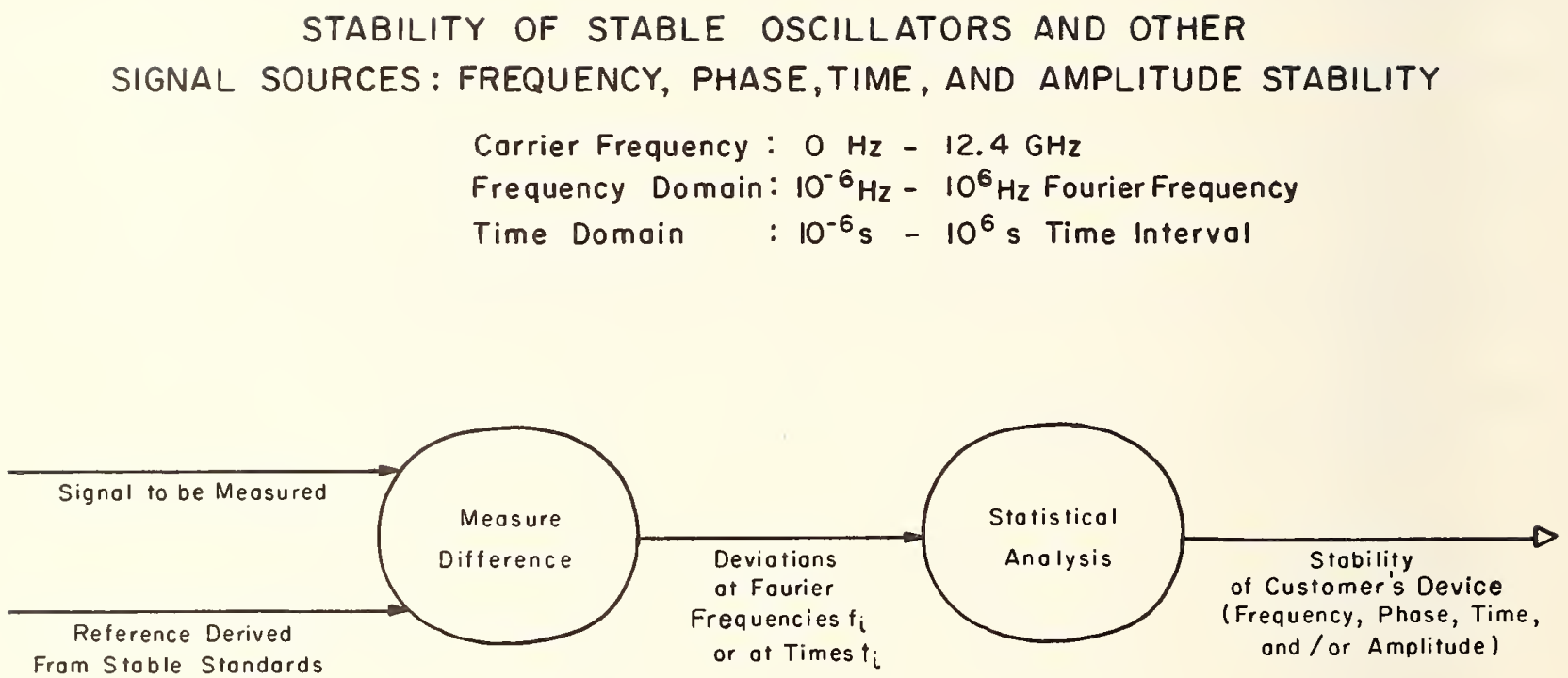
Stability of Stable Oscillators and Other Signal Sources: Frequency, Phase, Time, and Amplitude Stability

Carrier Frequency:

Frequency Domain:

Time Domain:
$0 \mathrm{~Hz}-12.4 \mathrm{GHz}$

$10^{-6} \mathrm{~Hz}-10^{6} \mathrm{~Hz}$ Fourier Frequency $10^{-6} s-10^{6} s$ Time Interval

Bias Uncertainties: Less than $3 \mathrm{~dB}$ typical, to as low as $0.1 \mathrm{~dB}$

Random Errors: Less than $3 \mathrm{~dB}$ typical, to as low as $0.1 \mathrm{~dB}$

Total Uncertainty: Less than $5 \mathrm{~dB}$ typical, to as low as $0.2 \mathrm{~dB}$

Uncertainty quoted customer: Same as Total Uncertainty.

Notes: These calibrations can be performed on quartz crystal oscillators, atomic frequency standards, signal generators, frequency synthesizers, frequency multiplier chains, frequency dividers, amplifiers, buffers, phase shifters, and in general any device which generates or processes a frequency, phase, or time signal. Spectrum analysis can be done directly at Fourier frequencies $f$ greater than 1 hertz, with an analyzer bandwidth as narrow as 1 hertz. The entire range of frequency domain stability can be obtained by Fourier transformation of time domain data.

References: D. W. Allan, Statistics of atomic frequency standards, Proc. IEEE, 54, 221 (1966), and L. S. Cutler and C. L. Searle, Some aspects of the theory and measurement of frequency fluctuations in frequency standards, Proc. IEEE, 54, 136 (1966).

Personnel: $\quad$ J. H. Shoaf

D. Halford 


\title{
RF POWER IN COAXIAL SYSTEMS
}

\author{
$10-4000 \mathrm{MHz}$ \\ 1- $10 \mathrm{~mW}$ Power Level \\ BOLOMETER CALIBRATION FROM \\ DRY LOAD CALORIMETRIC MEASUREMENT
}

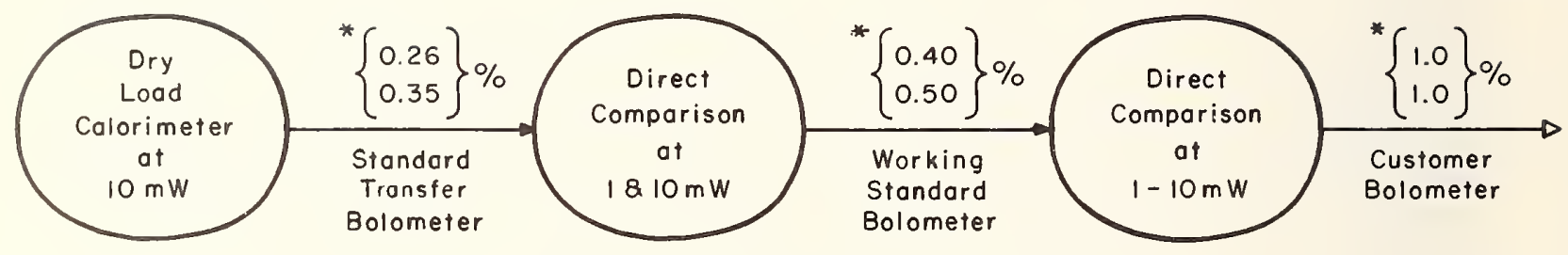

* $\left\{\begin{array}{c}10 \text { to } 1000 \mathrm{MHz} \\ 1000 \text { to } 4000 \mathrm{MHz}\end{array}\right\}$ 
DRY LOAD CALORIMETRIC MEASUREMENT:

$10-4000 \mathrm{MHz}$

$50 \mathrm{~mW}-5 \mathrm{~W}$

Bias Uncertainties:

$\begin{array}{lcc} & 10-1000 \mathrm{MHz} & 1000-4000 \mathrm{MHz} \\ \text { Calorimeter efficiency } & 0.04 \% & 0.08 \% \\ \text { VSWR mismatch } & \text { negligible } & \text { negligible } \\ \text { RF - dc substitution } & 0.05 & 0.10 \\ \text { dc power } & 0.02 & 0.02 \\ \text { Feedback loop error } & 0.15 & 0.15 \\ \text { dom Errors: } & \text { negligible } & \text { negligible } \\ & 0.26 \% & 0.35 \%\end{array}$

Uncertainty quoted customer: See Notes

Notes: Ordinarily this measurement is not offered to the public as a service, but is used for international comparisons and to calibrate standard transfer bolometers which are in turn used to calibrate working standard bolometers for the NBS Electronic Calibration Center.

Reference: M. L. Crawford, A new RF - dc substitution calorimeter with automatically controlled reference power, IEEE Trans. Instr. Meas. IM-17, 378 (Dec. 1968).

Personnel: P. A. Hudson 
TRANSFER BOLOMETER CALIBRATION BY DIRECT COMPARISON:

At $10 \mathrm{~mW}$ power level

Bias Uncertainties:

The bias uncertainties are taken to be equal to the total error estimated for the calibration of the standard transfer bolometer by the dry load calorimeter. See page 13-1.

Random Errors: Random errors are less than $0.1 \%$.

Total Uncertainty:

$10-1000 \mathrm{MHz}: 0.40 \%$

$1000-4000 \mathrm{MHz}: 0.50 \%$

Uncertainty quoted customer: See Notes

Notes: Ordinarily this measurement is not offered to the public as a service, but is used to calibrate working standard bolometer units for use in the NBS Electronic Calibration Center.

Reference: None

Personnel: P. A. Huds on 


\section{BOLOMETER CALIBRATION BY DIRECT COMPARISON:}

At 1, 3, $10 \mathrm{~mW}$ power levels

\section{Bias Uncertainties:}

Bias uncertainties are taken to be the total estimated error in the calibration of the working standard bolometer. See page 13-2.

Random Errors: Random errors in calibration of customer units by direct comparis on are less than $0.15 \%$.

\section{Total Uncertainty:}

$$
\begin{aligned}
& 10-300 \mathrm{MHz}: 0.50 \% \\
& 300-1000 \mathrm{MHz}: 0.65 \% \\
& 1000-4000 \mathrm{MHz}: 0.85 \%
\end{aligned}
$$

\section{Uncertainty quoted customer:}

$$
\begin{aligned}
& 10-300 \mathrm{MHz}: 1 \% \\
& 300-1000 \mathrm{MHz}: 1 \% \\
& 1000-4000 \mathrm{MHz}: 1 \%
\end{aligned}
$$

References: P. A. Hudson, A precision RF power transfer standard, IRE Trans. Instr. I-9, 280 (1960).

R. F. Desch and R. E. Larson, Bolometric microwave power calibration techniques at the National Bureau of Standards, IEEE Trans. Instr. Meas. IM-12, 29 (1963).

Personnel: F. X. Ries 


\section{RF POWER IN COAXIAL SYSTEMS}

$$
\begin{gathered}
d c-4000 \mathrm{MHz} \\
2-100 \text { W Power Level }
\end{gathered}
$$

\section{FLOW CALORIMETER MEASUREMENT}

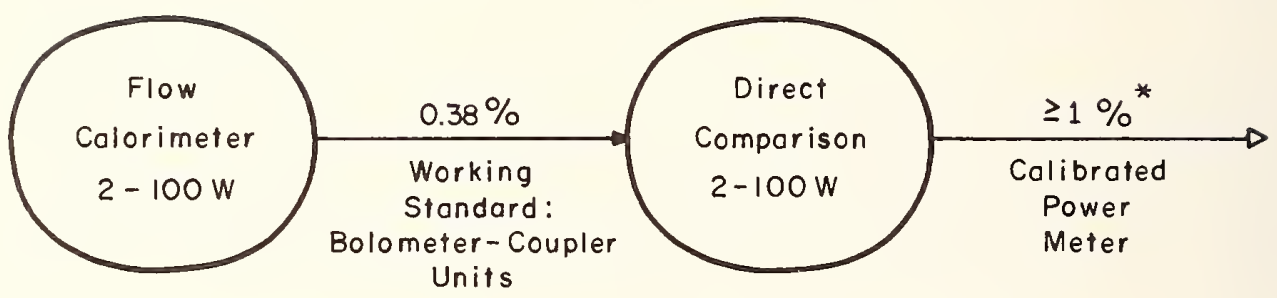

* Error Limits Are Often Quoted As Greater Than 1\%, Since Many Meters Calibrated Are Inherentiy Less Accurate Than $1 \%$. 


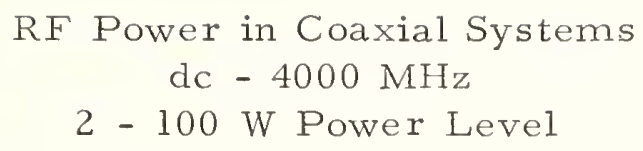

\section{FLOW CALORIMETRIC MEASUREMENT:}

$2-100$ watts

\section{Bias Uncertainties:}

dc power

RF - dc substitution

$0.02 \%$

Calorimeter efficiency

0.10

Thermal drift and flow rate variations

0.05

0.15

Random Errors: See Notes

0.06

Total Uncertainty:

$0.38 \%$

Uncertainty quoted customer: See Notes

Notes: Ordinarily this measurement is not offered to the public as a service, but is used only for international comparisons and to calibrate working standard bolometer-coupler units for use in the NBS Electronic Calibration Center.

The random error given here is the maximum observed variation.

Reference: None

Personnel: P. A. Huds on 
FLOW CALORIMETRIC MEASUREMENT, DIRECT COMPARISON:

2 - 100 watts

\section{Bias Uncertainties:}

Uncertainty of working standard

$0.5 \%$

VSWR mismatch and errors in meter to be calibrated

0.3

Random Errors:

0.2

Total Uncertainty:

$1.0 \%$

Uncertainty quoted customer: $1 \%$

Notes: Errors inherent in the meter to be calibrated can be more than the allowance made here, that is $0.3 \%$. Thus, occasionally the uncertainty quoted the customer is greater than $1 \%$.

Reference: None

Personnel: F. X. Ries 


\section{MICROWAVE POWER: COAXIAL BOLOMETER UNITS}

Type N Connector, Male : 4-10 GHz

Precision Connector $(G P C-14): 4-8.5 \mathrm{GHz}$

I-10 mW Power Level

ADAPTER METHOD OF MEASUREMENT

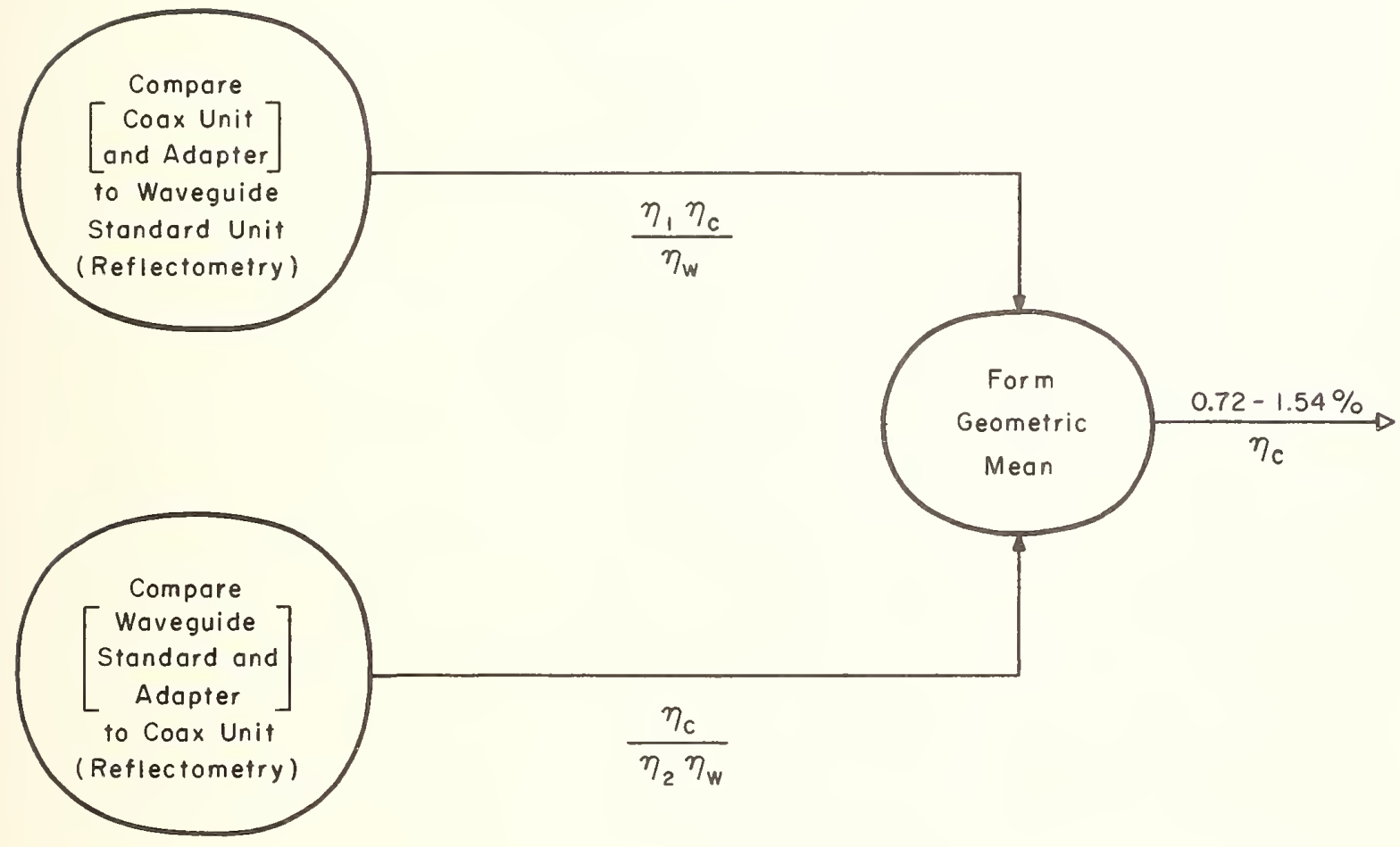

$\eta_{c}$ : Effective Efficiency of Coaxial Unit

$\eta_{W}$ : Effective Efficiency of Waveguide Standard Unit

$\eta_{1}$ : Efficiency of Adapter as Used In Step $\left(\begin{array}{l}1 \\ 2\end{array}\right)$ 
Microwave Power: Coaxial Bolometer Units

Type N Connector, Male: 4 - $10 \mathrm{GHz}$

Precision Connector (GPC-14): $4-8.5 \mathrm{GHz}$

1 - $10 \mathrm{~mW}$ Power Level

\section{ADAPTOR METHOD OF MEASUREMENT:}

\section{Bias Uncertainties:}

Random Errors:

Total Uncertainty:
See Error Flow Diagrams, pages $15-2$ and 15-3

Uncertainty quoted customer: $0.8 \%$ to $1.8 \%$

Notes: This measurement permits the comparis on of a coaxial bolometer unit directly with a waveguide standard bolometer unit. Thus, it is not necessary to develop a calorimetric technique for calibrating working standard coaxial bolometer units in this frequency range. See reference. The uncertainty in the waveguide standard in the frequency range 4 to $7.05 \mathrm{GHz}$ (where the impedance method of measurement is used) is $0.75 \%$. In the frequency range 7.05 to $10 \mathrm{GHz}$ (where the calorimetric method of measurement is used), the uncertainty in the waveguide standard is $0.2 \%$.

Symbols appearing in the error flow diagrams are defined in the reference below.

Reference: G. F. Engen, Coaxial power meter calibration using a waveguide standard, J. Res. NBS 70C, 127, (1966).

Personnel: R. F. Desch 
MICROWAVE POWER: COAXIAL BOLOMETER UNITS

ERROR FLOW DIAGRAM FOR CALIBRATION TRANSFER SYSTEM

FOR TYPE N CONNECTORS

\section{ADAPTOR METHOD}

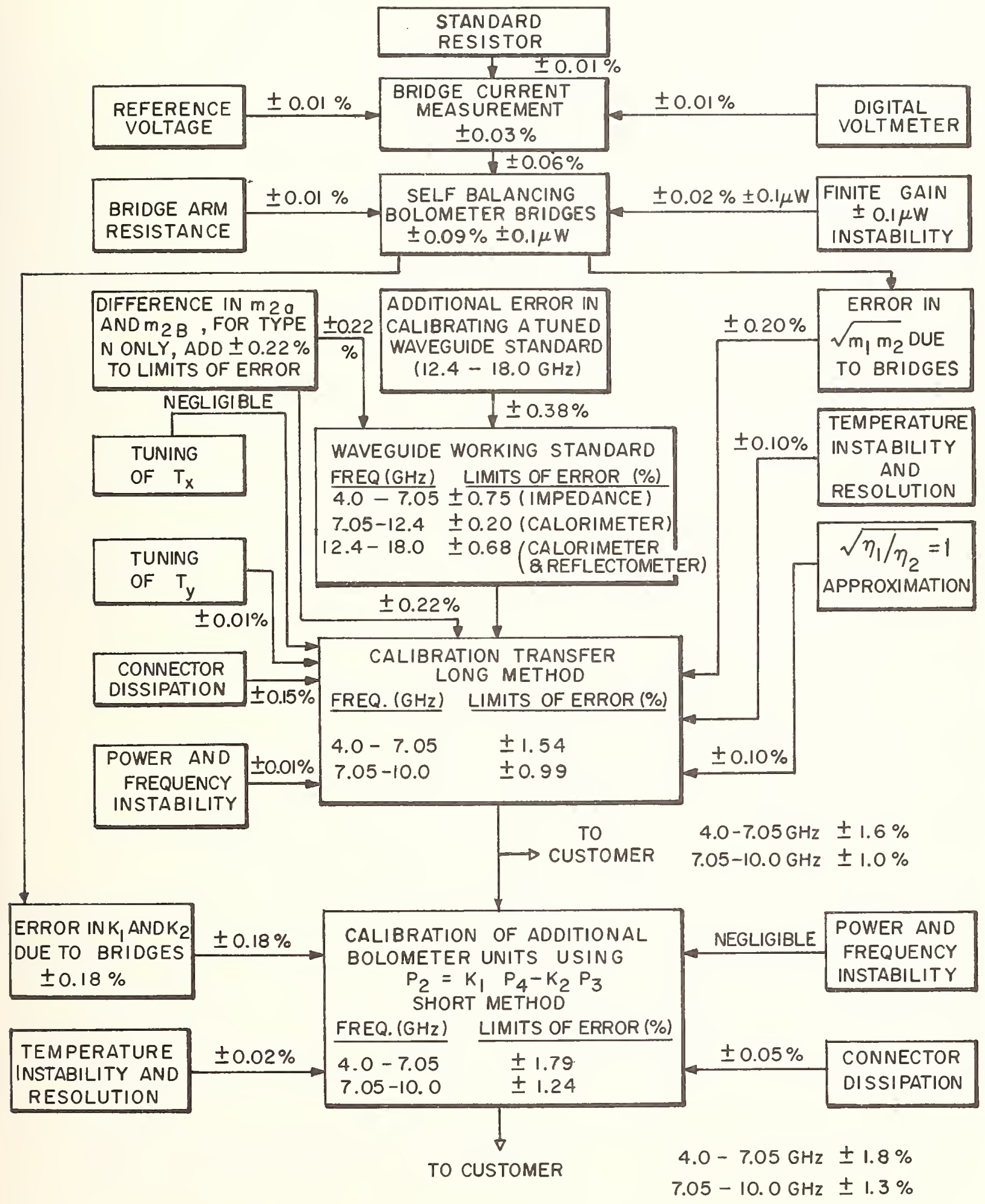


MICROWAVE POWER: COAXIAL BOLOMETER UNITS ERROR FLOW DIAGRAM FOR CALIBRATION TRANSFER SYSTEM FOR PRECISION CONNECTORS (GPC-14 STOPS AT $8.5 \mathrm{GHz}$ ) ADAPTOR METHOD

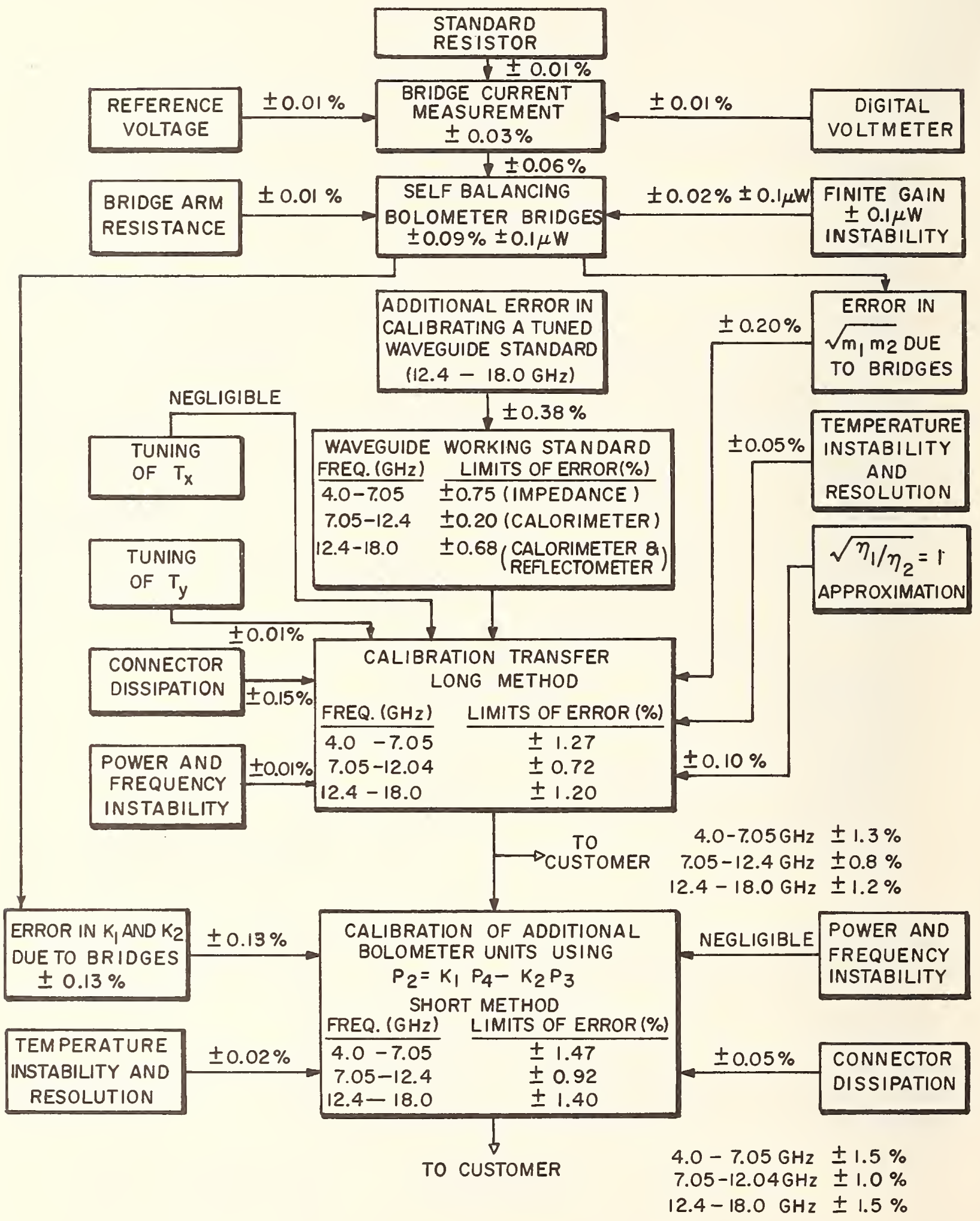


MICROWAVE POWER : WAVEGUIDE BOLOMETER UNITS

WR $28: 26.5-40.0 \mathrm{GHz}$

WR $42: 18.0-26.5 \mathrm{GHz}$

WR $62: 12.4-18.0 \mathrm{GHz}$

WR 90: $8.2-12.4 \mathrm{GHz}$

WR 112: $7.05-10.0 \mathrm{GHz}$

$10 \mathrm{~mW}$ Power Level

MICROCALORIMETRIC MEASUREMENT

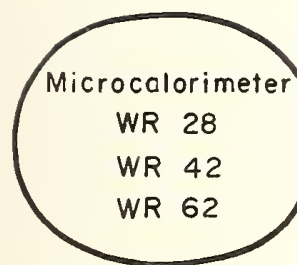

$\eta_{e}$ of Working Standard

Bolometer Units

$0.3 \%$

WR 62

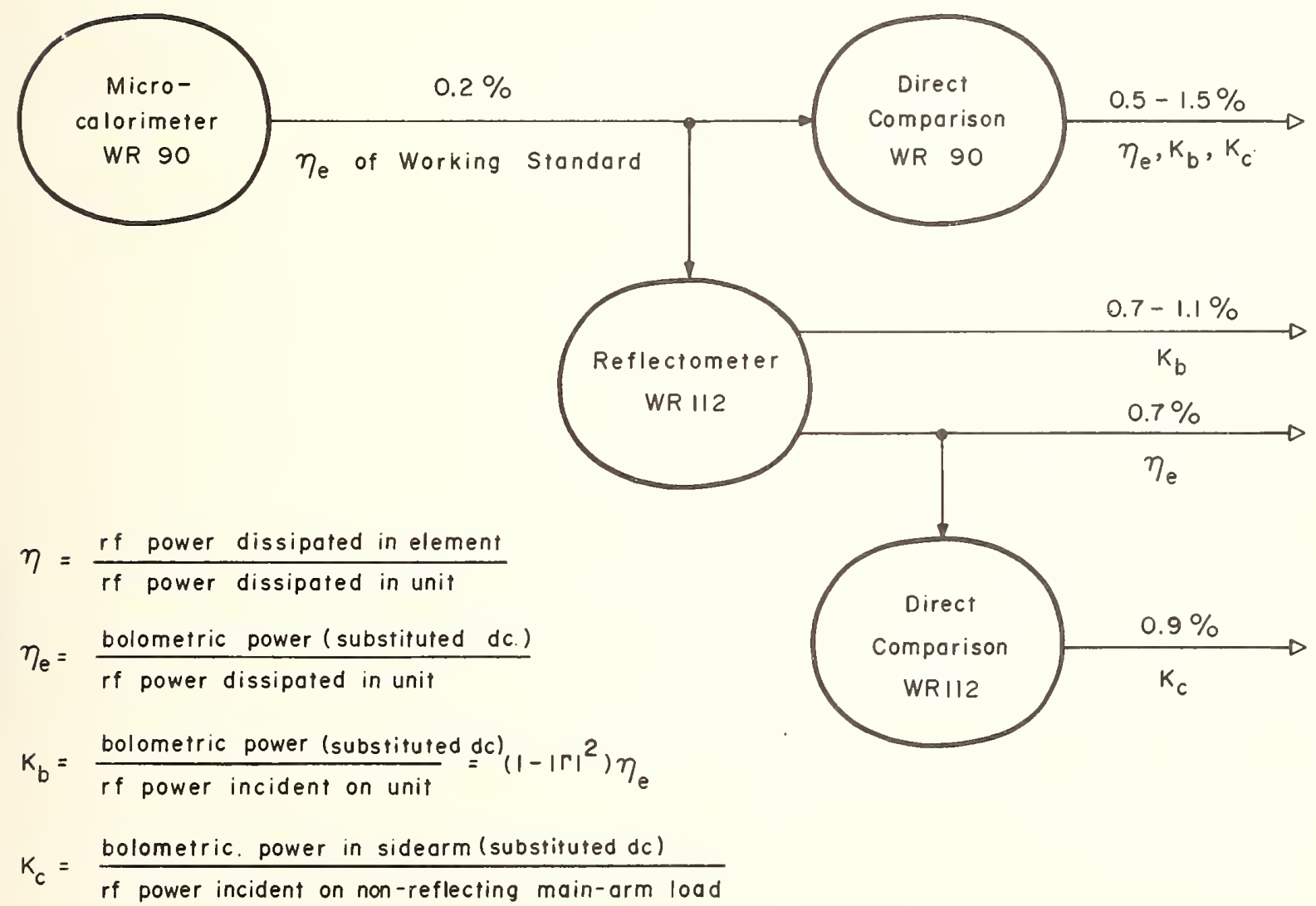


Mic rowave Power

WR 28: $26.5-40 \mathrm{GHz}$

WR $42: 18.0-26.5 \mathrm{GHz}$

WR $62: 12.4-18.0 \mathrm{GHz}$

WR 90: $8.2-12.4 \mathrm{GHz}$

$10 \mathrm{~mW}$ Power Level

MICROCALORIMETRIC MEASUREMENT:

Bias Uncertainties:

Random Errors: $\quad$ See Error Flow Diagram, p. 16-2

Total Uncertainty:

Uncertainty quoted customer: See Notes

Notes: Ordinarily this measurement is not offered to the public as a service, but is used only for international comparisons and to calibrate working standard bolometer units for use in the NBS Electronic Calibration Center.

Reference: G. F. Engen, A refined $\mathrm{X}$-band microwave microcalorimeter, J. Res. NBS 63ㄷ, 77 (1959). 


\section{MICROWAVE POWER: WAVEGUIDE BOLOMETER UNITS ERROR FLOW DIAGRAM FOR REFERENCE STANDARD MICROCALORIMETRIC MEASUREMENT WR9O AND WR62}

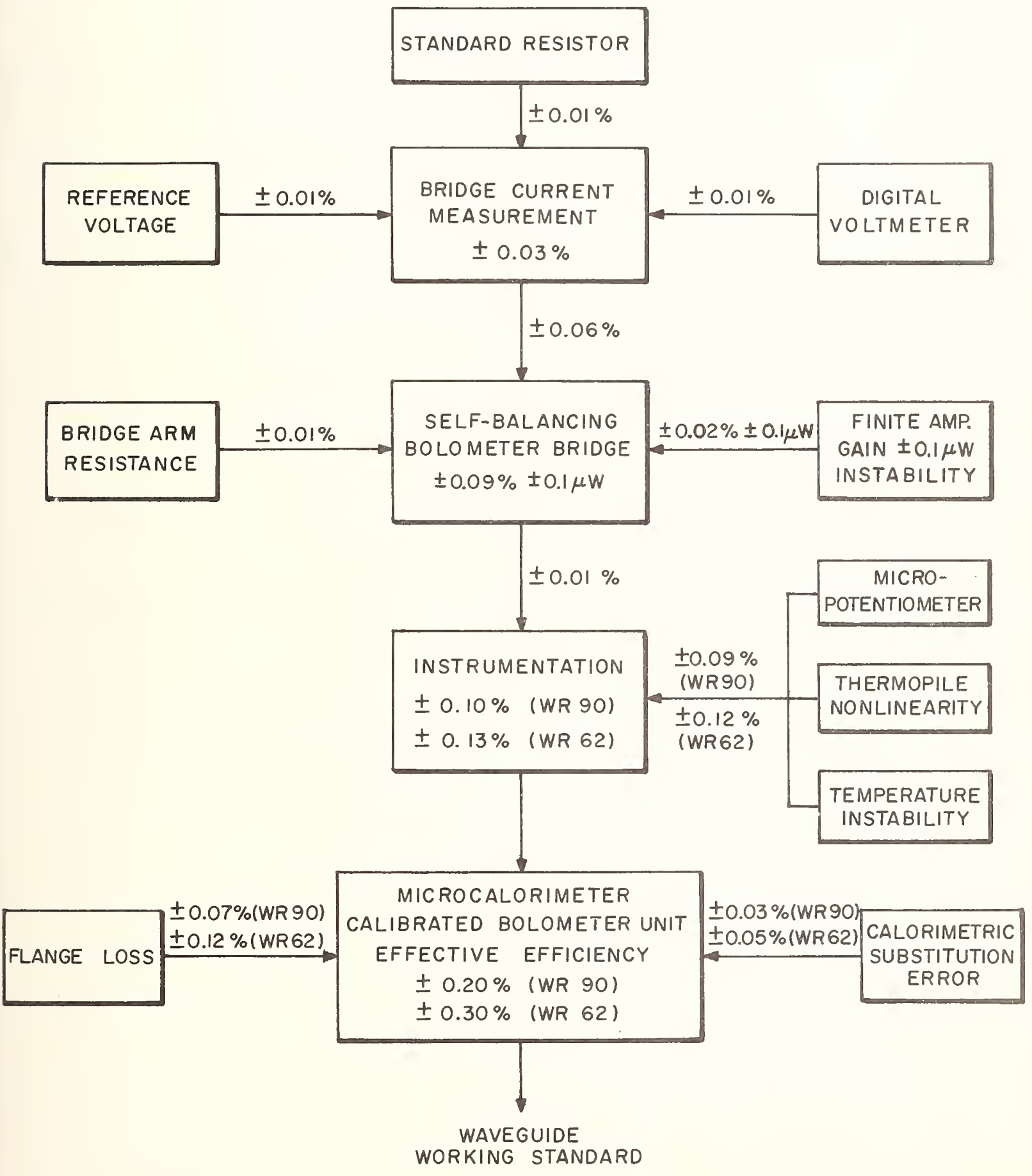




\section{Microwave Power}

MICROCALORIMETRIC MEASUREMENT, DIRECT COMPARISON

METHOD:

Bias Uncertainties:

Calorimetric measurement of

working standard

0.2 to $0.3 \%$

RF power, temperature, and

frequency stability

0.02

dc power

0.1

Flange dissipation and misalignment

0.05 to 0.1

VSWR mismatch (for $0.01<|\Gamma|<0.20$ )

0.03 to 1.23

Random Errors: Typical value

0.04

Total Uncertainty: (for $0.01<|\Gamma|<0.20)$

0.40 to $1.75 \%$

Uncertainty quoted customer: 0.5 to $1.8 \%$

Notes: This measurement method is used for $\mathrm{K}$ conly. (See definition below.)

$|\Gamma|$ is the absolute value of the complex reflection coefficient of the bolometer unit.

An error flow diagram for the measurement in the WR 90 waveguide size is given on page $16-5$.

In this document the term "bolometer element" will refer to the thermoelement in which the RF power is detected. "Bolometer mount" will refer to the waveguide in which the element is mounted, and "bolometer unit" will refer to the combination. A 'bolometer-coupler unit' is a bolometer unit mounted on an arm of a directional coupler.

The definitions of efficiency $(\eta)$, effective efficiency $\left(\eta_{\mathrm{e}}\right)$, and calibration factor $\left(\mathrm{K}_{\mathrm{b}}\right)$ of bolometer units are as follows:

$$
\begin{aligned}
\eta & =\frac{\mathrm{RF} \text { power dissipated in bolometer element }}{\mathrm{RF} \text { power dissipated in bolometer unit }} \\
\eta_{\mathrm{e}} & =\frac{\text { bolometer power (substituted dc in the bolometer unit) }}{\mathrm{RF} \text { power dissipated in bolometer unit }} \\
\mathrm{K}_{\mathrm{b}} & =\frac{\text { bolometer power (substituted dc) }}{\mathrm{RF} \text { power inc ident on unit }}=\left(1-|\Gamma|^{2}\right) \eta_{\mathrm{e}}
\end{aligned}
$$


The calibration factor $\left(K_{C}\right)$ for a bolometer-coupler unit is:

$$
K_{C}=\frac{\text { bolometer power in the sidearm (substituted } \frac{d c}{\text { RF power incident }} \text { on a non-reflecting main-arm load }}{\text { now }}
$$

The nominal $10 \mathrm{~mW}$ power level is for direct incidence on the unit attached to the main arm.

Bolometer-coupler units are calibrated at the power level appropriate to the coupler.

Symbols appearing in the error flow diagram are defined in the reference below.

Reference: R. F. Desch and R. E. Larson, Bolometric microwave power calibration techniques at the National Bureau of Standards, IEEE Trans. Instr. Meas., IM-12, 29 (1963).

Personnel: R. F. Desch 
昘

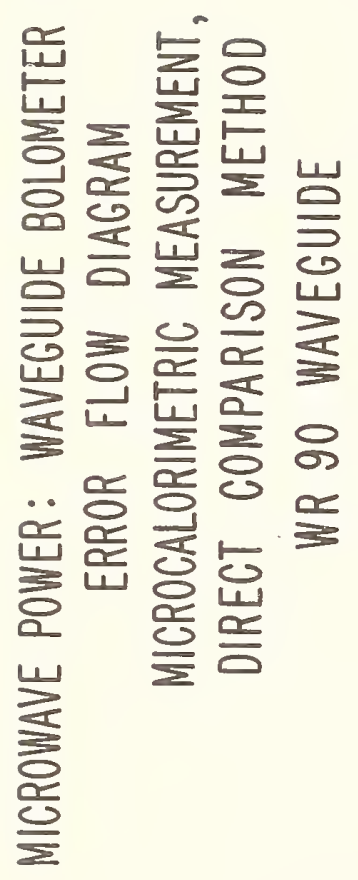

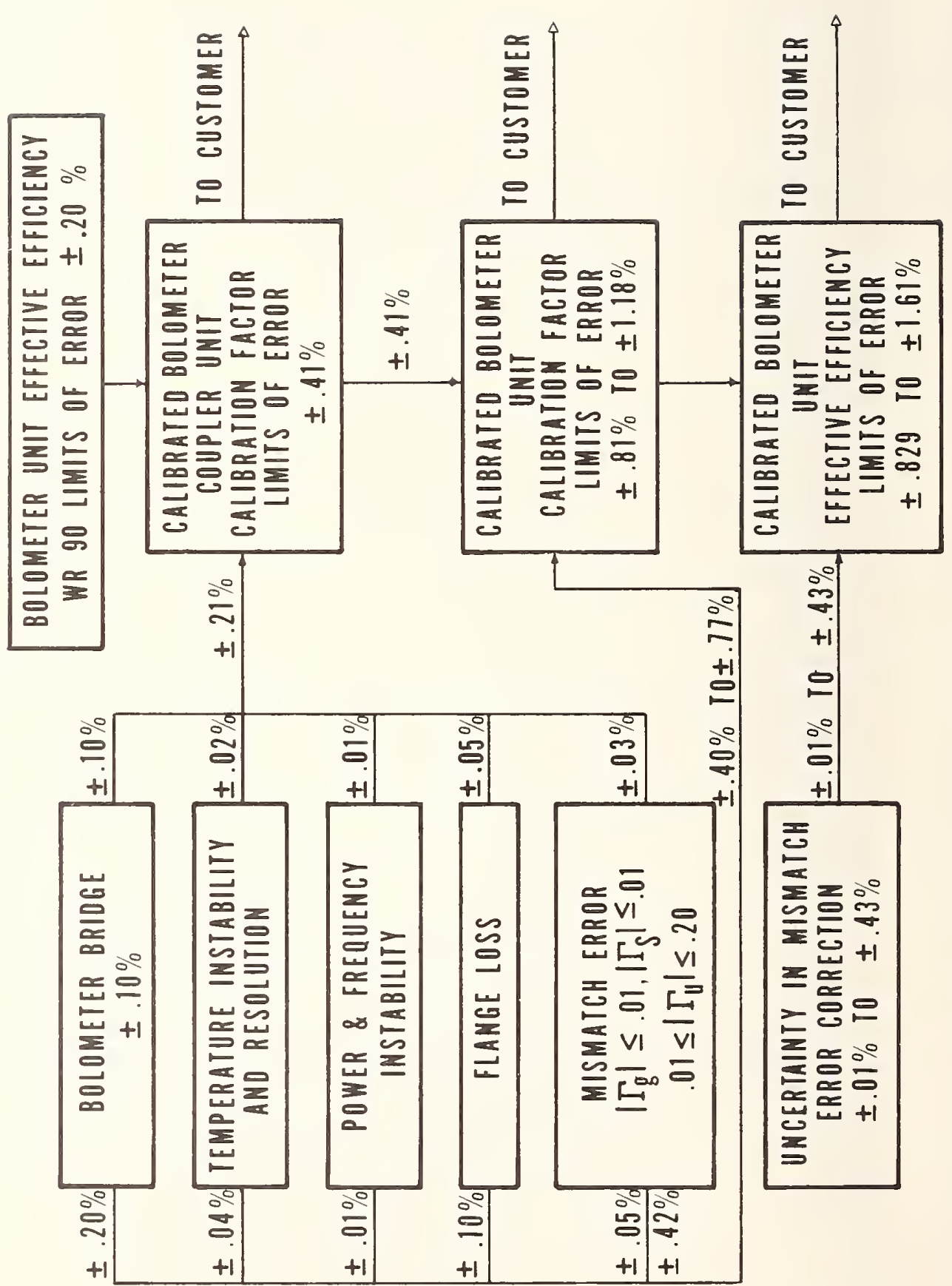


MICROCALORIMETER MEASUREMENT, REFLECTOMETER METHOD:

\section{Bias Uncertainties:}

Random Errors:

Total Uncertainty:

Uncertainty quoted customer:
See Error Flow Diagram, page 16-7

Notes: See notes for Direct Comparison method (see p. 16-3).

This measurement method is used for $\eta_{\mathrm{e}}$ and $\mathrm{K}_{\mathrm{b}}$ only. (See definitions on p. $16-3$.

The estimated uncertainty in a measurement of $\mathrm{K}_{\mathrm{b}}$ is actually about $0.1 \%$ higher than that for $\eta_{e}$, because reflection at the waveguide junction has an effect in that case. The uncertainty is still considerably less than $1 \%$, however.

Symbols appearing in the Error Flow Diagram are defined in the reference below.

The self-balancing bolometer bridge (see p. 16-7) with an uncertainty at $0.10 \%$ contributes $0.20 \%$ to the total uncertainty because the bridge is used more than once in the power measurement.

Reference: G. F. Engen, A transfer instrument för the intercomparison of microwave power meters, IRE Trans. Instr., I-9, 203 (1960).

Personnel: N. T. Larsen

R. F. Desch 
MICROWAVE POWER: WAVEGUIDE BOLOMETER UNITS ERROR FLOW DIAGRAM

MICROCALORIMETRIC MEASUREMENT,

REFLECTOMETER METHOD

WR 284, WR 187, WR 137, WR 112 , WR 90, WR 62, WR 42, WR 28

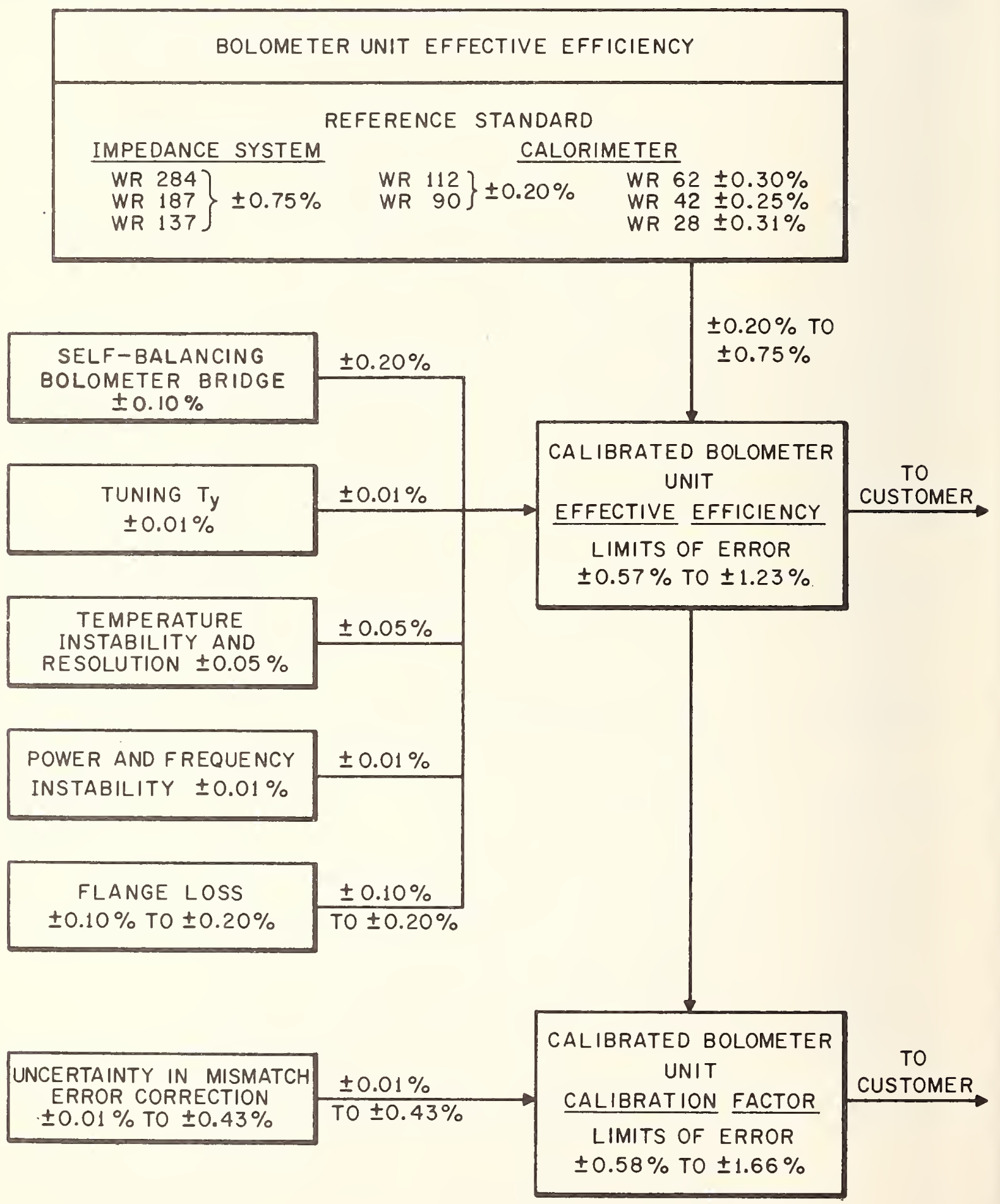




\section{MICROWAVE POWER : WAVEGUIDE BOLOMETER UNITS}

WR 137:5.85-8.20 GHz

WR $187: 3.95-5.85 \mathrm{GHz}$

WR $284: 2.60-3.95 \mathrm{GHz}$

$10 \mathrm{~mW}$ Power Level

IMPEDANCE METHOD OF MEASUREMENT

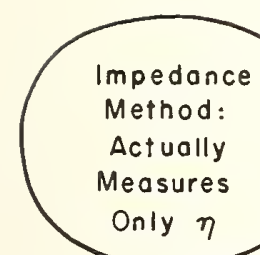

$\eta=\frac{r f \text { power dissipoted in element }}{\text { rf power dissipoted in unit }}$

$\eta$ of Borretter Units

$0.8 \%$

$\eta_{e}$ of Working Standard

or Customer's

Borretter Units

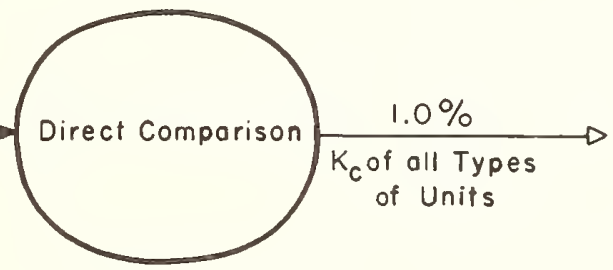

$\eta_{e}=\frac{\text { bolometric power (substiluted } d c \text { ) }}{\text { if power dissipoted in unit }}$

$K_{b}=\frac{\text { bolometric power (substifuted } d c \text { ) }}{r^{\dagger} \text { power incident on unit }}=\left(1-|\Gamma|^{2}\right) \eta_{e}$

$K_{c}=\frac{\text { bolometric power in sidearm (substituted } d c \text { ) }}{\text { rf power incident on non-reflecting main-arm load }}$ 
Microwave Power

WR 137: $5.85-8.20 \mathrm{GHz}$

WR 187: $3.95-5.85 \mathrm{rHz}$

WR 284:2.60 - 3.95 GHz

$10 \mathrm{~mW}$ Power Level

IMPEDANCE METHOD OF MEASUREMENT:

Bias Uncertainties:

Random Errors:

Total Uncertainty:
See Error Flow Diagram, page 17-2

\section{Uncertainty quoted customer: $1 \%$}

Notes: The impedance method actually measures only $\eta$, the efficiency of a bolometer unit. The limits on the effective efficiency of the working standard are obtained from the measured efficiency, $\eta$, and an estimate of the RF-dc substitution error. The standard is then used, as shown on page $1 \%$, to calibrate the customer's units when $\eta_{\mathrm{e}}, \mathrm{K}_{\mathrm{b}}$, or $\mathrm{K}_{\mathrm{c}}$ is desired.

Symbols appearing in the Error Flow Diagram are defined in reference below.

Reference: G. F. Engen, A bolometer mount efficiency measurement technique, J. Res., NBS, 65 2 , 113 (1961).

Personnel: R. F. Desch 
MICROWAVE POWER: WAVEGUIDE BOLOMETER UNITS ERROR FLOW DIAGRAM FOR WORKING STANDARD IMPEDANCE METHOD

WR 284, WRI87, WRI37

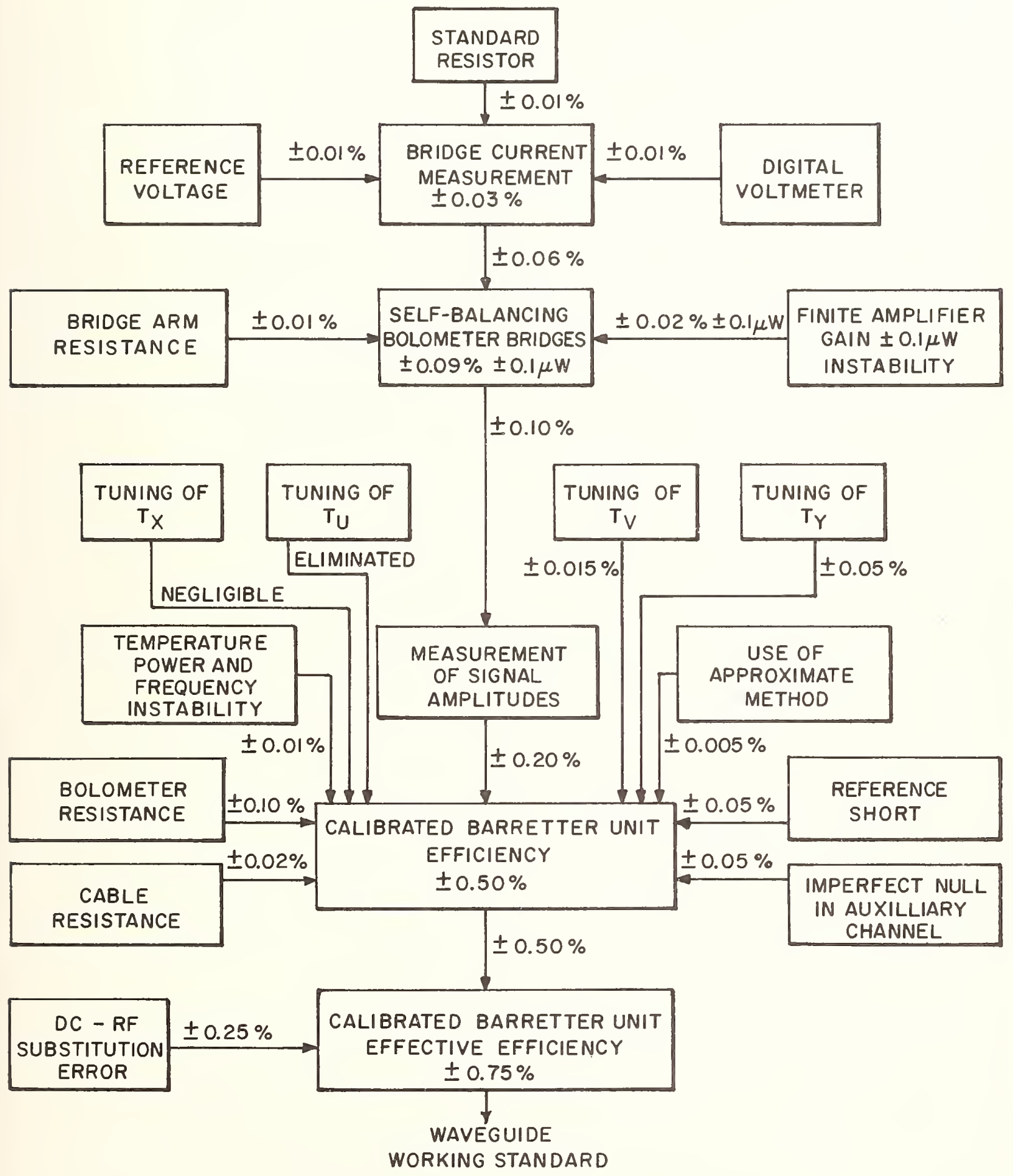


IMPEDANCE METHOD OF MEASUREMENT, DIRECT COMPARISON METHOD:

Bias Uncertainties:

Random Errors:

Total Uncertainty:

Uncertainty quoted customer: $1.5 \%$

Notes: This measurement is used to obtain $\mathrm{K}_{\mathrm{C}}$ for bolometer-coupler units with any type of element.

Reference: None

Personnel: R. F. Desch
See Error Flow Diagram, page 16-5 


\section{Microwave Power}

IMPEDANCE METHOD OF MEASUREMENT,

REFLECTOMETER METHOD:

Bias Uncertainties:

$\underline{\text { Random Errors: }}$

Total Uncertainty:

Uncertainty quoted customer: $\eta_{\mathrm{e}}$ for $|\Gamma|<0.01: 1 \%$

$$
K_{b} \text { for }|\Gamma|<0.2: 1 \%
$$

Notes: This measurement is used to obtain $\eta_{\mathrm{e}}$ and $\mathrm{K}_{\mathrm{b}}$ for bolometer units with thermistor-type elements.

Reference: None

Personnel: R. F. Desch 
RF PEAK-PULSE POWER IN COAXIAL SYSTEMS

$$
\begin{aligned}
& 300-500 \mathrm{MHz} \\
& 950-1200 \mathrm{MHz}
\end{aligned}
$$

Pulse Duration : $2-10 \mu \mathrm{sec}$

Pulse Repetition Rate: $100-1600$ pps

Maximum Duty Factor : $33 \times 10^{-4}$

Peak-Pulse Power : $1.0 \mathrm{~mW}-3.0 \mathrm{~kW}$

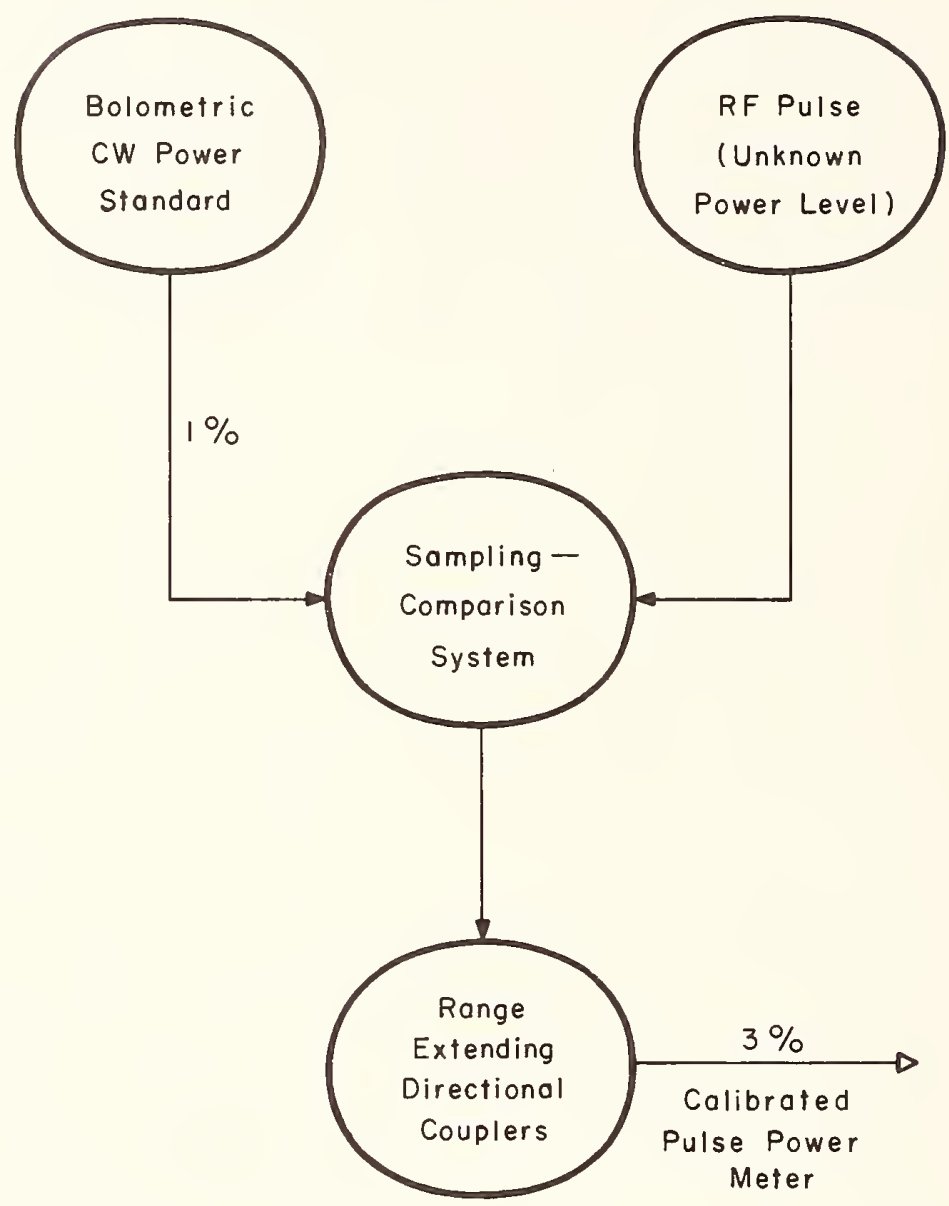




$$
\begin{aligned}
& \text { Peak-Pulse Power in Coaxial Systems } \\
& 300-500 \mathrm{MHz} \\
& 950-1200 \mathrm{MHz} \\
& \text { Peak-Pulse Power: } 1.0 \mathrm{~mW}-3.0 \mathrm{~kW}
\end{aligned}
$$

\section{Bias Uncertainties:}

RF power measurement
a. signal level (CW)
b. direction coupler calibration
1
c. comparison system

Random Errors:

negligible

Total Uncertainty:

$$
3 \%
$$

Uncertainty quoted customer: $3 \%$

Notes: This measurement can be made with the uncertainties stated only on the following conditions:

(1) Pulse duration must be between 2 and 10 microseconds.

(2) Pulse repetition rate range: 100 to $1600 \mathrm{pps}$.

(3) The duty factor (duty cycle) must be less than $33 \times 10^{-4}$.

(4) The peak-pulse power range must be between $1.0 \mathrm{~mW}$ and 3. $0 \mathrm{~kW}$.

References: P. A. Hudson, W. L. Ecklund and R. A. Ondrejka, Measurement of RF peak-pulse power by a sampling-comparison method, IRE Trans. Instr., I-11, 280 (1962).

Peak-pulse power calibrations initiated, NBS, RSL, Engineering Division, IEEE Trans. Microwave Theory and Tech., MTT-14, 47 (1966).

Personnel: P.A. Hudson

P. A. Simpson 
NOISE TEMPERATURE

Coaxial Noise Generator of $3 \mathrm{MHz}$

$75 \mathrm{~K}$ to $30,000 \mathrm{~K}$

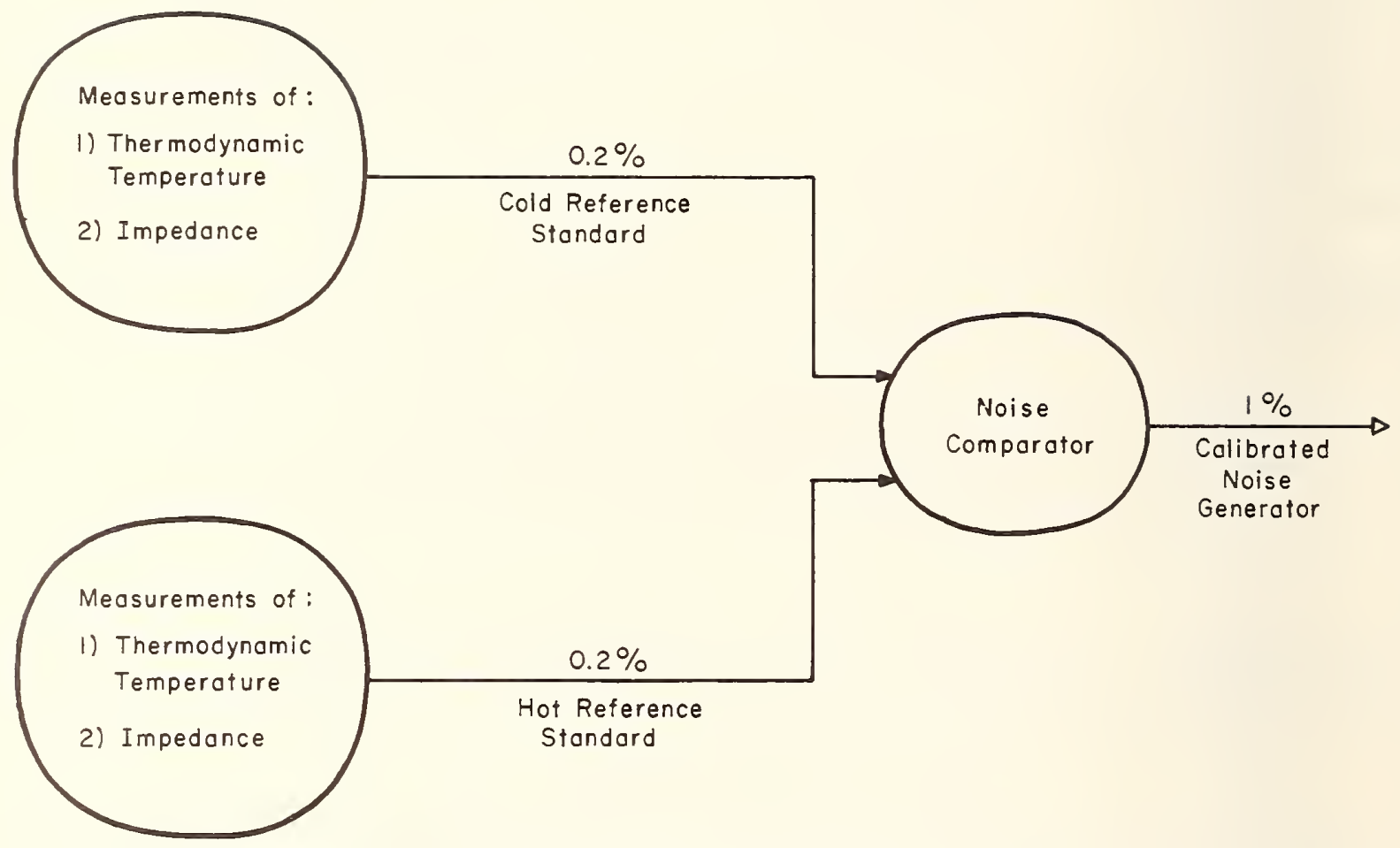


NOISE TEMPERATURE

COAXIAL NOISE GENERATOR AT $3 \mathrm{MHZ}$

$75 \mathrm{~K}$ TO $30,000 \mathrm{~K}$
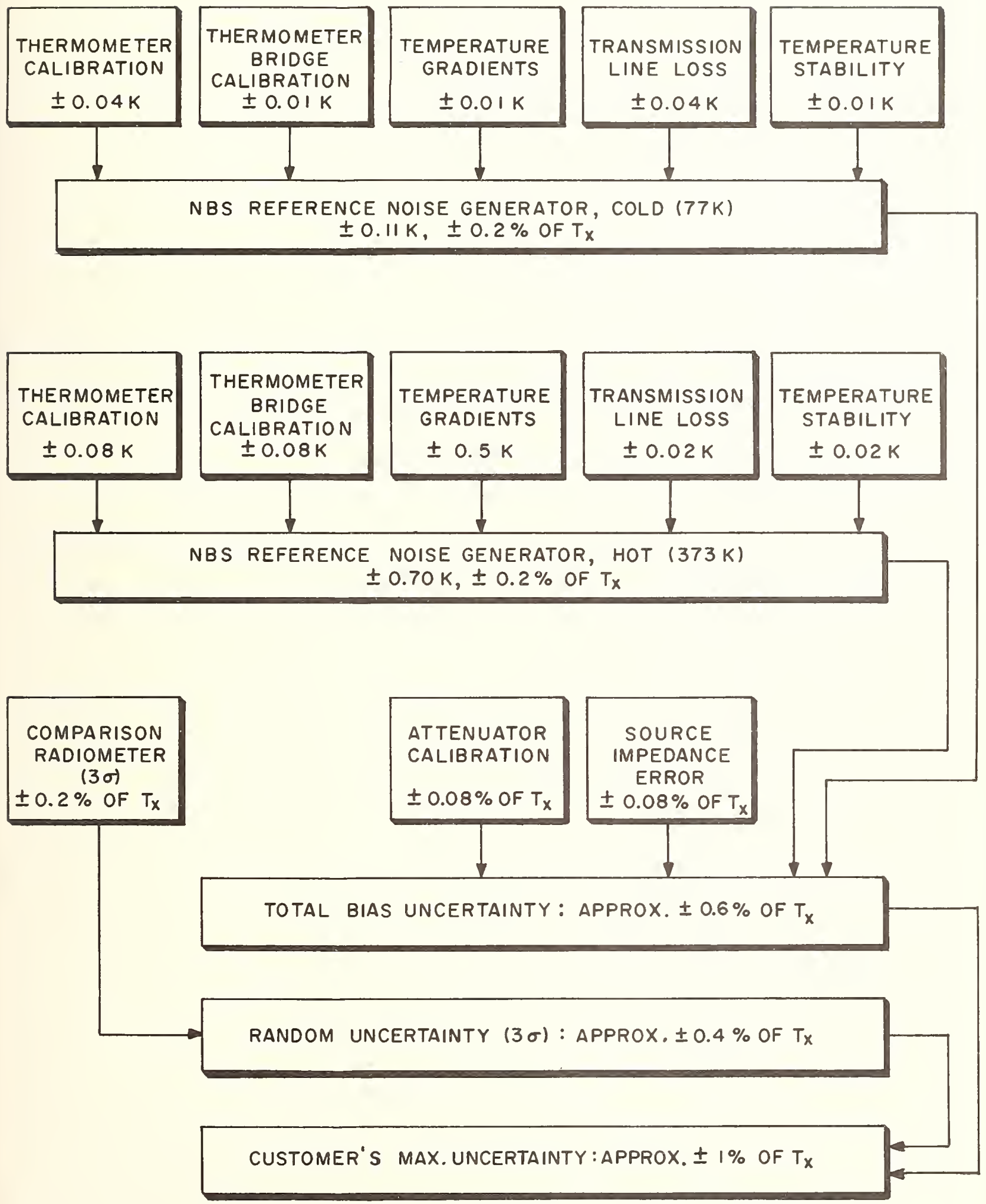
Noise Temperature

Coaxial Noise Generator at $3 \mathrm{MHz}$

$75 \mathrm{~K}$ to $30,000 \mathrm{~K}$

Bias Uncertainties: Approximately $+0.6 \%$

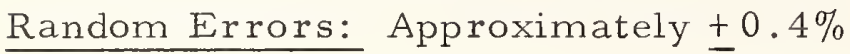

Total Uncertainty: Approximately $\pm 1 \%$

Uncertainty quoted customer: Actual total uncertainty as computed from the measurement data, using the error equation for the measurement process.

Notes: The uncertainties on the diagram (page 19-1)are typical values. Two values are given for each reference generator. The first is the actual uncertainty in the noise temperature of the reference generator; the second is the contribution by that reference generator to the total uncertainty in the measured value of the unknown noise temperature, $T_{X}$.

Reference: M. G. Arthur, C. M. Allred, and M. K. Cannon, A precision noise-power comparator, IEEE Trans. Instr. Meas., IM-13, 301 (1964).

Personnel: M. G. Arthur 
EFFECTIVE NOISE TEMPERATURE

FOR ARGON NOISE SOURCE, OR

WAVEGUIDE NOISE SOURCE AT $9 \mathrm{GHz}$

OPERATING AT $11,000 \mathrm{~K}$

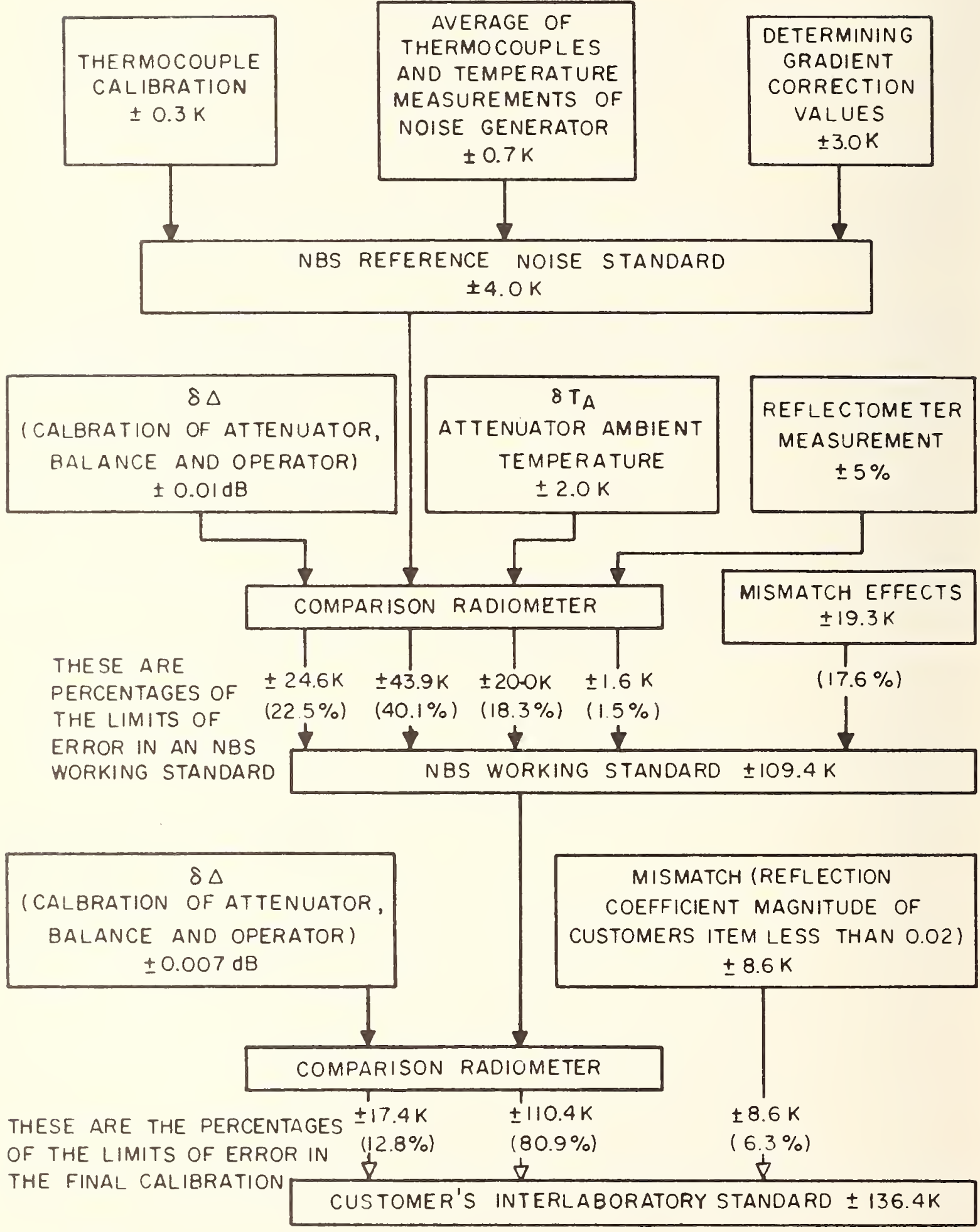


Effective Noise Temperature

For Argon Noise Source, or

Waveguide Noise Source at $9 \mathrm{GHz}$

$11,000 \mathrm{~K}$

Bias Uncertainties:

Random Errors:

Total Uncertainty:
See page 20-1

Uncertainty quoted customer: Same as Total Uncertainty.

Notes: The uncertainties on the diagram (page 20-1) are typical values of systematic error at $9.0 \mathrm{GHz}$. The error limits depend in a very complicated way on several parameters.

Reference: J. S. Wells, W. C. Daywitt and C. K. S. Miller, Measurement of effective temperatures of microwave noise sources, IEEE Trans. Instr. Meas., IM-13, 17 (1964).

Personnel: C. K. S. Miller 


\title{
RF VOLTAGE, COAXIAL SYSTEMS
}

\author{
$30 \mathrm{kHz}-1000 \mathrm{MHz}$ \\ $0.1-300$ Volts
}
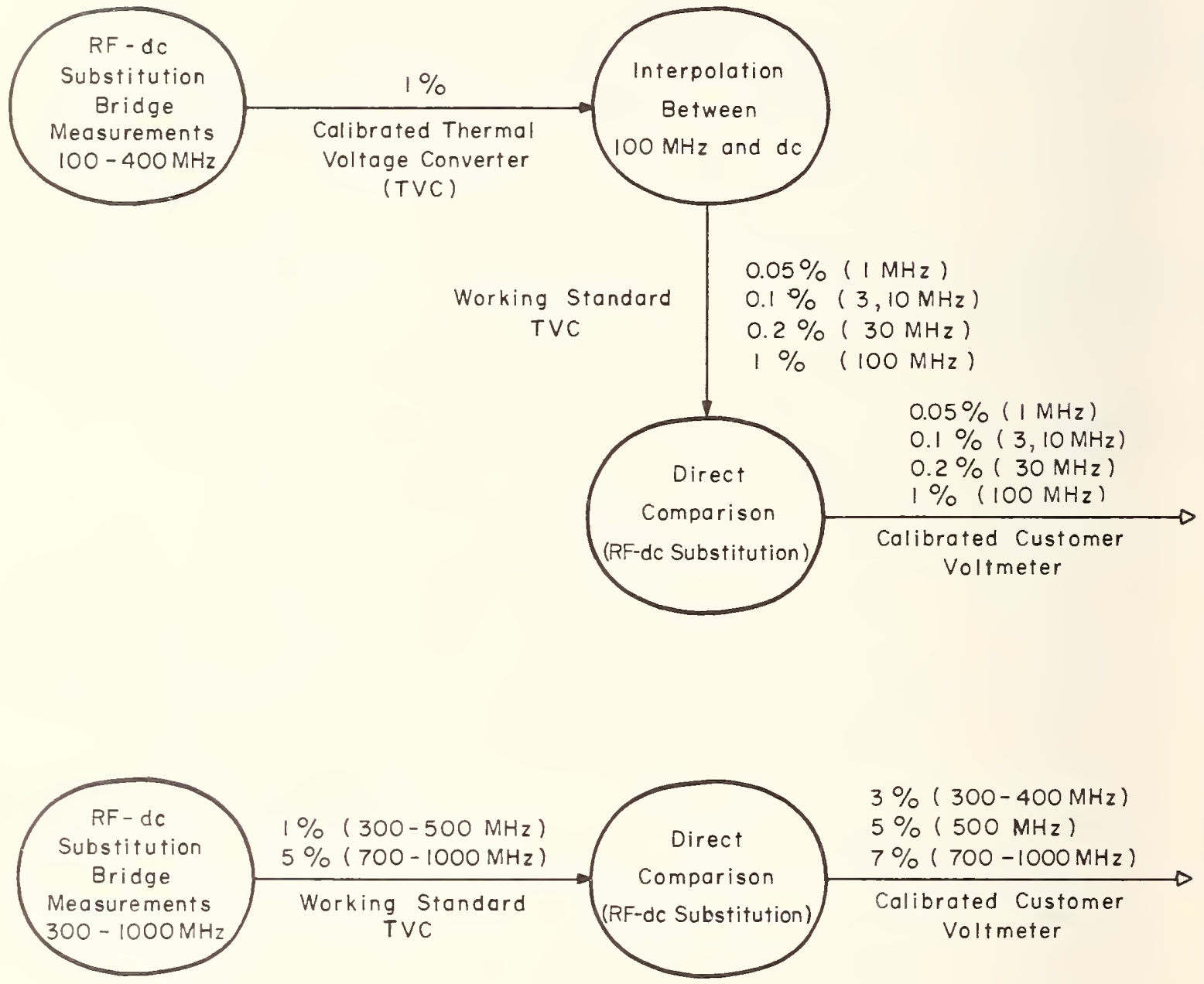
RF Voltage (cw) in Coaxial Systems

$30 \mathrm{kHz}-1000 \mathrm{MHz}$

$0.1-300$ Volts

BOLOMETER BRIDGE MEASUREMENT:

A. Frequencies $30 \mathrm{kHz}-100 \mathrm{MHz}$

Bias Uncertainties:

dc voltages and resistances

$0.061 \%$

RF source drift

0.020

Galvanometer noise

0. 050

Stability of interlaboratory standard resistor

0.010

Short time thermal effects on standard resistor

0.005

$\underline{\text { Random Errors }}(3 \sigma)$ :

0.251

Total Uncertainty:

$0.397 \%$

B. Frequencies $100-1000 \mathrm{MHz}$

Analysis similar to the above yields the following estimated error limits:

\begin{tabular}{cc}
$\begin{array}{c}\text { Frequency } \\
(\mathrm{MHz})\end{array}$ & $\begin{array}{c}\text { Total Uncertainty } \\
(\%)\end{array}$ \\
\hline 100 & 1 \\
300,500 & 1 \\
700,1000 & 5
\end{tabular}

\section{Uncertainty quoted customer: See Notes}

Notes: Ordinarily this measurement is not offered to the public as a service, but is used only for international comparisons and to calibrate working standards for use in the NBS Electronic Calibration Center.

Reference: M. C. Selby and L. F. Behrent, A bolometer bridge for standardizing radio-frequency voltmeters, J. Res. NBS, 44, 15 (1950).

Personnel: M. C. Selby 
THERMAL VOLTAGE CONVERTERS at frequencies $30 \mathrm{kHz}-100 \mathrm{MHz}$

At frequencies below $100 \mathrm{MHz}$ the uncertainties involved in using thermal voltage converters (TVC's) to compare directly dc and ac voltage, without calibration of the converter on a bridge, have been shown by Hermach and Williams to be generally less than the bridge uncertainties (See p. 21). The most important error in this direct procedure is the ac-dc substitution error, which has been investigated theoretically by Hermach and Williams (see Reference p. 2l-3). They checked their theoretical results by making measurements of the ac-dc difference on the bolometer bridge at frequencies up to $400 \mathrm{MHz}$, and found satisfactory agreement. In particular, the theory was verified at frequencies above $100 \mathrm{MHz}$, where the ac-dc substitution error is greatest and the bridge uncertainties are less than that error. On the basis of this verification of the theory, the converters are used as devices (working standards) to compare ac voltages to dc standards without the use of a bridge. The uncertainty in the TVC as a working standard is taken to be just the substitution error, as follows:

$\begin{gathered}\text { Frequency } \\ (\mathrm{MHz})\end{gathered}$
$\begin{gathered}1 \\ 3,10 \\ 30 \\ 100\end{gathered}$

\begin{tabular}{l}
$\begin{array}{c}\text { Uncertainty } \\
(\%)\end{array}$ \\
\hline 0.05 \\
0.1 \\
0.2 \\
1.0
\end{tabular}


DIRECT COMPARISON of customer voltmeters with NBS working standard TVC's:

Bias Uncertainties: In addition to the substitution error considered on page 21-2, other possible sources of error in an actual comparison of ac voltage with dc are:

Measurement of the dc voltage

Mismatch

Determination of the reference plane

It is felt that these errors are negligible with respect to the uncertainty of the working standard at frequencies up to $100 \mathrm{MHz}$, and that they add between two and four percent to the uncertainties of the working standard at frequencies between 300 and $1000 \mathrm{MHz}$.

Random Errors: Negligible

Total Uncertainty:

\begin{tabular}{lc}
$\begin{array}{c}\text { Frequency } \\
(\mathrm{MHz})\end{array}$ & $\begin{array}{c}\text { Uncertainty } \\
(\%)\end{array}$ \\
\cline { 2 - 2 } 3,10 & 0.05 \\
30 & 0.1 \\
100 & 0.2 \\
300,400 & 1 \\
$500 \quad$ & 3 \\
700,1000 & 5 \\
& 7
\end{tabular}

Uncertainty quoted customer: Same as Total Uncertainty above.

Notes: None

References: F. L. Hermach and E. S. Williams, Thermal voltage converters for accurate voltage measurements to 30 megacycles per second, Trans. AIEE, Communication and Electronics, No. 49, 200 (July 1960).

M. C. Selby and L. F. Behrent, A bolometer bridge for standardizing radio frequency voltmeters, J. Res. NBS, 44, 15 (1950).

M. C. Selby, Voltage measurement at high and microwave frequencies in coaxial systems, Proc. IEEE, 55, 877 (1967).

Personnel: M. C. Selby, F. X. Ries 


\section{RF MICROVOLTAGE \\ I- 100 Microvolts, $\quad 50 \mathrm{kHz}-500 \mathrm{MHz}$ \\ $100-100,000$ Microvolts, $50 \mathrm{kHz}-900 \mathrm{MHz}$}

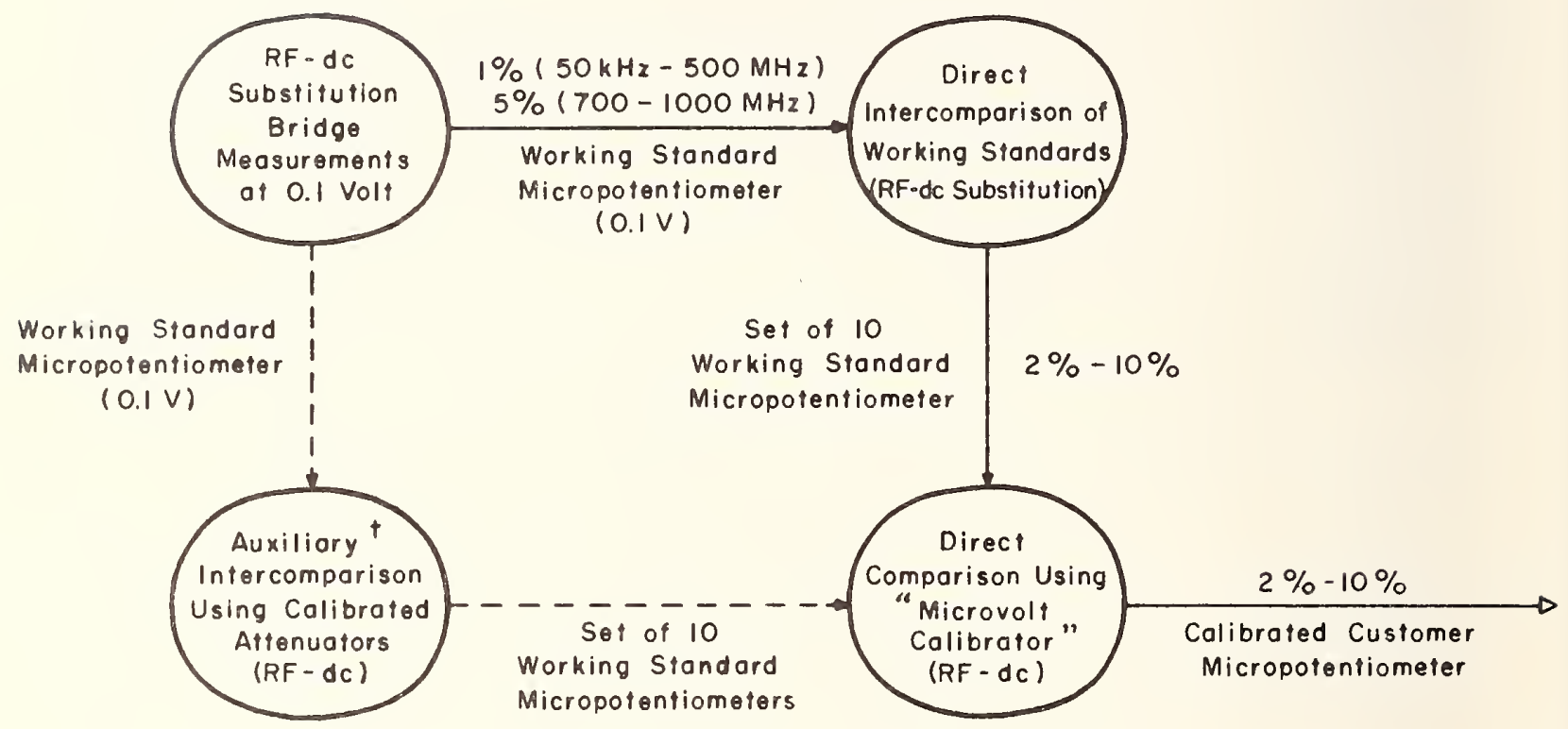

$\uparrow$ Each Sef of 10 Working Standards is Intercompared by Two Different Technlques as an Internal Check. 


$$
\begin{gathered}
\text { RF Microvoltage } \\
1-100 \text { Microvolts; } 50 \mathrm{kHz}-500 \mathrm{MHz} \\
100-100,000 \text { Microvolts; } 50 \mathrm{kHz}-900 \mathrm{MHz}
\end{gathered}
$$

\section{MICROPOTENTIOMETER CALIBRATION:}

Bias Uncertainties:

Uncertainty of the standard (thermal voltage converter)

dc voltage measurement

dc current measurement

attenuation measurement

RF leakage

ground currents (dc)

transfer instrument ( $R F$ receiver) sensitivity

determination of voltage reference plane

The largest of these is the uncertainty of the thermal voltage converter.

Random Errors: Negligible

Total Uncertainty:

\begin{tabular}{llr}
$\begin{array}{c}\text { Frequency } \\
\text { MHz }\end{array}$ & $\begin{array}{c}\text { Voltage Range } \\
\text { microvolts }\end{array}$ & $\begin{array}{r}\text { Uncertainty } \\
\%\end{array}$ \\
\hline $0.05-300$ & $1-100$ & 5 \\
$300-500$ & $1-100$ & 10 \\
$0.05-10$ & $100-100,000$ & 2 \\
$10-300$ & $100-100,000$ & 3 \\
$300-900$ & $100-100,000$ & 5
\end{tabular}

Uncertainty quoted customer: Same as Total Uncertainty, above.

Notes: None

Reference: M. C. Selby, Accurate radio-frequency microvoltages, Trans. AIEE, Communication and Electronics, No. 6, 158-164 (May 1953).

Personnel: M. C. Selby

F. X. Ries 


\section{PULSE VOLTAGE$$
5 \text { - } 1000 \text { Volts }
$$

Pulse Length : $\geq 10$ Nanoseconds

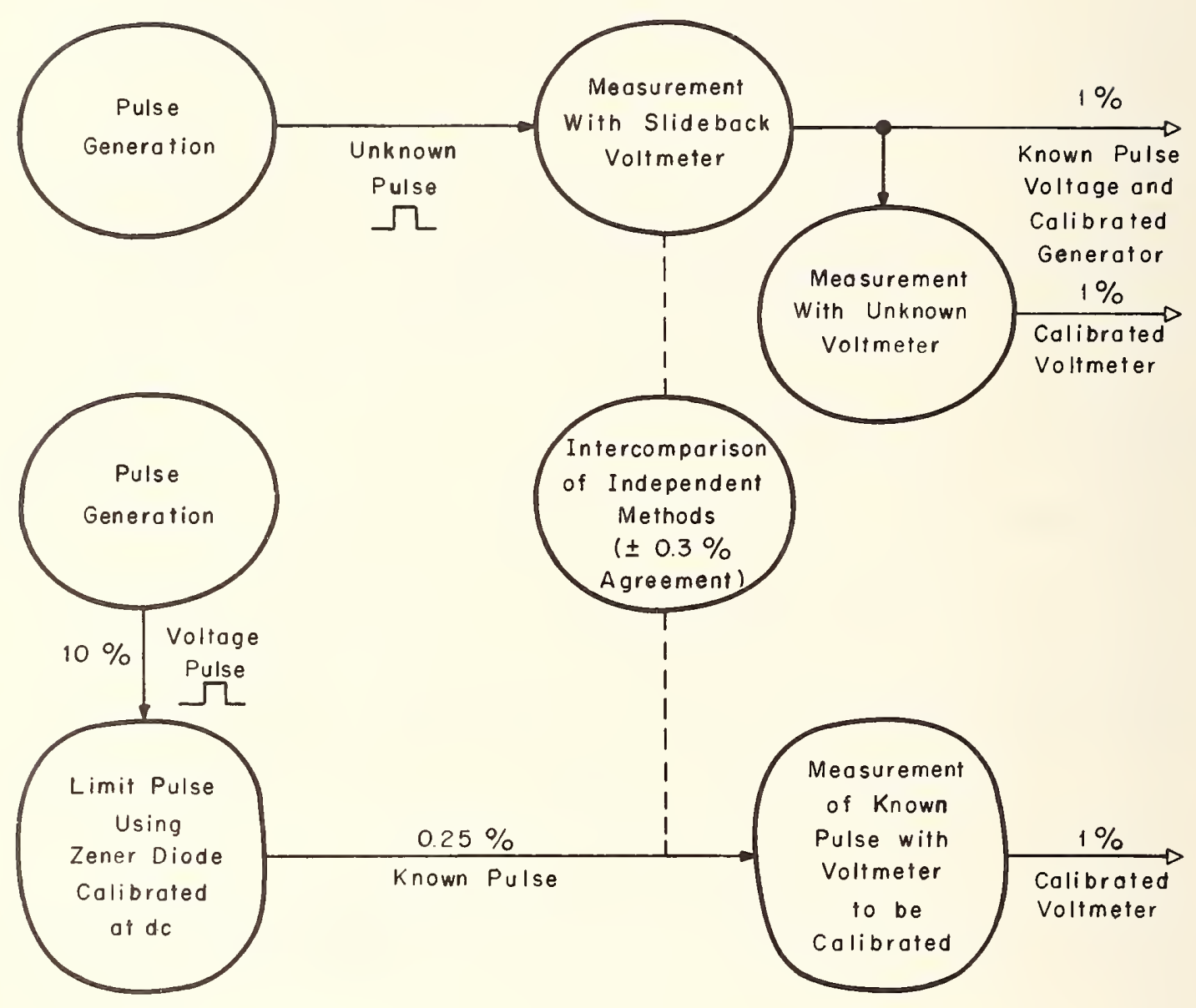




$$
\begin{gathered}
\text { Pulse Voltage } \\
5-1000 \text { Volts } \\
\text { Pulse Duration: } \leq 10 \text { Nanoseconds }
\end{gathered}
$$

SLIDEBACK VOL TMETER METHOD:

Bias Uncertainties:

Thermal effects

Detector null sensitivity

dc voltage

\section{Random Errors:}

Total Uncertainty:

$$
\begin{aligned}
& 10 \mathrm{mV} \\
& 10 \mathrm{mV} \\
& 0.05 \%
\end{aligned}
$$

$\underline{0.1 \%}$

$$
0.15 \% \pm 20 \mathrm{mV}
$$

Uncertainty quoted customer: $1 \%$

Notes: This measurement is made only for pulses longer than 10 nanoseconds.

Measurement agreement between this slideback voltmeter method and the standard pulse generator method is $0.3 \%$. See page $23-2$.

Reference: A. R. Ondrejka and P. A. Hudson, Measurement standards for low and medium peak-pulse voltages, J. Res. NBS, 70C, 13 (1966).

Personnel: P. A. Hudson

P. A. Simpson 
Bias Uncertainties:

Thermal effects

$10 \%$ uncertainty in input pulse voltage dc voltage

Random Errors:

Total Uncertainty:
$0.1 \%$

0.1

0.05

Uncertainty quoted customer: $1 \%$

Notes: This measurement is made only for pulses longer than 10 nanos econds.

The $10 \%$ uncertainty in input pulse voltage can be either an amplitude variation of the flat top of an individual pulse or an amplitude modulation in a series of pulses, or a combination of both.

Measurement agreement between this standard pulse generator system and the slideback voltmeter system is $0.3 \%$. See page 23-1.

Reference: A. R. Ondrejka and P. A. Hudson, Measurement standards for low and medium peak-pulse voltages, J. Res. NBS, 70C, 13 (1966).

Personnel: P. A. Hudson

P. A. Simpson 


\section{FIELD STRENGTH}

$$
\begin{aligned}
& 30 \mathrm{~Hz}-1 \mathrm{GHz} \\
& 20-400 \mathrm{mV} / \mathrm{m}
\end{aligned}
$$

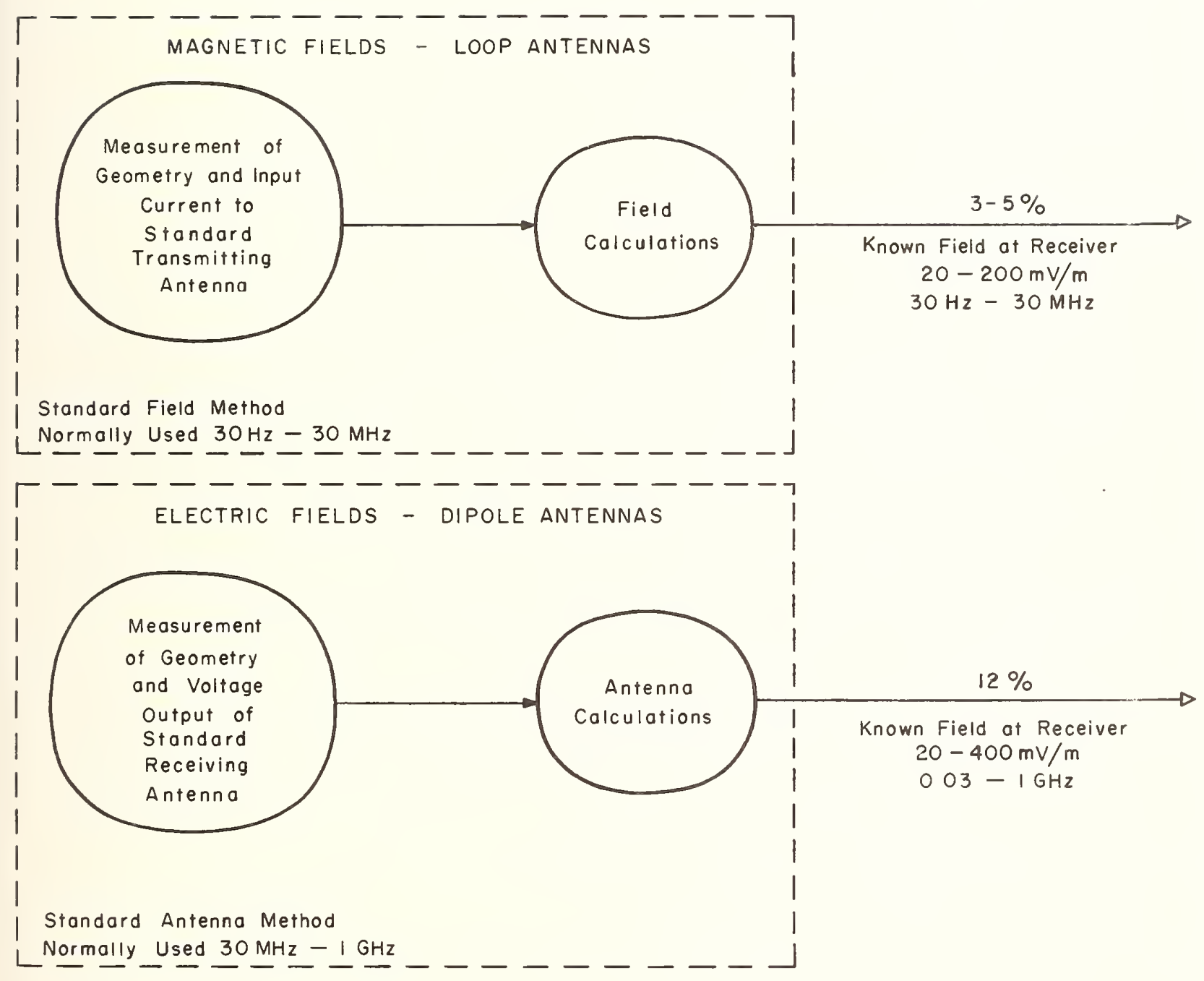


$30 \mathrm{~Hz}-30 \mathrm{MHz}$

$20-200 \mathrm{mV} / \mathrm{m}$

\section{Bias Uncertainties:}

Antenna dimensions

Input current

Output voltage (RF)

Effect of earth and other objects

Attenuation measurement

Random Errors: Not reported.

Total Uncertainty: 3\% (See Notes)

Uncertainty quoted customer: $3 \%$

Notes: The uncertainty of calibration is determined from two independent measurement methods: (1) the standard-field method, (2) the standard-antenna method. The standard-field method is used to calibrate loop antennas. The loop is calibrated in terms of a quasi-static magnetic field and converted to the equivalent electric field based on free space calibrations.

References: F. M. Greene, NBS field-strength standards and measurements $(30 \mathrm{~Hz}$ to $1000 \mathrm{MHz}$ ), Proc. IEEE, 55, 970 (June 1967).

H. E. Taggart, Field-strengths and RFI standards at the National Bureau of Standards, 1968 IEEE Electromagnetic Compatability Symposium Record, IEEE 68CIZ-EMC, 149-158.

Personnel: F. M. Greene

H. E. Taggart 
DIPOLE ANTENNAS, STANDARD ANTENNA METHOD:

$30-1000 \mathrm{MHz}$

$20-400 \mathrm{mV} / \mathrm{m}$

Bias Uncertainties:

Antenna dimensions

Output voltage (dc or RF)

Effect of earth and other objects

Attenuation measurements

Random Errors: Not reported.

Total Uncertainty: $12 \%$ (See notes)

Uncertainty quoted customer: $12 \%$

Notes: The uncertainty of calibration is determined from two independent measurement methods: (1) the standard-field method, (2) the standard-antenna method. The standard-antenna method is used to calibrate dipole antennas. The dipole antenna is calibrated by placing it in a known field at a specified height above ground.

References: F. M. Greene, NBS field-strength standards and measurements $(30 \mathrm{~Hz}$ to $1000 \mathrm{MHz})$, Proc. IEEE, 55, 970 (June 1967).

H. E. Taggart, Field-strengths and RFI standards at the National Bureau of Standards, 1968 IEEE Electromagnetic Compatability Symposium Record, IEEE 68CIZ-EMC, 149-158.

Personnel: F. M. Greene

H. E. Taggart 


\section{FIELD STRENGTH METER}

$$
\begin{gathered}
30 \mathrm{~Hz}-1 \mathrm{GHz} \\
(20-400 \mathrm{mV} / \mathrm{m})
\end{gathered}
$$

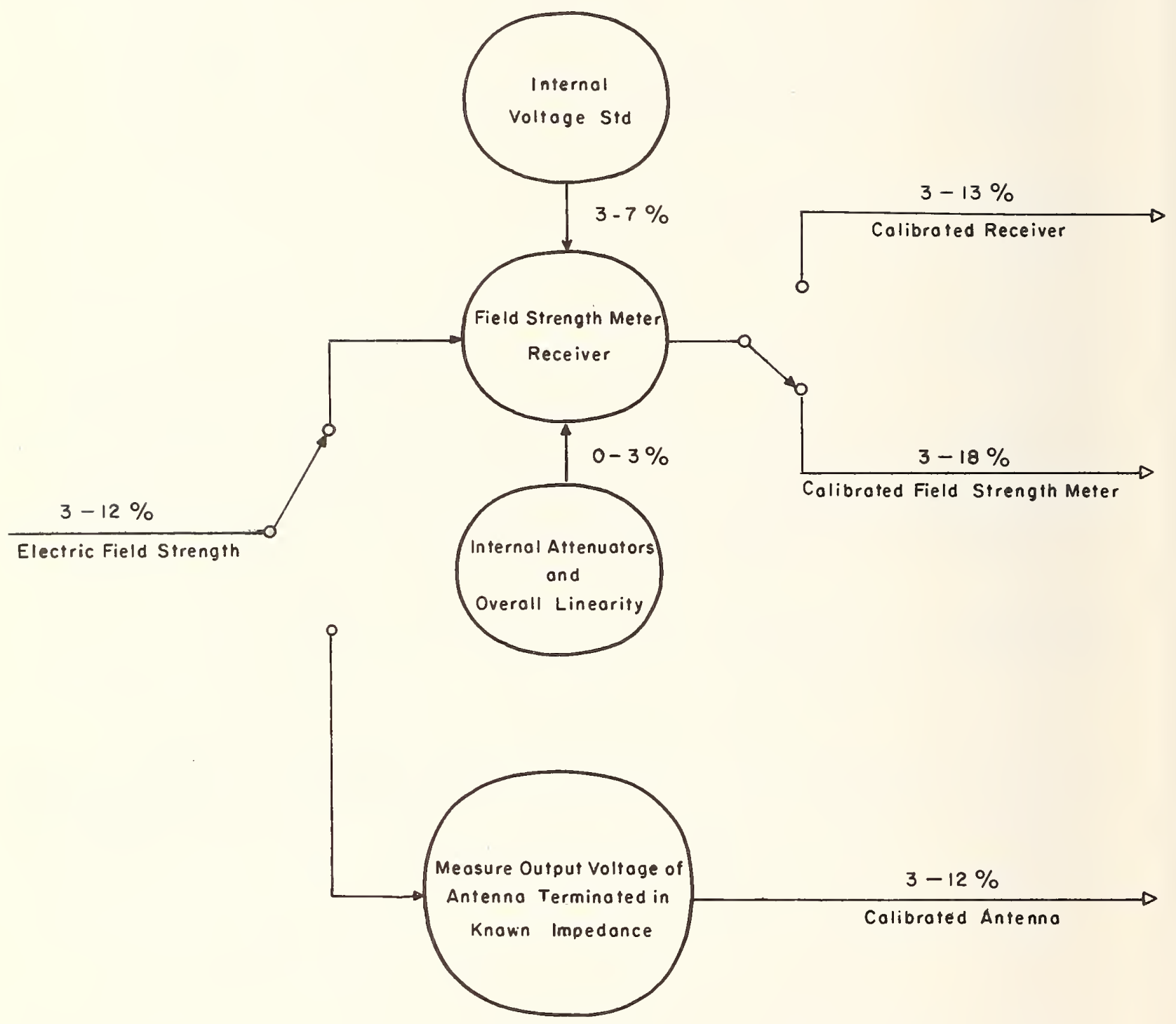


Field Strength Meter

$30 \mathrm{~Hz}-1 \mathrm{GHz}$

$20-400 \mathrm{mV} / \mathrm{m}$

RECEIVER CALIBRATION: (See Notes)

Bias Uncertainties:

Voltage measurement

$\begin{array}{ll}30 \mathrm{~Hz}-100 \mathrm{MHz} & 3 \% \\ 100-500 \mathrm{MHz} & 5 \% \\ 500-900 \mathrm{MHz} & 7 \%\end{array}$

Calibration of attenuators and

$30 \mathrm{~Hz}-400 \mathrm{MHz} 0.1 \mathrm{~dB}+0.03 \mathrm{~dB} / 10 \mathrm{~dB}$ overall linearity of receiver $400-1000 \mathrm{MHz}$

$0.1 \mathrm{~dB}+0.05 \mathrm{~dB} / 10 \mathrm{~dB}$

Random Errors: Not reported.

Total Uncertainty: $3 \%+0.1 \mathrm{~dB}+0.03 \mathrm{~dB} / 10 \mathrm{~dB}$ to

$7 \%+0.1 \mathrm{~dB}+0.05 \mathrm{~dB} / 10 \mathrm{~dB}$

Uncertainty quoted customer:

$\begin{array}{lr}30 \mathrm{~Hz}-100 \mathrm{MHz} & 5 \% \\ 100-500 \mathrm{MHz} & 7 \% \\ 500-1000 \mathrm{MHz} & 10 \%\end{array}$

Notes: As shown on page 25, a field strength meter consisting of an antenna and a receiver (which itself consists of a detector, internal attenuators and a voltmeter) can be calibrated as a unit (the "switch" is shown in that position), or the receiver and the antenna can be calibrated separately (the other "switch" position). When calibrated as a unit, the uncertainties are those as given on pages 24-1 and 24-2. When calibrated separately, the uncertainties are as given on pages $25-1$ and 25-2.

Reference: None

Personnel: F.M. Greene

H. E. Taggart 
ANTENNA CALIBRATION:

Loop antennas: $30 \mathrm{~Hz}-30 \mathrm{MHz}$

Dipole antennas: $30-1000 \mathrm{MHz}$

Bias Uncertainties: See Notes.

Random Errors: Not reported.

Total Uncertainty: Loop antennas, 3\%; dipole antennas, $12 \%$.

Uncertainty quoted customer: Loop antennas, 3\%; dipole antennas, $12 \%$.

Notes: As shown on page 25 the calibration of an antenna by itself is done by placing the antenna in a known field, terminating it in a known impedance, and measuring its output voltage. The total uncertainty is taken to be equal to that of the uncertainty in the field itself, which is obtained as on pages 24, 24-1, and 24-2.

References: F. M. Greene, NBS field-strength standards and measurements (30 Hz to $1000 \mathrm{MHz}$ ), Proc. IEEE, 55, 970 (June 1967).

H. E. Taggart, Field-strengths and RFI standards at the National Bureau of Standards, 1968 IEEE Electromagnetic Compatability Symposium Record, IEEE 68CIZ-EMC, $149-158$.

Personnel: F. M. Greene

H. E. Taggart 


\title{
ATTENUATION: COAXIAL SYSTEMS
}

\author{
$10-18,000 \mathrm{MHz}$ \\ $0-140 \mathrm{~dB}$
}

Meosurements of

1) Guide Diameter

2) Lineor Displacement

3) Velocity of Light in Guide

4) Conductivity

5) Permeability

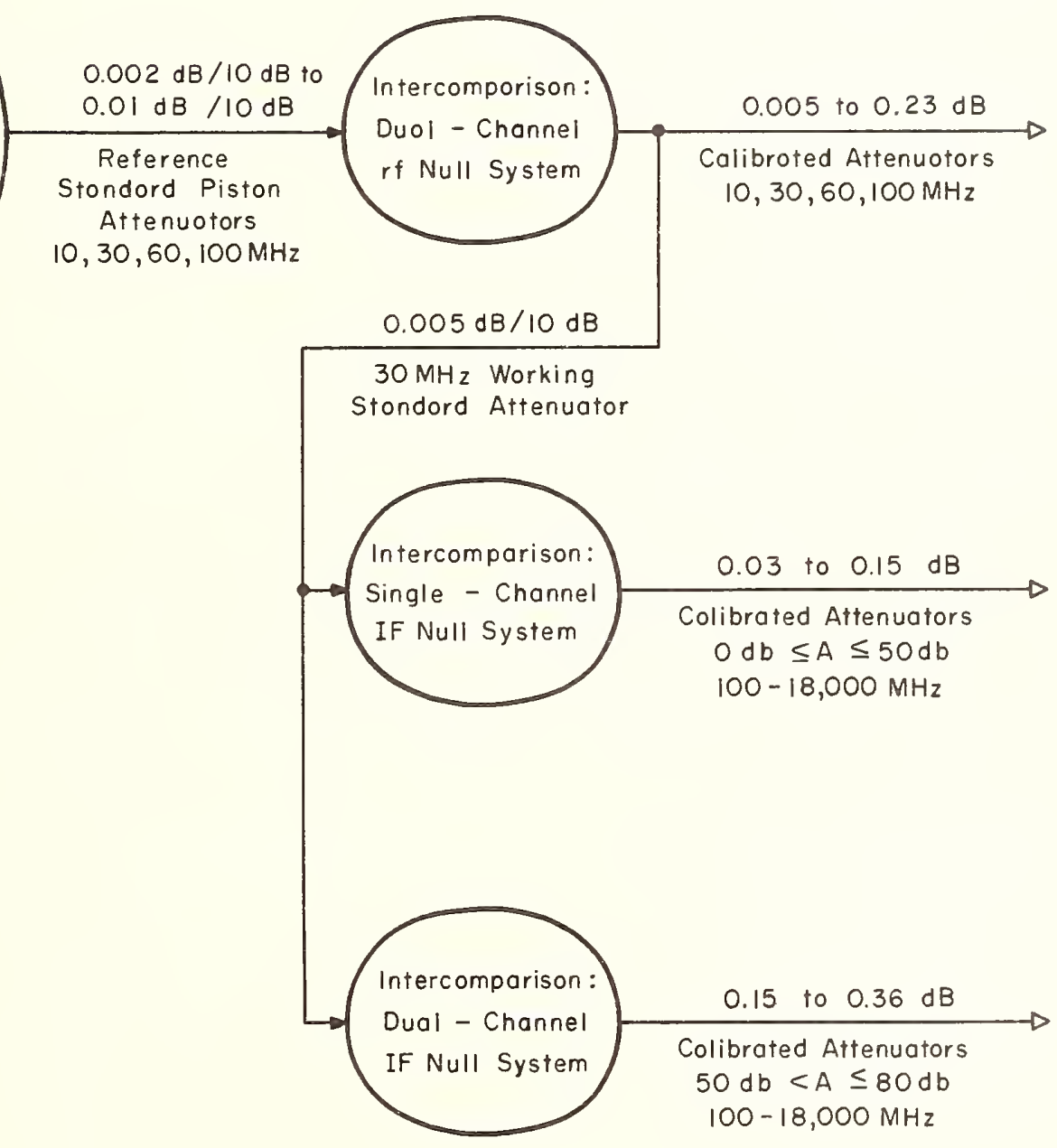


PISTON ATTENUATION:

$10,30,60,100 \mathrm{MHz}$

$0-140 \mathrm{~dB}$

Bias Uncertainties:

Coaxial waveguide diameter

Linear displacement of receiving coil

Velocity of electromagnetic waves in medium inside guide

RF conductivity of guide

RF permeability of guide

Random Errors:

Total Uncertainty:
$0.0003 \mathrm{~dB} / 10 \mathrm{~dB}$

$0.001 \mathrm{~dB} / 10 \mathrm{~dB}-0.01 \mathrm{~dB} / 10 \mathrm{~dB}$

negligible

$0.00026 \mathrm{~dB} / 10 \mathrm{~dB}$

negligible

negligible

$0.002 \mathrm{~dB} / 10 \mathrm{~dB}-0.01 \mathrm{~dB} / 10 \mathrm{~dB}$

Uncertainty quoted customer: See Notes.

Notes: Lower limits of these measurements are not available to customers, but are used only to establish the uncertainty in the National Bureau of Standards reference standard piston attenuators.

Reference: C. M. Allred and C. C. Cook, A precision RF attenuation calibration system, IRE Trans. Instr. I-9, 268 (1960).

Personnel: R. T. Adair 
DUAL-CHANNEL RF NULL SYSTEM:

$10,30,60,100 \mathrm{MHz}$

$0-140 \mathrm{~dB}$

Bias Uncertainties:

Reference standard piston attenuator $0.002 \mathrm{~dB} / 10 \mathrm{~dB}-0.01 \mathrm{~dB} / 10 \mathrm{~dB}$

Mismatch errors

$0.001 \mathrm{~dB} / 10 \mathrm{~dB}$

Leakage

$0.001 \mathrm{~dB} / 10 \mathrm{~dB}$

Random Errors: See Notes.

$0.001-0.06 \mathrm{~dB}$

Total Uncertainty:

$0.005-0.23 \mathrm{~dB}$

Uncertainty quoted customer: Uncertainty is estimated for each individual case and those estimates are reported directly to the customer.

Notes: The random errors are reported to the customer as 3 times the standard error, which is defined on the calibration report. Typical standard errors range from about $0.001 \mathrm{~dB}$ at low attenuations up to about $0.06 \mathrm{~dB}$ at high attenuations.

Explicit numbers for mismatch errors and leakage errors are estimated for each individual case.

The maximum range of the standard piston attenuators is $140 \mathrm{~dB}$ at $30 \mathrm{MHz}$ and $100 \mathrm{~dB}$ at 10,60 , and $100 \mathrm{MHz}$.

The numbers quoted for bias uncertainties are typical values, and may not apply to a particular calibration.

Reference: C. M. Allred and C. C. Cook, A precision RE attenuation

calibration system, IRE Trans. Instr., I-9, 269 (1960).

Personnel: R. T. Adair 
SINGLE-CHANNEL IF NULL SYSTEM:

$100-18,000 \mathrm{MHz}$

$0-50 d B$

Bias Uncertainties:

Mismatch errors

$0.01 \mathrm{~dB} / 10 \mathrm{~dB}$

Mixer non-linearity

$0.005 \mathrm{~dB} / 10 \mathrm{~dB}$

Noise, as a systematic error

$0.005 \mathrm{~dB} / 10 \mathrm{~dB}$

Leakage

$0.005 \mathrm{~dB} / 10 \mathrm{~dB}$

Working standard piston attenuator uncertainty

$0.005 \mathrm{~dB} / 10 \mathrm{~dB}$

Random Errors: See Notes.

Total Uncertainty:

$0.03-0.15 \mathrm{~dB}$

Uncertainty quoted customer: Reported as estimated in each individual case.

Notes: The random errors include such effects as connector precision, generator and detector fluctuations, and noise or instability in the unknown attenuator. They are reported to the customer as 3 times the standard error, with a sample size usually 6 , giving about a $96 \%$ confidence limit. These random errors are generally negligible.

Explicit numerical entries for the bias uncertainties are estimated in each individual case.

Reference: David H. Russell, An unmodulated twin-channel microwave measurement system, ISA Trans., 4, 162 (1965).

Personnel: R. T. Adair 
DUAL-CHANNEL IF NULL SYSTEM:

$100-18,000 \mathrm{MHz}$

$50-80 \mathrm{~dB}$

Bias Uncertainties:

Mismatch errors

Mixer non-linearity

Noise, as a systematic error

Leakage

Working standard piston attenuator

Random Errors: See Notes, page 26-3.
$0.01 \mathrm{~dB} / \mathrm{I} 0 \mathrm{~dB}-0.02 \mathrm{~dB} / 10 \mathrm{~dB}$
$0.005 \mathrm{~dB} / 10 \mathrm{~dB}-0.01 \mathrm{~dB} / 10 \mathrm{~dB}$
$0.005 \mathrm{~dB} / 10 \mathrm{~dB}$
$0.005 \mathrm{~dB} / 10 \mathrm{~dB}$
$0.005 \mathrm{~dB} / 10 \mathrm{~dB}$

Total Uncertainty:

$0.15-0.36 \mathrm{~dB}$

Uncertainty quoted customer: Reported as estimated in each individual case.

Notes: Explicit numerical entries for the bias uncertainties are estimated in each individual case.

References: D. Russell and W. Larson, RF attenuation, Proc. IEEE, 55, $942(1967)$.

B. O. Weinschel, G. U. Sorger, and A. L. Hedrich, Relative voltmeter for VHF/UHF signal generator attenuator calibration, IRE Trans. Instr., I-8, 22 (1959).

A. L. Hedrich, B. O. Weinschel, G. U. Sorger, and S. J. Raff, Calibration of signal generator output voltage in the range of 100 to 1000 megacycles, IRE Trans. Instr., I-7, 275 (1958).

Personnel: R. T. Adair 


\section{ATTENUATION: WAVEGUIDE SYSTEMS}

$$
\begin{gathered}
1.7-40 \mathrm{GHz} \\
0-50 \mathrm{~dB}
\end{gathered}
$$
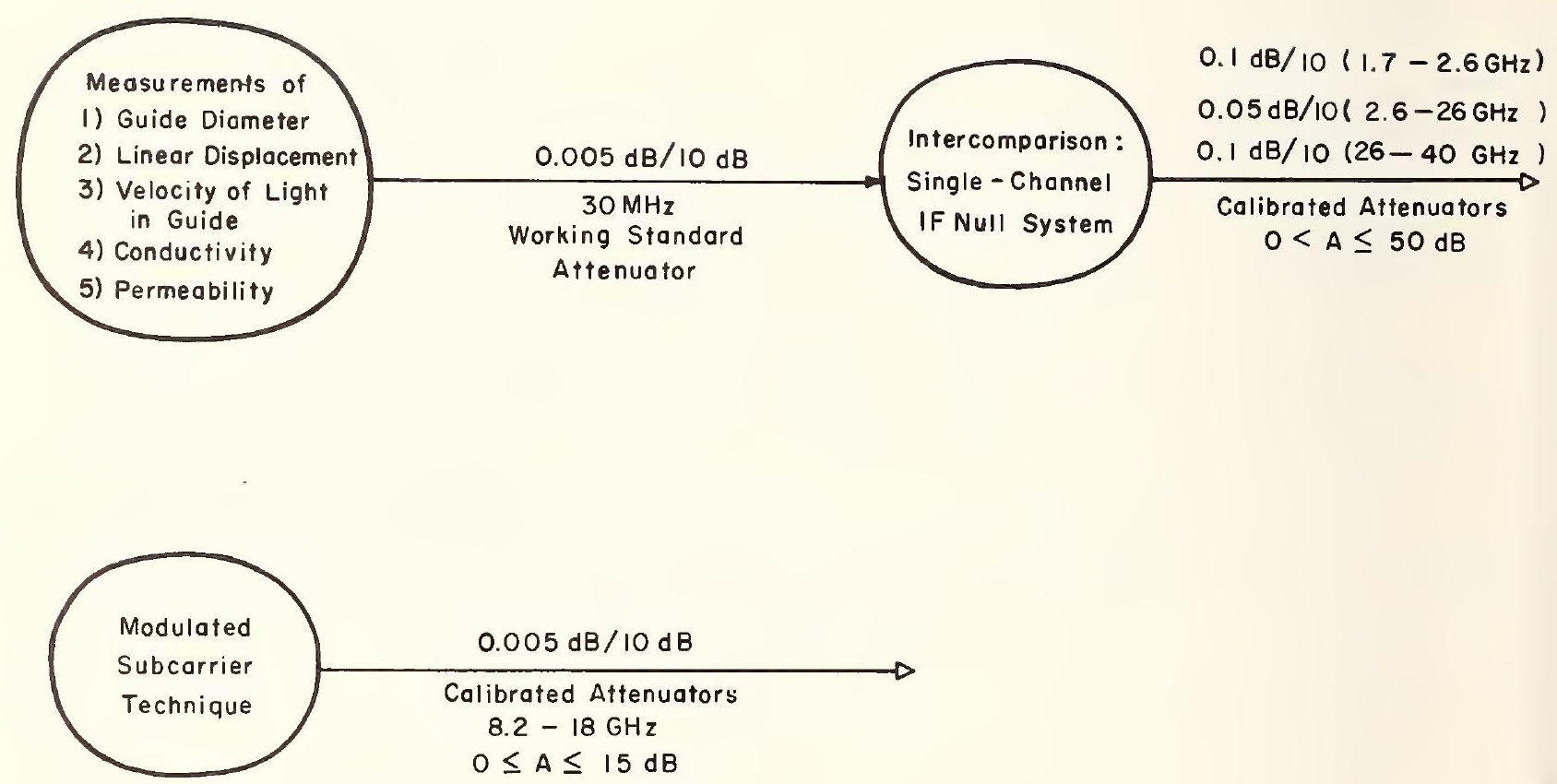
Attenuation: Waveguide Systems

$$
\begin{aligned}
1.7 & -40 \mathrm{GHz} \\
0 & -50 \mathrm{~dB}
\end{aligned}
$$

PISTON ATTENUATOR: See page 26-1.

SINGLE-CHANNEL IF SYSTEM:

Bias Uncertainties:

Random Errors: $\quad$ See Error Flow Diagram, page 27-2

Total Uncertainty:

Uncertainty quoted customer:

$\begin{array}{ll}0.1 \mathrm{~dB} / 10 \mathrm{~dB} ; & 1.7-2.6 \mathrm{GHz} \\ 0.05 \mathrm{~dB} / 10 \mathrm{~dB} ; & 2.6-26 \mathrm{GHz} \\ 0.1 \mathrm{~dB} / 10 \mathrm{~dB} ; & 26-40 \mathrm{GHz}\end{array}$

Notes: None

Reference: R. E. Larson, Microwave measurements in the NBS Electronic Calibration Center, Proc. IEE (London), 109, part B, suppl. 23, 644 (1962).

Personnel: W. Larson 


\section{IF ATTENUATION CALIBRATION SYSTEM ERROR FLOW DIAGRAM}

FREQUENCY 1.7 - $40 \mathrm{GHz}$ WR $430 \ldots \ldots$. . WR 28

ESTIMATED

RANDOM ERRORS

(INSERTION LOSS)

- - - - - - - $]$

CONNECT

DISCONNECT

3 Sigmo

0.2
ESTIMATED

SYSTEMATIC ERRORS

[ATTENUATION DIFFERENCE]

(WR $284 \ldots$ - - - WR 28)

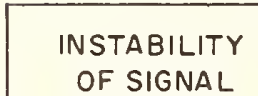

$\pm 0.004 \mathrm{~dB}$

\begin{tabular}{|c|c|}
\hline \multicolumn{2}{|c|}{ ATTENUATOR } \\
RESETTABILITY \\
\hline DIAL & dB \\
SETTING & ERROR \\
\hline 10 & 0.002 \\
\hline 20 & 0.005 \\
\hline 30 & 0.008 \\
\hline 40 & 0.015 \\
\hline 50 & 0.025 \\
\hline
\end{tabular}

\begin{tabular}{|c|c|}
\hline \multicolumn{2}{|c|}{ OPERATOR } \\
PERFORMANCE \\
\hline $\begin{array}{c}\text { DIAL } \\
\text { SETTING }\end{array}$ & $\begin{array}{c}\text { dB } \\
\text { ERROR }\end{array}$ \\
\hline 10 & 0.003 \\
\hline 20 & 0.005 \\
\hline 30 & 0.010 \\
\hline 40 & 0.018 \\
\hline 50 & 0.030 \\
\hline
\end{tabular}

RANDOM ERRORS

TOTAL TOLERANCE ALLOWED 3 Sigmo

\begin{tabular}{|c|c|}
\hline $\begin{array}{c}\text { DIAL } \\
\text { SETTING }\end{array}$ & $\begin{array}{c}\text { dB } \\
\text { ERROR }\end{array}$ \\
\hline 10 & 0.009 \\
\hline 20 & 0.014 \\
\hline 30 & 0.022 \\
\hline 40 & 0.037 \\
\hline 50 & 0.059 \\
\hline
\end{tabular}

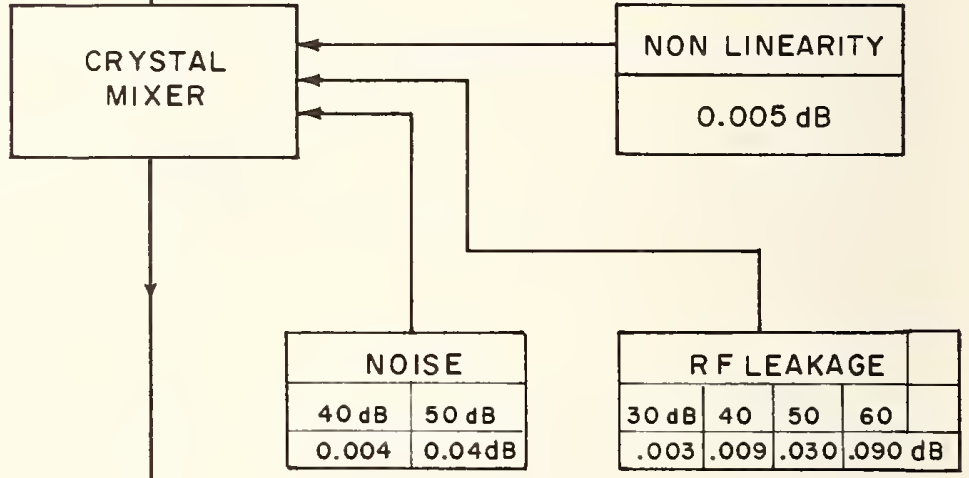

INSERTION POINT
MISMATCH

LINE 1.02 VSWR

ATTENUATOR VSWR

\begin{tabular}{|l|l|l|l|}
\hline 1.05 & 1.10 & 1.15 & 1.20 \\
\hline 0.005 & 0.008 & 0.013 & $0.017 \mathrm{~dB}$ \\
\hline
\end{tabular}
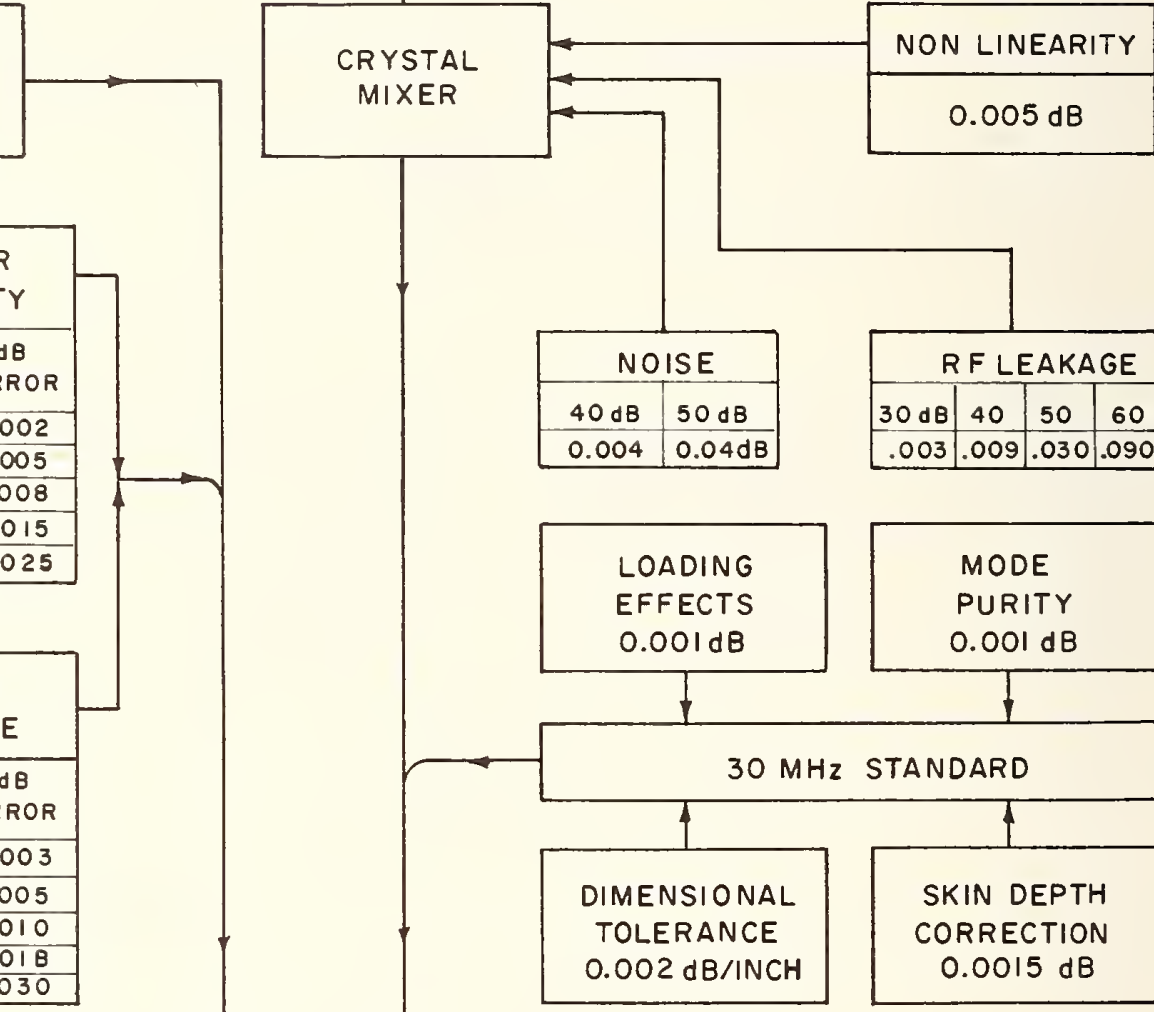

TO CUSTOMER

TOTAL SYSTEMATIC ERRORS

\begin{tabular}{|c|l|l|l|l|}
\hline \multirow{2}{*}{ DIAL } & \multicolumn{2}{|c}{ ATTEN. } & \multicolumn{2}{c|}{ VSWR } \\
\cline { 2 - 5 } SETTING & 1.05 & 1.10 & 1.15 & 1.20 \\
\hline 10 & $0.015 \mathrm{~dB}$ & 0.018 & 0.023 & 0.027 \\
\hline 20 & 0.015 & 0.018 & 0.023 & 0.027 \\
\hline 30 & 0.018 & 0.021 & 0.026 & 0.030 \\
\hline 40 & 0.028 & 0.030 & 0.036 & 0.040 \\
\hline 50 & 0.085 & 0.088 & 0.093 & 0.097 \\
\hline
\end{tabular}


Attenuation: Waveguide Systems

\section{MODULATED SUBCARRIER TECHNIQUE:}

Bias Uncertainties:

Random Errors: $\quad$ See Error Flow Diagram, page 27-4

Total Uncertainty:

Uncertainty quoted customer: $0.005 \mathrm{~dB} / 10 \mathrm{~dB} ; 8.2-18.0 \mathrm{GHz}$

\section{Notes: none}

Reference: G. E. Schafer and R. R. Bowman, A modulated subcarrier technique of measuring microwave attenuation, Proc. IEE (London), 109, part B, suppl. 23, 783 (1962).

Personnel: W. Larson 


\section{ATTENUATION : WAVEGUIDE SYSTEMS \\ ERROR FLOW CHART FOR MODULATED SUBCARRIER}

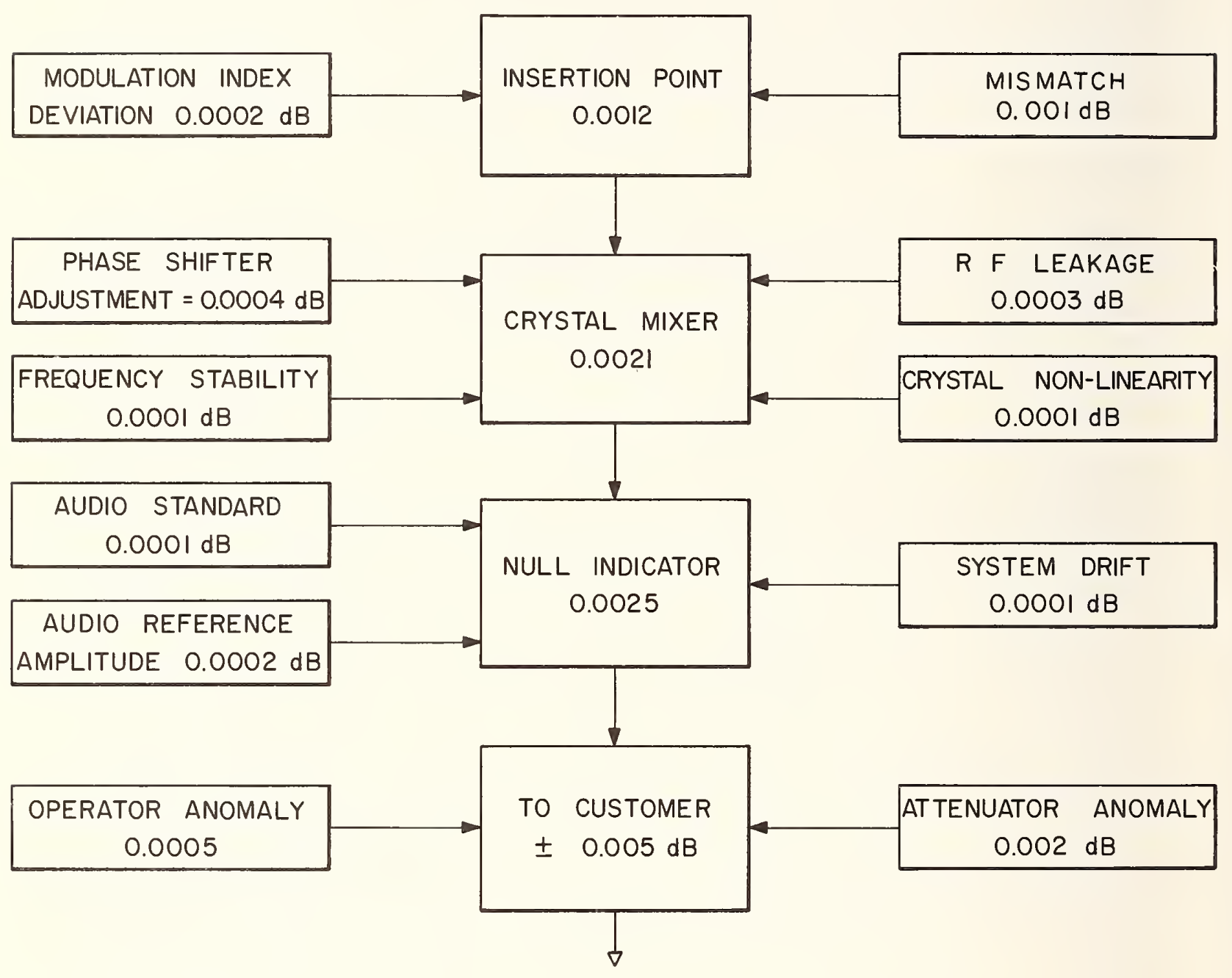


PHASE SHIFT

IN COAXIAL PHASE SHIFTERS

$$
\begin{gathered}
30-12,400 \mathrm{MHz} \\
0-360 \text { Degrees }
\end{gathered}
$$

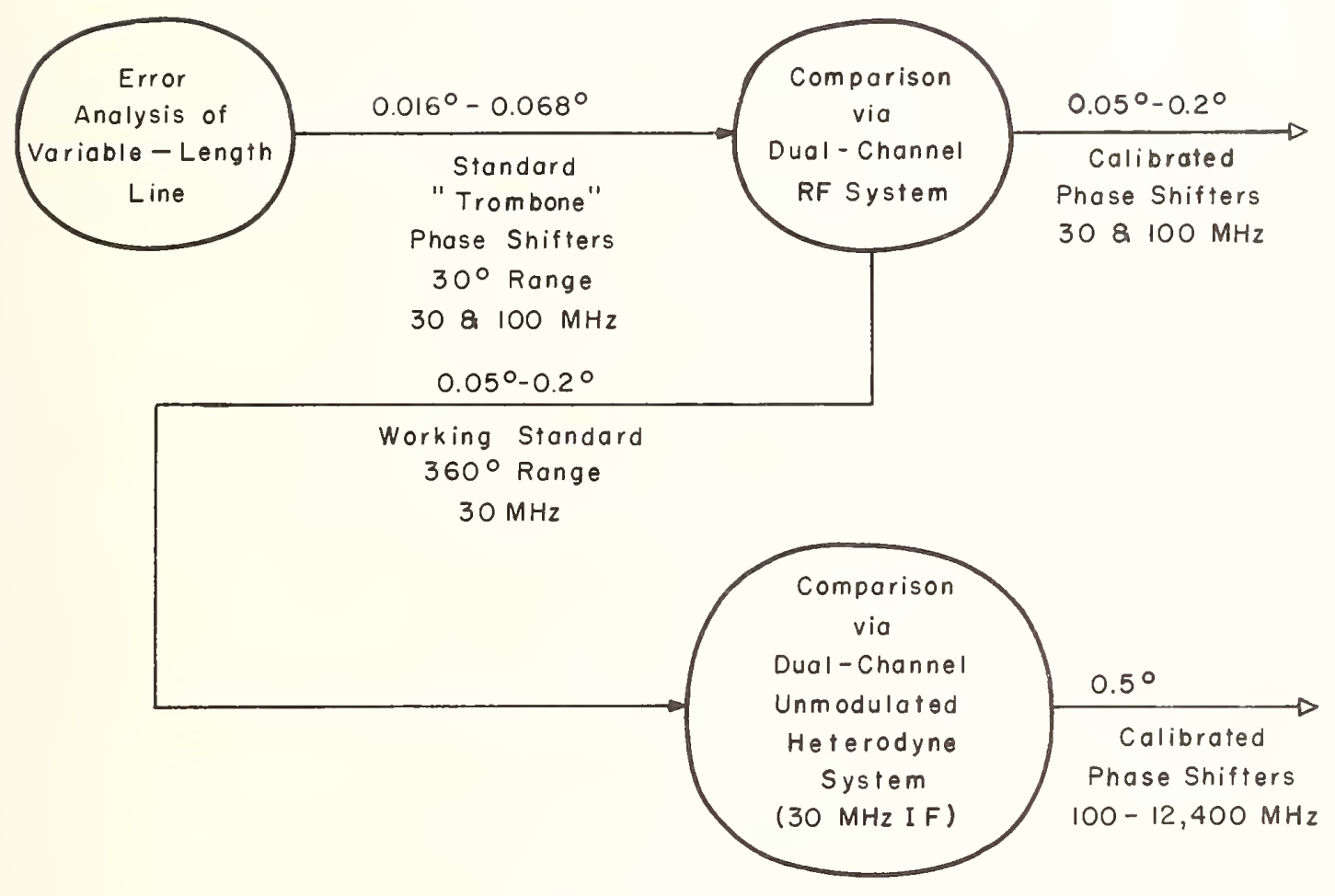


Phase Shift in Coaxial Two-Ports

30 and $100 \mathrm{MHz}$

0.05 - 360 Degrees

\section{DUAL-CHANNEL RF COMPARISONS:}

Bias Uncertainties:

Mechanical stability and length

measurement in trombone phase shifter

$0.004-0.048$ degree

(30 $\mathrm{MHz}$ )

Mismatch of trombone

$0.012-0.144$

$(100 \mathrm{MHz})$

Phase shift in standard attenuator

0.012

Resolution in auxilary phase shifter

0.01

$0.02-0.13$

Random Errors:

\section{negligible}

Total Uncertainty:

$$
\begin{aligned}
& 0.046-0.2 \text { degree }(30 \mathrm{MHz}) \\
& 0.054-0.208 \text { degree }(100 \mathrm{MHz})
\end{aligned}
$$

Uncertainty quoted customer: Reported as estimated for each individual case.

Notes: Where there is a range of uncertainty in the list above, the uncertainty is a function of the phase shift in the coaxial two-port.

Reference: David H. Russell, An unmodulated twin-channel microwave measurement system, ISA Trans., 4, 162 (1965).

Personnel: R. T. Adair 
Phase Shift in Coaxial Phase Shifters

$$
\begin{gathered}
30-12,400 \mathrm{MHz} \\
0=360 \text { degrees }
\end{gathered}
$$

\section{DUAL-CHANNEL RF COMPARISONS:}

\section{Bias Uncertainties:}

Mechanical stability and length measurement in trombone phase shifter

$0.004-0.048$ degree (30 MHz)

$$
0.012-0.144 \quad \text { (100 MHz) }
$$

Mismatch of trombone

0.012

Phase shift in standard attenuator

0.01

Resolution in auxiliary phase shifter

$0.02-0.13$

\section{Random Errors:}

Total Uncertainty: negligible

$$
\begin{aligned}
& 0.05-0.2 \text { degree }(30 \mathrm{MHz}) \\
& 0.05-0.21 \text { degree }(100 \mathrm{MHz})
\end{aligned}
$$

Uncertainty quoted customer: Reported as estimated for each individual case.

Notes: Where there is a range of uncertainty in the list above, the uncertainty is a function of the phase shift in the coaxial phase shifter.

Reference: David H. Russell, An unmodulated twin-channel microwave measurement system, ISA Trans., 4, 162 (1965).

Personnel: R. T. Adair 


\section{DUAL-CHANNEL IF UNMODULATED COMPARISON SYSTEM:}

$100-18,000 \mathrm{MHz}$

$0-360$ degrees

Bias Uncertainties:

$30 \mathrm{MHz}$ working standard (resolver)

0.2 degree

Mismatch of unknown phase shifter

0.05

Mixer non-linearity (See Notes)

Resolution (null sensitivity)

0.1

Random Errors:

negligible

Total Uncertainty:

$<0.35$ degree

Uncertainty quoted customer: 0.5 degree.

Notes: The mixer non-linearity error is determined separately for each calibration.

Reference: David H. Russell, An unmodulated twin-channel microwave measurement system, ISA Trans., 4, 162 (1965).

Personnel: R. T. Adair 


\section{PHASE SHIFT}

IN WAVEGUIDE PHASE SHIFTERS

$$
\begin{gathered}
\text { WR } 62: 12.4-18.0 \mathrm{GHz} \\
\text { WR } 90: 8.20-12.4 \mathrm{GHz} \\
\text { WR } 137: 5.85-8.20 \mathrm{GHz} \\
0-720 \text { Degrees }
\end{gathered}
$$

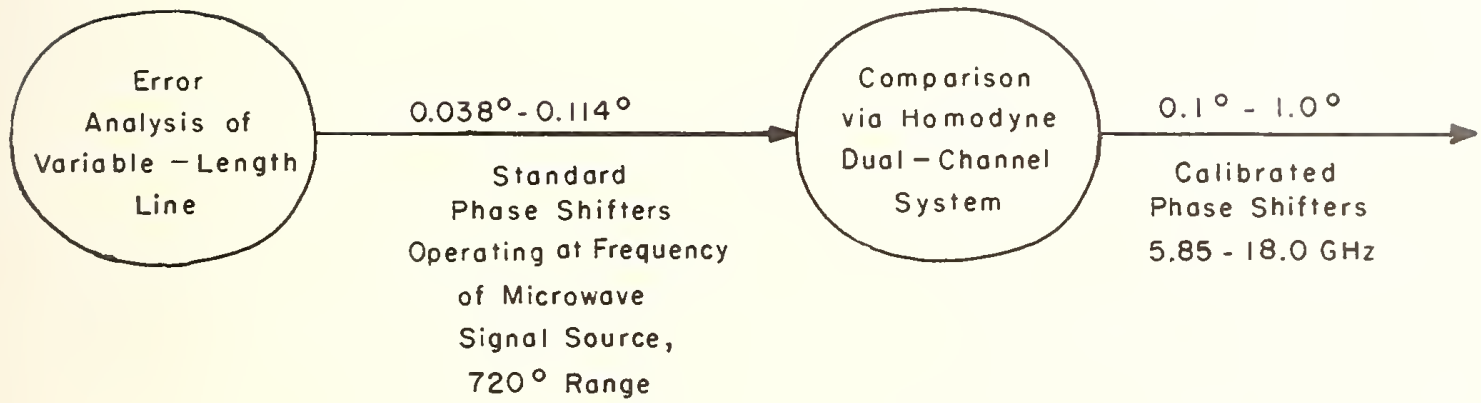


PHASE SHIFT IN WAVEGUIDE PHASE SHIFTERS

\section{ERROR FLOW DIAGRAM}

FREQUENCY $5.85-18.0 \mathrm{GHz}$ WR 62, WR 90 and WR 137
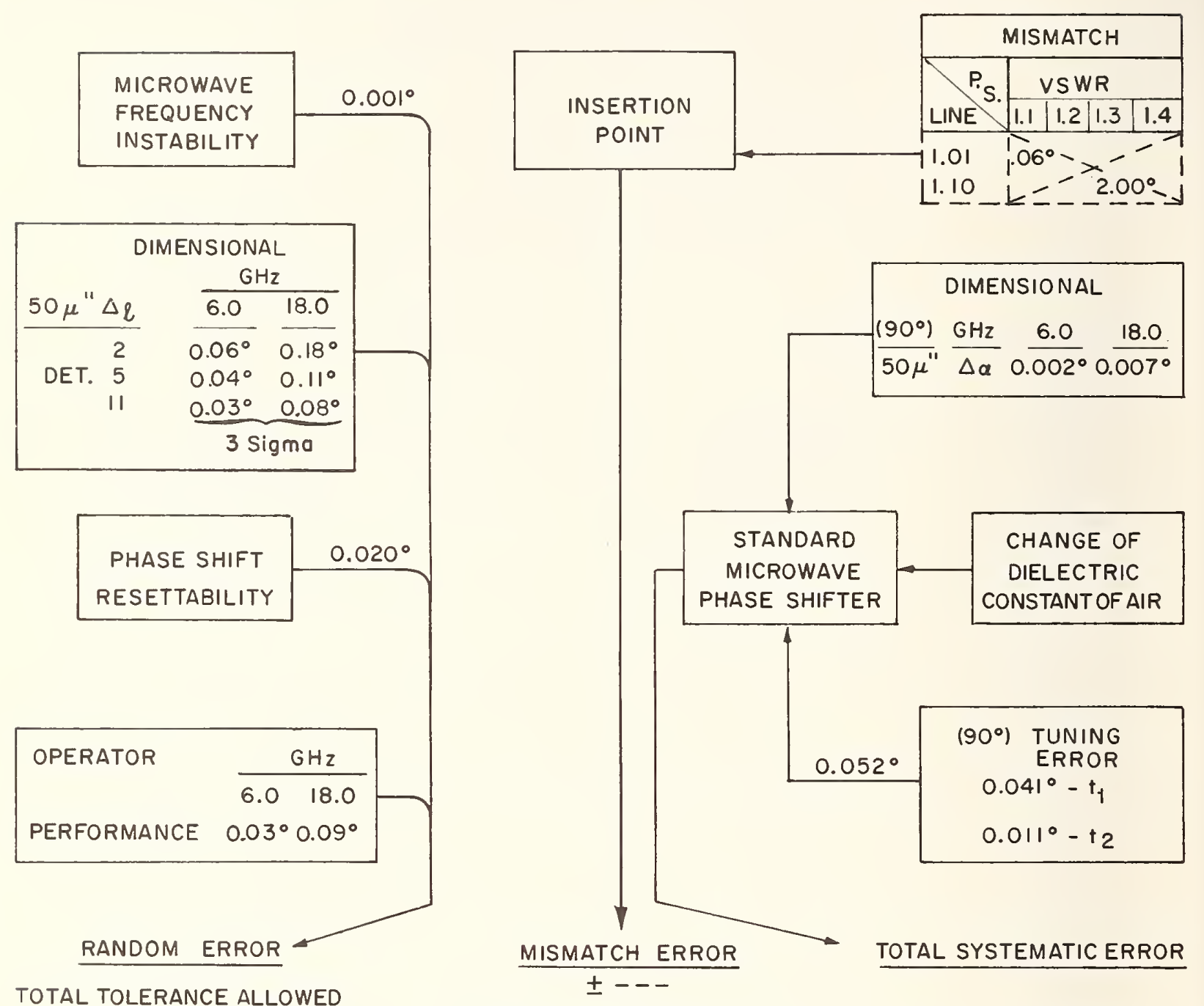

TOTAL TOLERANCE ALLOWED

\begin{tabular}{|c|c|c|}
\multicolumn{3}{|c|}{3 Sigma } \\
\hline Det. & \multicolumn{2}{|c|}{$6.0^{\mathrm{GHz}} 18.0$} \\
\hline 2 & $0.11^{\circ}$ & $0.29^{\circ}$ \\
\hline 5 & $0.09^{\circ}$ & $0.22^{\circ}$ \\
\hline 11 & $0.08^{\circ}$ & $0.19^{\circ}$ \\
\hline
\end{tabular}

\begin{tabular}{|c|c|c|c|c|}
\hline \multirow{2}{*}{ P. S. } & \multicolumn{4}{|c|}{ VS WR } \\
\cline { 2 - 5 } & 1.10 & 1.20 & 1.30 & 1.40 \\
\hline 1.01 & $.060^{\circ}$ & $.110^{\circ}$ & $.150^{\circ}$ & $.195^{\circ}$ \\
\hline 1.02 & $.120^{\circ}$ & $.210^{\circ}$ & $.300^{\circ}$ & $.400^{\circ}$ \\
\hline 1.05 & $.320^{\circ}$ & $.560^{\circ}$ & $.810^{\circ}$ & $.960^{\circ}$ \\
\hline 1.10 & $.780^{\circ}$ & $1.25^{\circ}$ & $1.60^{\circ}$ & $2.00^{\circ}$ \\
\hline
\end{tabular}

\begin{tabular}{|c|c|c|}
\hline$\phi$ & \multicolumn{2}{|c|}{$\mathrm{GHz}$} \\
& 6.0 & 18.0 \\
\hline $90^{\circ}$ & $0.055^{\circ}$ & $0.056^{\circ}$ \\
\hline $180^{\circ}$ & $0.079^{\circ}$ & $0.081^{\circ}$ \\
\hline $360^{\circ}$ & $0.011^{\circ}$ & $0.013^{\circ}$ \\
\hline
\end{tabular}

TOTAL UNCERTAINTY IS ARITHMETICAL SUM (LIKE SIGNS) OF THE RANDOM ERROR, AND TOTAL SYSTEMATIC ERROR

TO CUSTOMER 
Phase Shift in Waveguide Phase Shifters

$$
\begin{aligned}
& 5.85-18 \mathrm{GHz} \\
& 0-720 \text { degrees }
\end{aligned}
$$

Bias Uncertainties:

\section{Random Errors:}

Total Uncertainty:
See Error Flow Diagram, page 28-1

Uncertainty quoted customer: Same as Total Uncertainty.

Notes: The VSWR of the phase shifter must be less than 1.5. Resolution of the phase shifter should be $0.5^{\circ}$ or better.

Reference: D. A. Ellerbruch, Evaluation of a mic rowave phase measurement system, J. Res. NBS, 6으, 55 (1965).

Personnel: W. Larson

E. D. Hall 


\section{REFLECTION COEFFICIENT MAGNITUDE OF WAVEGUIDE DEVICES}

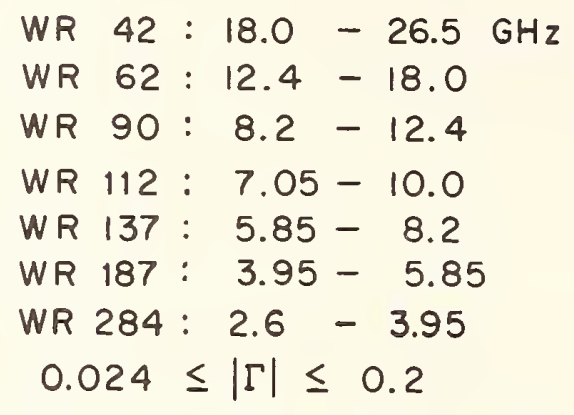

Power Level : $0.01 \mathrm{~mW}$
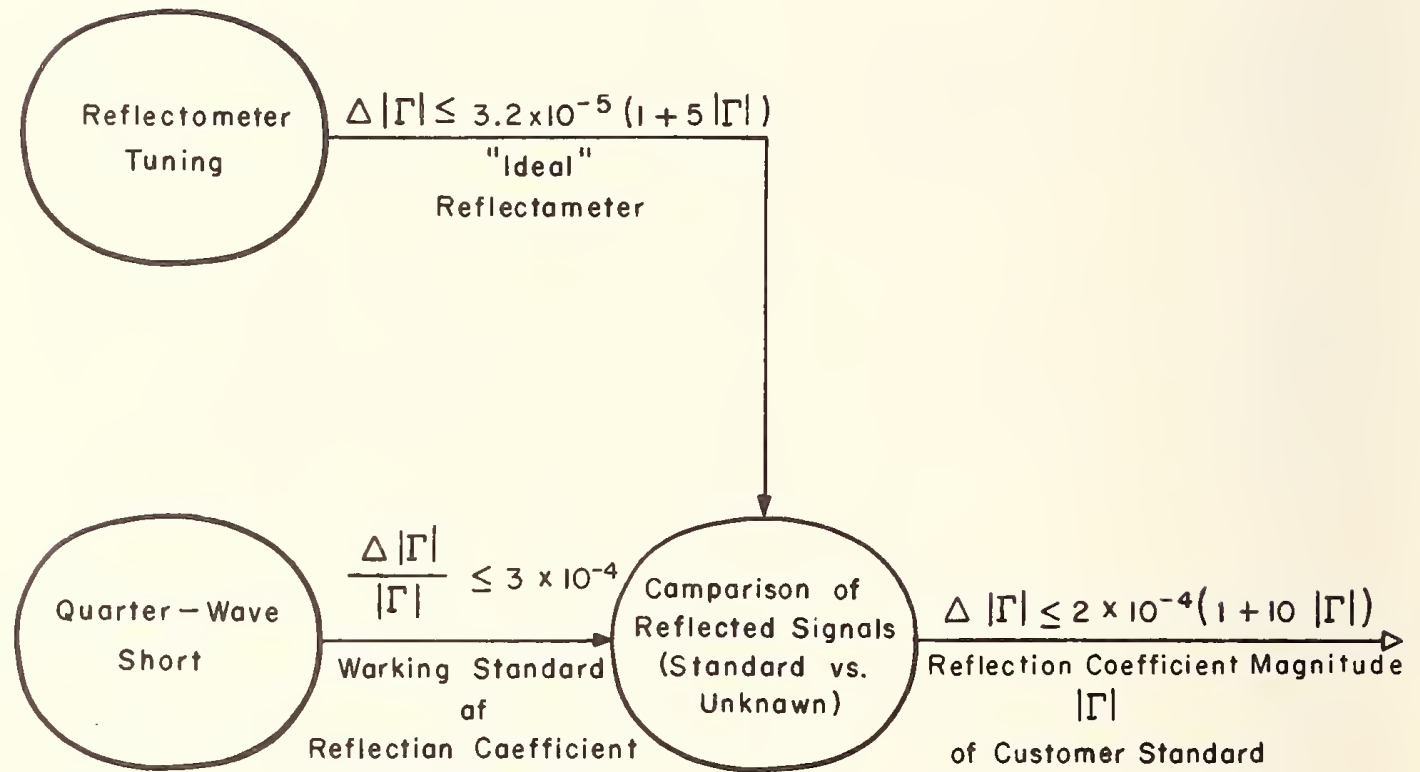
Magnitude $|\Gamma| \approx 1$

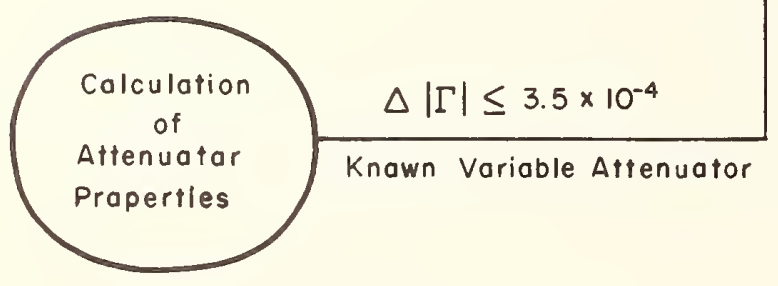


Reflection Coefficient Magnitude of Waveguide Devices

$\begin{array}{lcc}\text { WR 42: } & 18.0-26.5 \mathrm{GHz} \\ \text { WR 62: } & 12.4-18.0 \\ \text { WR 90: } & 8.2-12.4 \\ \text { WR 112: } & 7.05-10.0 \\ \text { WR 137: } & 5.85-8.2 \\ \text { WR 187: } & 3.95-5.85 \\ \text { WR 284: } 2.6-3.95 \\ \text { Power Level: } 0.01-4 \mathrm{~mW}\end{array}$

Bias Uncertainties:

Random Errors:

See Error Flow Diagrams, pages $30-2$ and 30-3

Total Uncertainty:

Uncertainty (typical) quoted customer: $|\Gamma| \geq 0.024$,

$$
\begin{aligned}
& \Delta|\boldsymbol{\Gamma}|=2 \times 10^{-4}(1+6|\boldsymbol{\Gamma}|) . \\
& |\boldsymbol{\Gamma}|<0.024 \\
& \Delta|\boldsymbol{\Gamma}|=2 \times 10^{-4}(1+10|\boldsymbol{\Gamma}|) .
\end{aligned}
$$

Notes: The uncertainties due to the precision waveguide section (see error flow diagrams, pages $30-2$ and $30-3$ ) are as follows:

$\begin{array}{cc}\text { Waveguide } & \text { Uncertainty in }|\Gamma| \\ \text { WR } 284 & <0.0001 \\ \text { WR } 187 & <0.0001 \\ \text { WR } 137 & <0.0001 \\ \text { WR } 112 & <0.0001 \\ \text { WR } 90 & <0.00015 \\ \text { WR 62 } & <0.0001 \\ \text { WR 42 (square flange) } & <0.0004 \\ \text { WR 42 (round flange) } & <0.0003\end{array}$

Reference: Wilbur J. Anson, A guide to the use of the modified reflectometer technique of VSWR measurement, J. Res. NBS, 65C, 217 (1961).

Personnel: B. C. Yates 


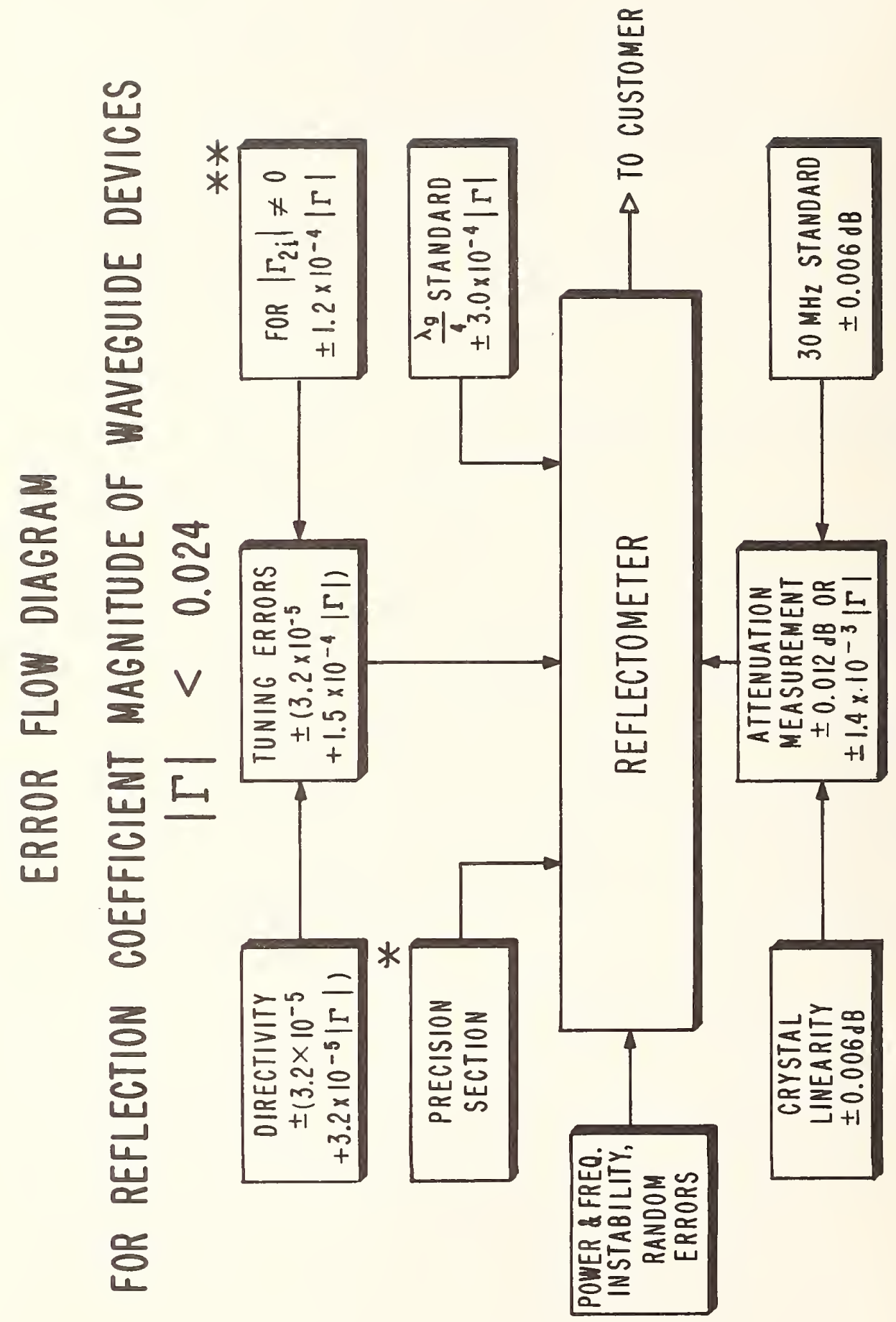

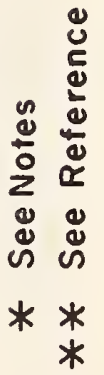




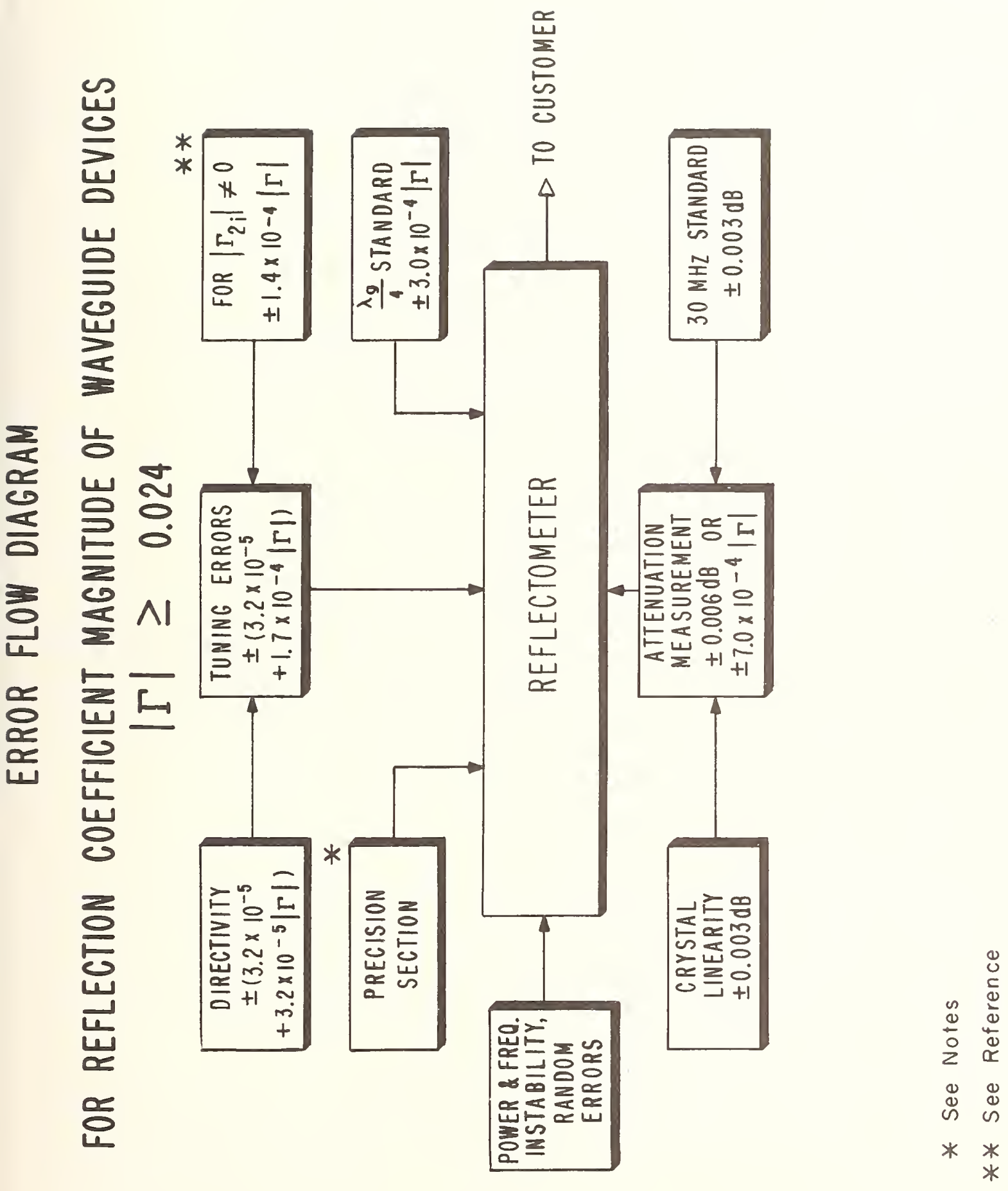




\section{DISTRIBUTED PARAMETERS IN COAXIAL SYSTEMS}

$$
0.5-8 \mathrm{GHz}
$$
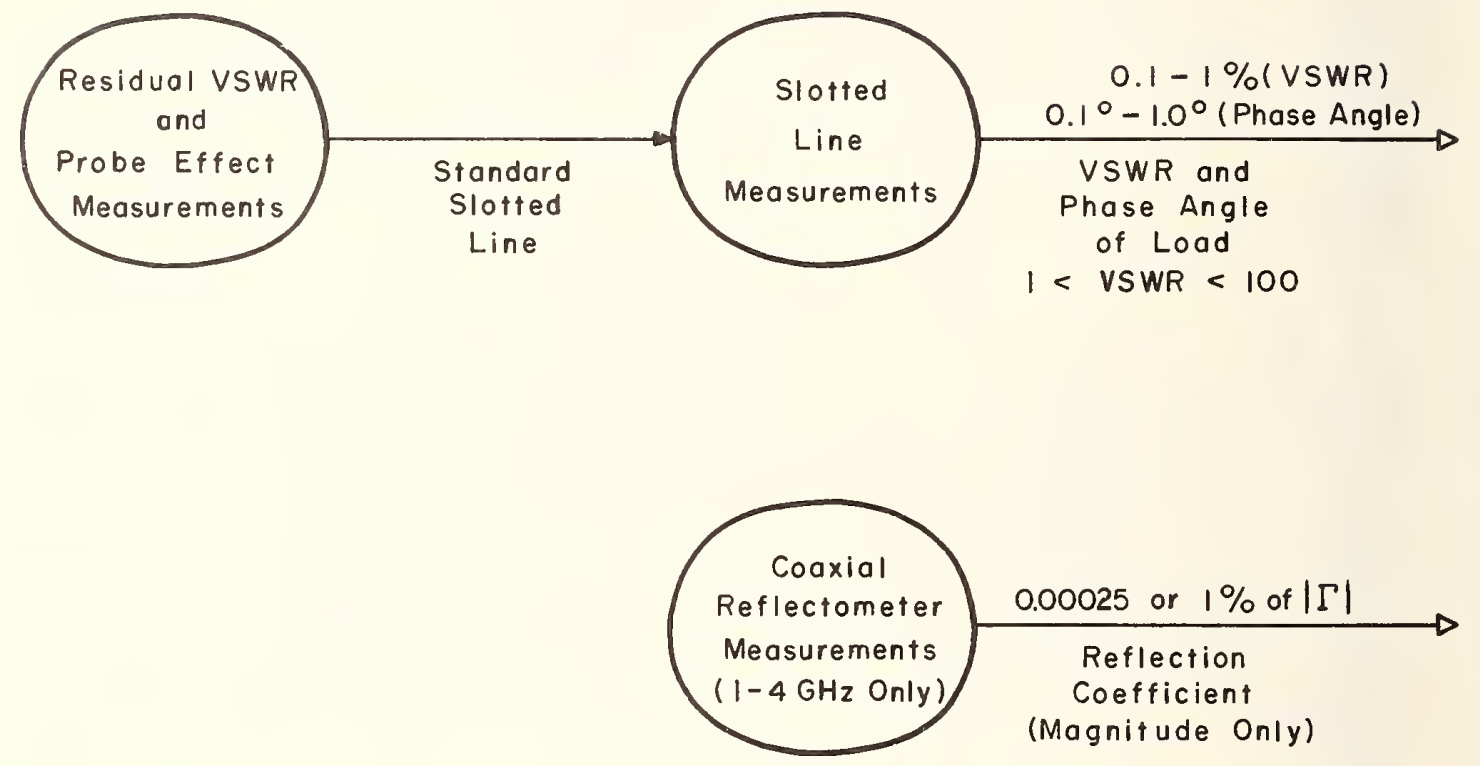
Distributed Parameters in Coaxial Systems

$$
0.5-8 \mathrm{GHz}
$$

SLOTTED LINE MEASUREMENTS:

$500 \mathrm{MHz}-8 \mathrm{GHz}$

$1 \leq \mathrm{VSWR} \leq 100$

Bias Uncertainties:

Residual VSWR

(a) Imperfect transition from connector to slotted line

(b) Variation in characteristic impedance

(c) Slot effects

Probe Effects

(a) Variation of probe coupling with probe position

(b) Probe loading of the slotted line

Line losses

Detector nonlinearity

Determination of the position of a voltage minimum

Power and frequency instability

Random Errors: Negligible

Total Uncertainty:

$0.1-1.0 \%$ for $1 \leq($ VSWR $) \leq 4$

0.1 - l degree (phase angle)

Uncertainty quoted customer: As above.

Notes: Page 31-2 gives some details of the error sources. Further details are available from R. L. Jesch (below).

Uncertainty figures assume precision $14 \mathrm{~mm}$ coaxial connectors. Uncertainties for other connectors and larger VSWR's will, in most cases, be larger.

Reference: R. L. Jesch and R. M. Jickling, Impedance measurements in coaxial waveguide systems, Proc. IEEE, 55, 912 (June 1967).

Personnel: R. L. Jesch 


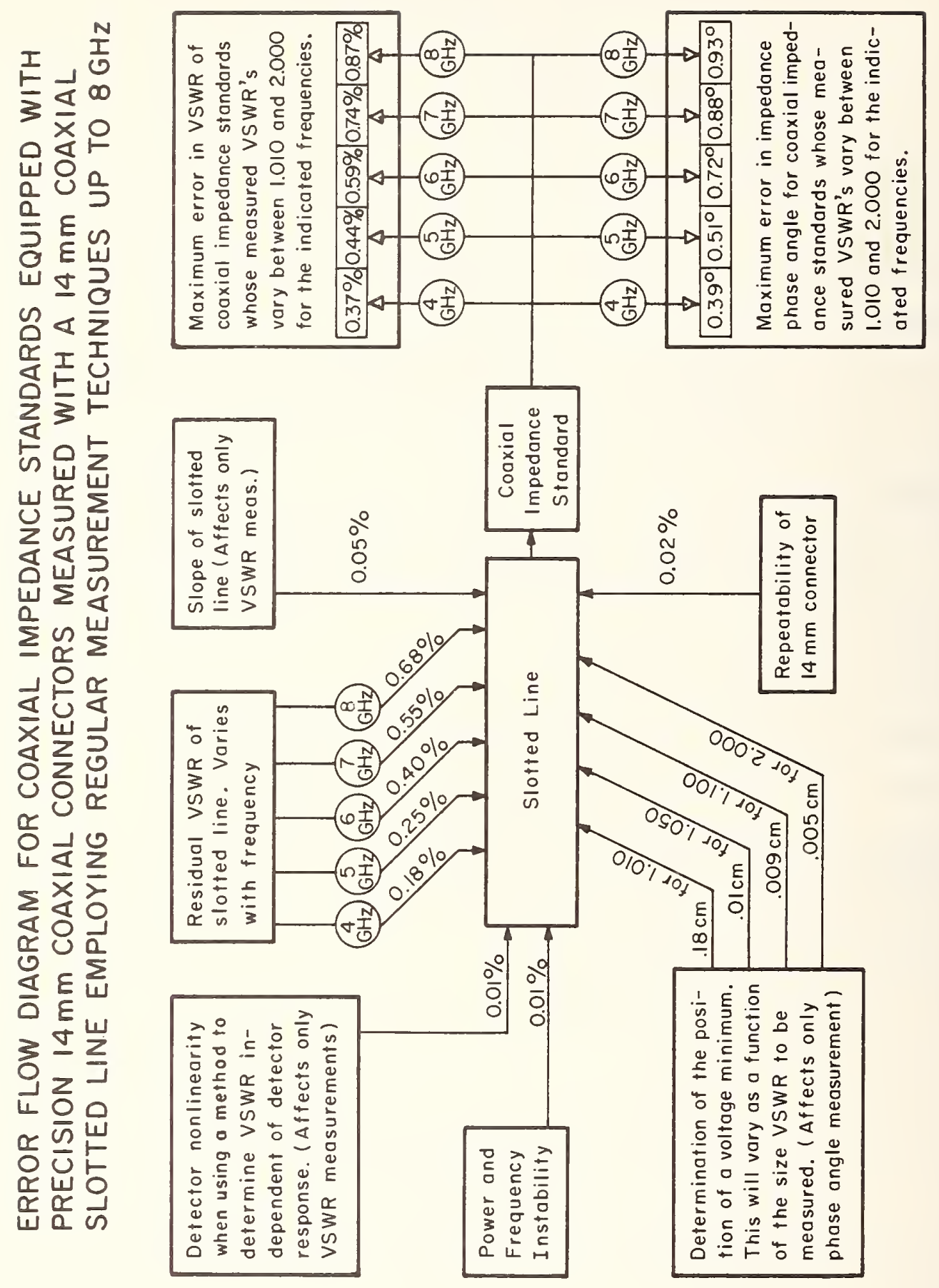


Distributed Parameters in Coaxial Systems

$1-4 \mathrm{GHz}$

COAXIAL REFLECTOMETER MEASUREMENTS:

$$
\begin{aligned}
& 1-4 \mathrm{GHz} \\
& 0 \leq|\Gamma| \leq 1
\end{aligned}
$$

Bias Uncertainties:

Tuning errors

Detector errors

Precision air-line section

Power and frequency instability

Random Errors: Negligible

Total Uncertainty:

$$
\begin{aligned}
& \text { for } 0 \leq|\Gamma| \leq 0.025: \Delta|\Gamma| \leq 0.00025 \\
& \text { for } 0.025 \leq|\leq| \leq|\Gamma| \leq 1 \%|\Gamma|
\end{aligned}
$$

Uncertainty_quoted customer: As above

Notes: In other than exacting standards work, or unless specially

requested, this measurement is rarely done for customers. Satisfactory results may be obtained at a much lower cost by the slotted-line technique.

Reference: W. E. Little and J. P. Wakefield, Measurement of Precision coaxial connectors using reflectometer techniques, IEEE International Conv. Rec., pt. 11, 89-97, March 1965.

Personnel: R. J. Jesch 


\section{HIGH FREQUENCY IMMITTANCE}

$$
\begin{aligned}
& 30 \mathrm{KHz}-300 \mathrm{MHz} \\
& \mathrm{C}: 10^{-12}-10^{-7} \mathrm{~F} \\
& \mathrm{~L}: 10^{-8}-1 \mathrm{H} \\
& \mathrm{R}: 0.1-10^{6} \Omega
\end{aligned}
$$

Effective Resonating Capacitance (Ce): $35 \times 10^{-17}-450 \times 10^{-2} \mathrm{~F}$ Effective Quality Factor (Qe) : $90-700$

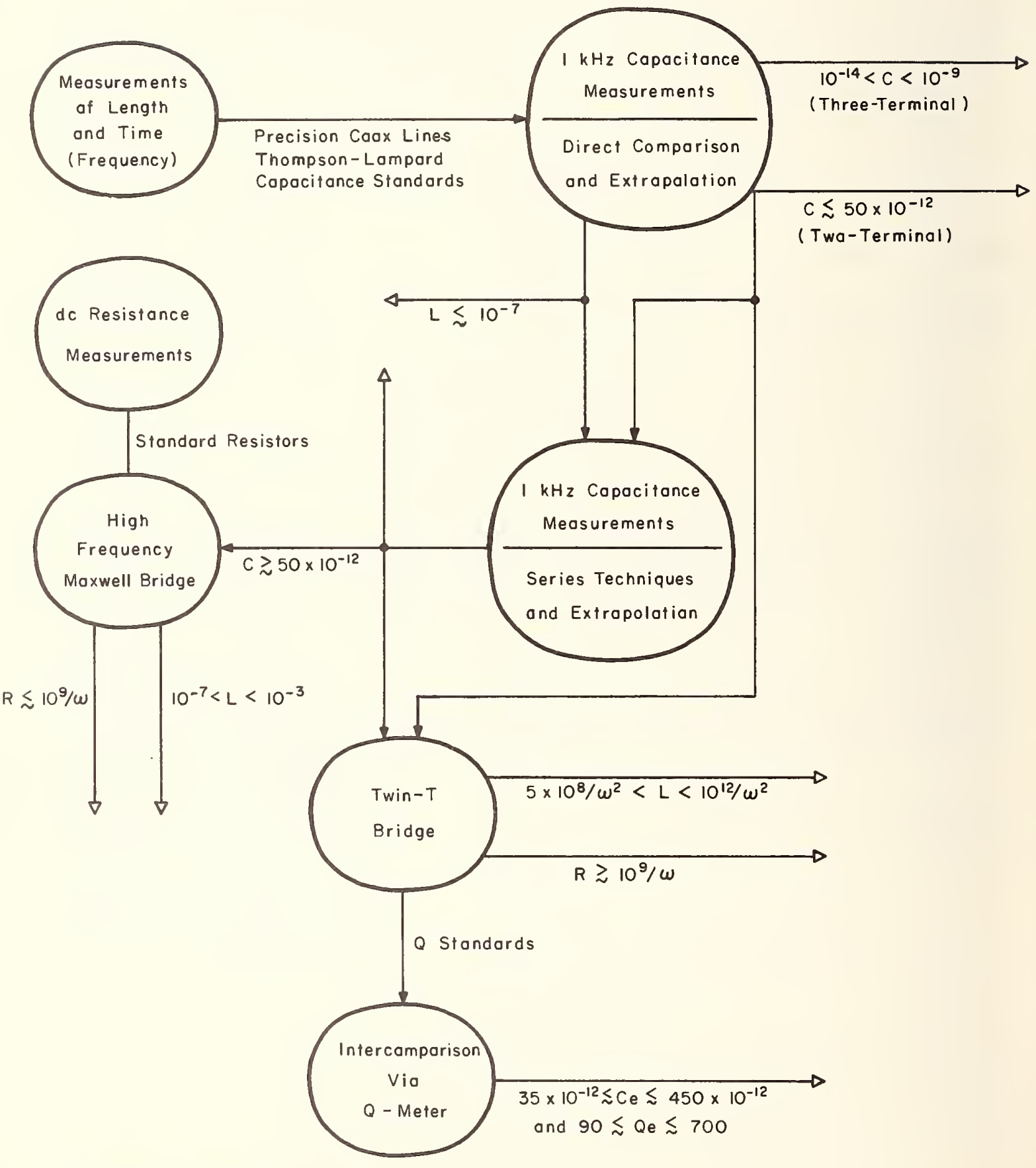

$\omega$ : Angulor Frequency 
High Frequency Immittance

$30 \mathrm{kHz}-300 \mathrm{MHz}$

$\begin{aligned} \text { Capacitance: } & 10^{-12}-10^{-7} \mathrm{~F} \\ \text { Inductance: } & 10^{-8}-16 \mathrm{H} \\ \text { Resistance: } & 0.1-10^{6} \Omega\end{aligned}$

Bias Uncertainties:

Null detection

Generator frequency stability

Mechanical errors (e.g., gears)

Connectors

Random Errors: 0.01 to $0.05 \%$ (see Notes).

Total Uncertainty:

Capacitance (2 terminal)

$0.1-0.5 \%$

Capacitance (3 terminal, see Notes)

$0.01-2 \%$

Induc tance

$0.1-20 \%$

Resistance

$0.1-10 \%$

Uncertainty quoted customer: Quoted as estimated for each individual case.

Notes: The 3-terminal capacitance measurements are made only in the frequency range $100 \mathrm{kHz}-1 \mathrm{MHz}$, and in the capacitance range 0.01 $1000 \mathrm{pF}$.

A more detailed listing of the uncertainties as a function of frequency and value of the immittance is available from $R$. N. Jones or R. E. Nelson (below).

The distribution of random errors depends strongly on the nature of the device being calibrated. In the field of immittance there is little uniformity in the transfer standards used throughout the industry. Thus, it is not generally possible for NBS to give information on random errors based on a large amount of experience with a particular type of transfer standard.

The uncertainties are stated on the basis of the use of precision connectors, which are not always used on devices NBS is asked to calibrate. Where precision connectors are not used the errors can be considerably larger than those quoted.

The uncertainties listed under bias uncertainties above apply to all bridge measurements shown on page 32 . 
The chart on page 32 shows the most commonly used sequence of measurements. The procedure varies somewhat for specific frequencies and magnitudes.

Reference: L. F. Huntley and R. N. Jones, Lumped parameter impedance measurements, Proc. IEEE 55, 900 (1967).

Personnel: R. N. Jones

R. E. Nelson 
Quality Factor and Effective Resonating Capacitance $50 \mathrm{kHz}-45 \mathrm{MHz}$

Ranges: Effective Quality Factor ( $\left.Q_{\text {f }}\right): 100-700$

Effective Resonating Capacitance $\left(C_{\mathrm{e}}\right): 30-500 \mathrm{pF}$

Bias Uncertainties:

Inductance and resistance measurements using NBS standards

Connector errors

Random Errors: See Notes

Effective resonating capacitance $\left(\mathrm{C}_{\mathrm{e}}\right) \quad 0.15-0.5 \%$

Effective quality factor $\left(\mathrm{Q}_{\mathrm{e}}\right) \quad 0.8-2.3 \%$

Total Uncertainty: See Notes

Uncertainty quoted customer: Same as Random Errors. See Notes.

Notes: The Q standards calibrated by NBS are used largely to establish measurement agreement, with less concern with the absolute accuracy of the measurement of quality factor or effective resonating capacitance. The bias uncertainties are believed to be about the same as the random errors stated above, except for $Q$ above $5 \mathrm{MHz}$, where difficulties due to connectors and measurement of small resistances become more severe.

As in the immittance standards calibrated by NBS, the uncertainties associated with connectors other than precision connectors are serious.

A more detailed display of the uncertainties as a function of frequency and magnitude of the parameter being measured is available from R. N. Jones or R. E. Nelson (below).

Reference: R. N. Jones, Standards for the calibration of Q-meters, $50 \mathrm{kHz}$ to $45 \mathrm{MHz}$, J. Res. NBS, 68C, 243 (1964).

Personnel: R. N. Jones

R. E. Nelson 
LARGE

COMPLEX RELATIVE DIELECTRIC PERMITTIVITY

$$
\begin{gathered}
30 \mathrm{kHz}-100 \mathrm{MHz} \\
\text { Ranges: } \epsilon^{\prime} \text { (Real Part) }>1 \\
10^{-2}<\tan \delta \text { (Loss Tangent) }<10^{2} \\
\text { Frequencies : } 30 \mathrm{kHz}-100 \mathrm{MHz}
\end{gathered}
$$

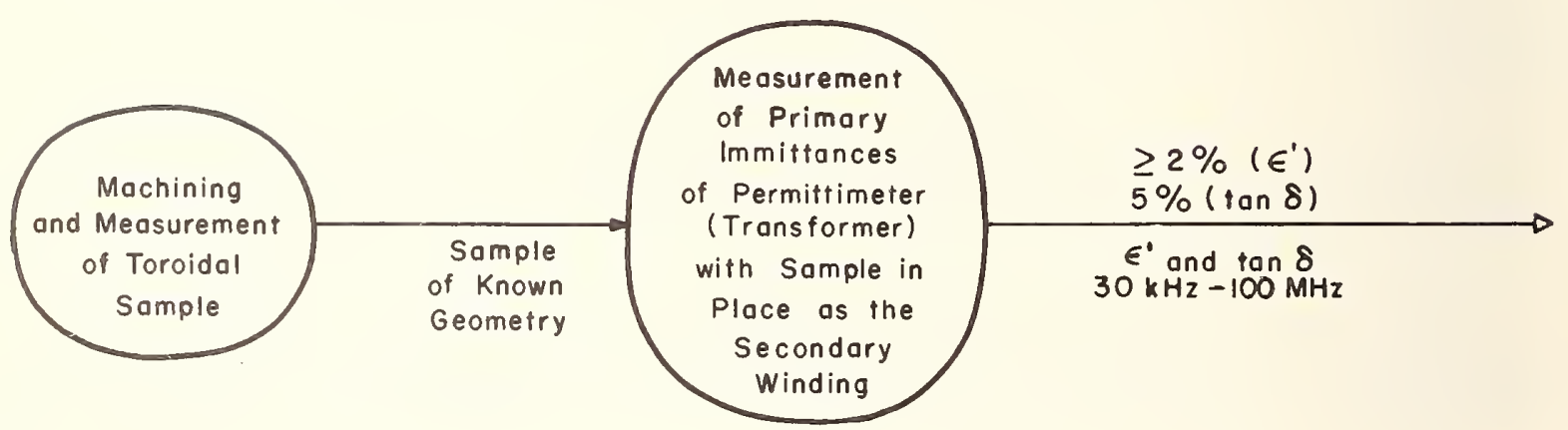




\section{PERMITTIMETER MEASUREMENT:}

$30 \mathrm{kHz}-100 \mathrm{MHz}$

$$
\begin{aligned}
\text { Range: } \epsilon^{\prime} & >10^{14} /[\mathrm{f}(\mathrm{Hz})]^{1.5} \\
\sigma & >10^{4} /[\mathrm{f}(\mathrm{Hz})]^{0.5} \\
10^{-2} & <\tan \delta<10^{2} \text { (see Notes) }
\end{aligned}
$$

\section{Bias Uncertainties:}

Toroidal sample geometry

Reproducibility of making and breaking magnetic circuit

Immittance measurements on primary winding of permittimeter

Random Errors: Not reported.

Total Uncertainty: $\epsilon^{\prime}: \geq 2 \%$

$$
\tan \delta: \geq 5 \%
$$

Uncertainty quoted customer: Same as Total Uncertainty.

Notes: The range of $\tan \delta$ is approximate. The specified rather large values of either $\epsilon^{\prime}$ or $\delta$, to give either displacement or real currents, is a fundamental requirement.

Reference: R. C. Powell and A. L. Rasmussen, A radio frequency permittimeter, IRE Trans. Instr., I-9, 179 (1960).

Personnel: H. E. Bussey 


\section{HIGH FREQUENCY}

\section{RELATIVE DIELECTRIC PERMITTIVITY, REAL PART}

$30 \mathrm{kHz}-1 \mathrm{GHz}$

Range : $1-10^{4}$

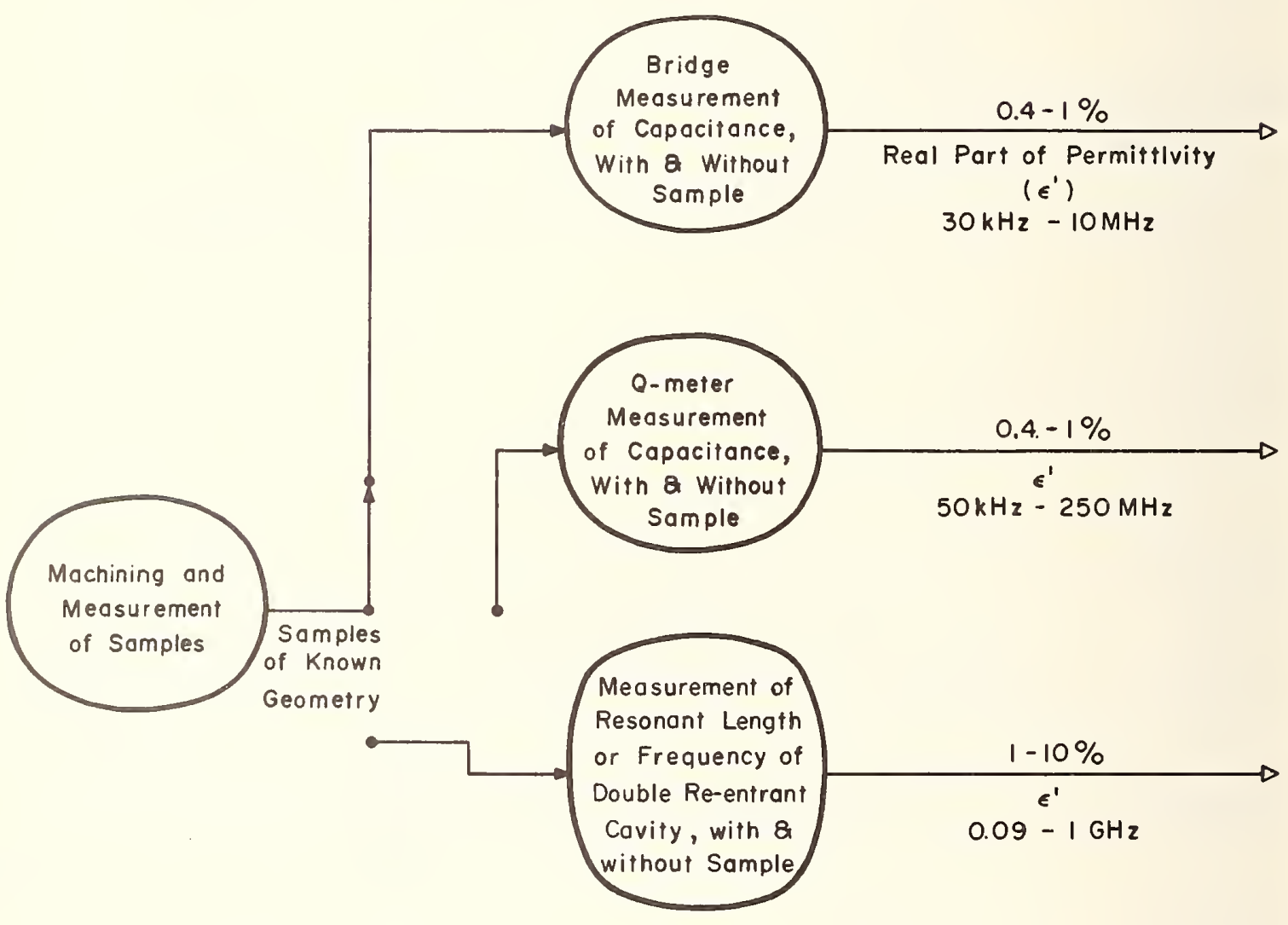


High Frequency Relative Dielectric Permittivity, Real Part, ‘ '

BRIDGE MEASUREMENT:

Capacitor-type sample holder

$30 \mathrm{kHz}-10 \mathrm{MHz}, \quad 1<\epsilon^{1}<10^{4}$

Bias Uncertainties:

Capacitance (see Notes)

$0.05 \%$

Lead inductance

negligible

Fringing capacitance

Sample geometry (see Notes)

Sample stability including humidity effects

negligible

Interaction of real and imaginary parts

$0.5\left(10^{-2} / \mathrm{t}\right) \%$

negligible

negligible

Random Errors:

not reported

Total Uncertainty:

$\left[0.05+0.5\left(10^{-2} / t\right)\right] \%$

Uncertainty quoted customer: $\quad 0.4-1 \%$

Notes: The capacitance measurement is a change in capacitance, with and without the sample. The error depends upon the thickness of the sample and upon $\epsilon^{\prime}$.

The sample geometry uncertainty depends upon the thickness of the sample, t, which is approximately 0.1 inch.

Reference: H. E. Bussey, Measurements of RF properties of materials, a survey, Proc. IEEE, 55, 1046 (June 1967).

Personnel: H. E. Bussey 
High Frequency Relative Dielectric Permittivity, Real Part, $\epsilon^{\prime}$ Q-METER MEASUREMENT:

Capacitor-type sample holder

$50 \mathrm{kHz}-250 \mathrm{MHz}, 1<\epsilon^{\mathrm{\gamma}}<10^{4}$

Bias Uncertainties:

Capacitance (see Notes)

$0.05 \%$

Lead inductance

Fringing capacitance

negligible

Sample geometry

negligible

Sample stability

$0.5\left(10^{-2} / t\right) \%$

Indirection of real and imaginary parts negligible negligible

Random Errors:

not reported

Total Uncertainty:

$\overline{\left[0.05+0.5\left(10^{-2} / \mathrm{t}\right)\right] \%}$

Uncertainty quoted customer: $0.4-1 \%$

Notes: The capacitance measurement is a change in capacitance, with and without the sample. The error depends upon the thickness of the sample and upon $\epsilon^{\prime}$.

The sample geometry uncertainty depends upon the thickness of the sample, $t$, which is approximately 0.1 inch.

Reference: See page 34-1

Personnel: H. E. Bussey 
High Frequency Relative Dielectric Permittivity, Real Part, $\epsilon^{\prime}$ RE-ENTRANT CAVITY MEASUREMENT:

Capacitive gap in coaxial transmission line $0.09-1 \mathrm{GHz}, \quad 1<\epsilon^{\prime}<10^{4}$

\section{Bias Uncertainties:}

Capacitance

Sample geometry, including foil contact

Fringing fields

Random Errors:

Total Uncertainty:
0.2 to $0.5 \%$

$2(10-2 / t) \%$

$0.2 \%$

not quoted

$\left[0.4\right.$ to $\left.0.7+2\left(10^{-2} / \mathrm{t}\right)\right] \%$

Uncertainty quoted customer: $\quad 1-10 \%$

Notes: The sample thickness, $t_{2}$ is approximately 0.05 inch.

Reference: $\quad$ See page 34-1

Personnel: H. E. Bussey 


\title{
HIGH FREQUENCY DIELECTRIC LOSS
}

\author{
$30 \mathrm{kHz}-1 \mathrm{GHz}$ \\ Range : $10^{-4}-10^{3}(\tan \delta)$
}

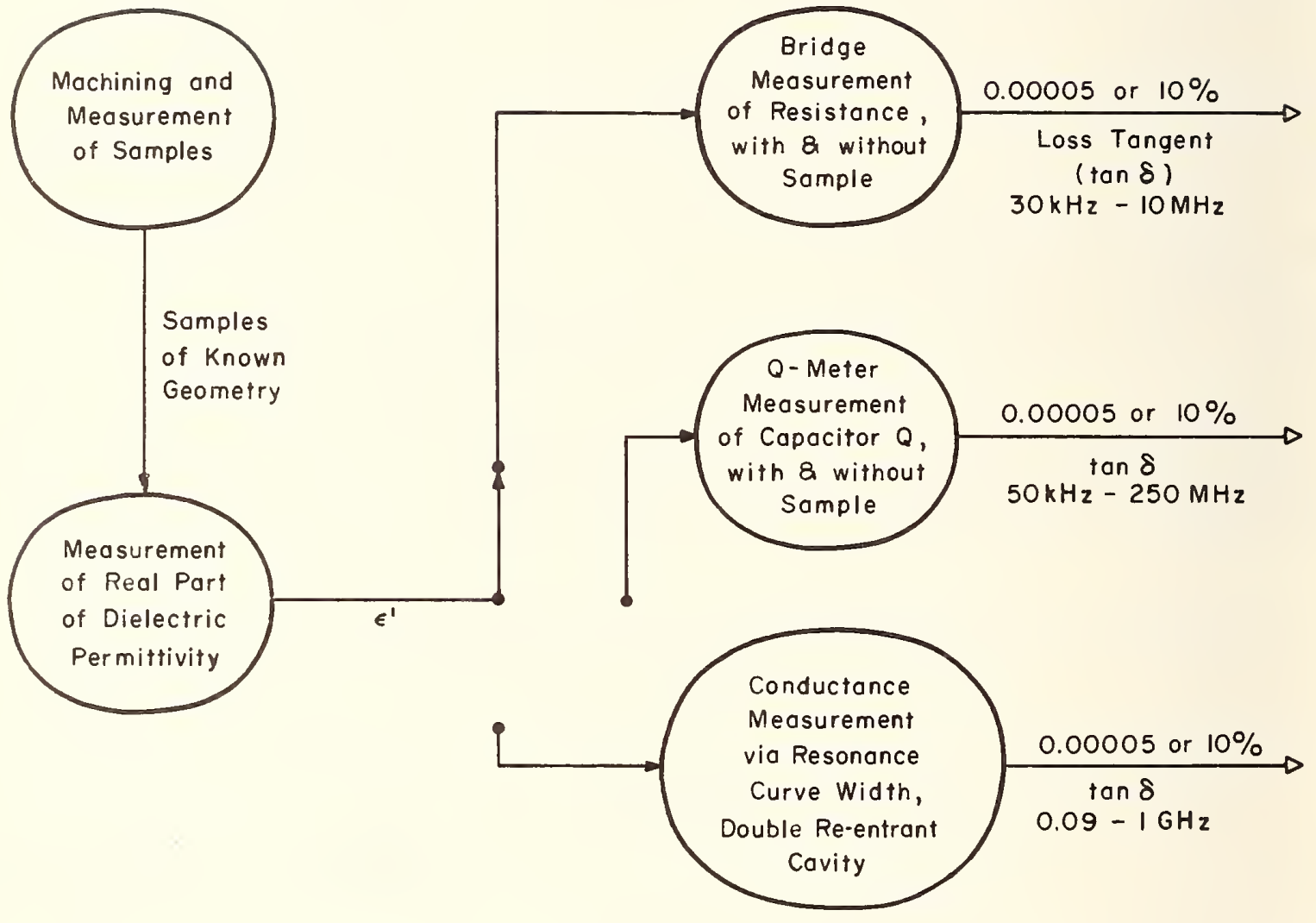


BRIDGE MEASUREMENTS:

Capacitox-type sample holder

$30 \mathrm{kHz}-10 \mathrm{MHz}, 10^{-4}<\tan \delta<10$

Bias Uncertainties:

Sample geometry

Bridge measurement of conductance

Random Errors:

Total Uncertainty:
0.5 to $1 \%$

$2 \%$

$5 \times 10^{-3} / \tan \delta \%$

$\left[2.5\right.$ to $\left.3+5 \times 10^{-3} / \tan \delta\right] \%$

Uncertainty quoted customer: $\quad 0.00005$ or 10\%, whichever is larger.

Notes: None

Reference: See page 34-1

Personnel: H. E. Bussey 
Q-METER MEASUREMENT:

Capacitor-type sample holder

$50 \mathrm{kHz}-250 \mathrm{MHz}, 10^{-4}<\tan \delta<10$

Bias Uncertainties:

Geometry of sample

0.5 to $1 \%$

Q-meter measurement $5 \%$

Random Errors:

$5 \times 10^{-3} / \tan \delta \%$

Total Uncertainty:

$\overline{\left[5.5 \text { to } 6+5 \times 10^{-3} / \tan \delta\right] \%}$

Uncertainty quoted customer: 0.00005 or $10 \%$, whichever is larger.

Notes: By special request, loss tangents as low as 0.00001 are measured.

Reference: See page 34-1.

Personnel: H. E. Bussey 
RE-ENTRANT CAVITY MEASUREMENT:

Capacitive gap in coaxial transmission line $0.09-1 \mathrm{GHz}, 10^{-4}<\tan \delta<1$

Bias Uncertainties:

Attenuation measurement

$0.3 \%$

Sample geometry

1 to $2 \%$

Q measurement, including attenuation errors

2 to $3 \%$

Bias from unknown sources (see Notes)

$4 \times 10^{-2} / \tan \delta \%$

Random Errors:

not quoted

Total Uncertainty:

$\overline{\left[3 \text { to } 5+4 \times 10^{-2} / \tan \delta\right] \%}$

Uncertainty quoted customer: 0.00005 or $10 \%$, whichever is larger.

Notes: There are some bias errors from sources which have not yet been identified. Their total magnitude is determined by calibration against samples having known loss tangents.

Reference: See page 34-1.

Personne1: H. E. Bussey 


\title{
MICROWAVE \\ COMPLEX RELATIVE DIELECTRIC PERMITTIVITY \\ Dielectric Loaded Transmission Lines
}

\author{
$0.3-8.6 \mathrm{GHz}$ \\ Range: $1-20$ (Real Part) \\ $10^{-4}-10^{-1}$ (Loss Tangent)
}

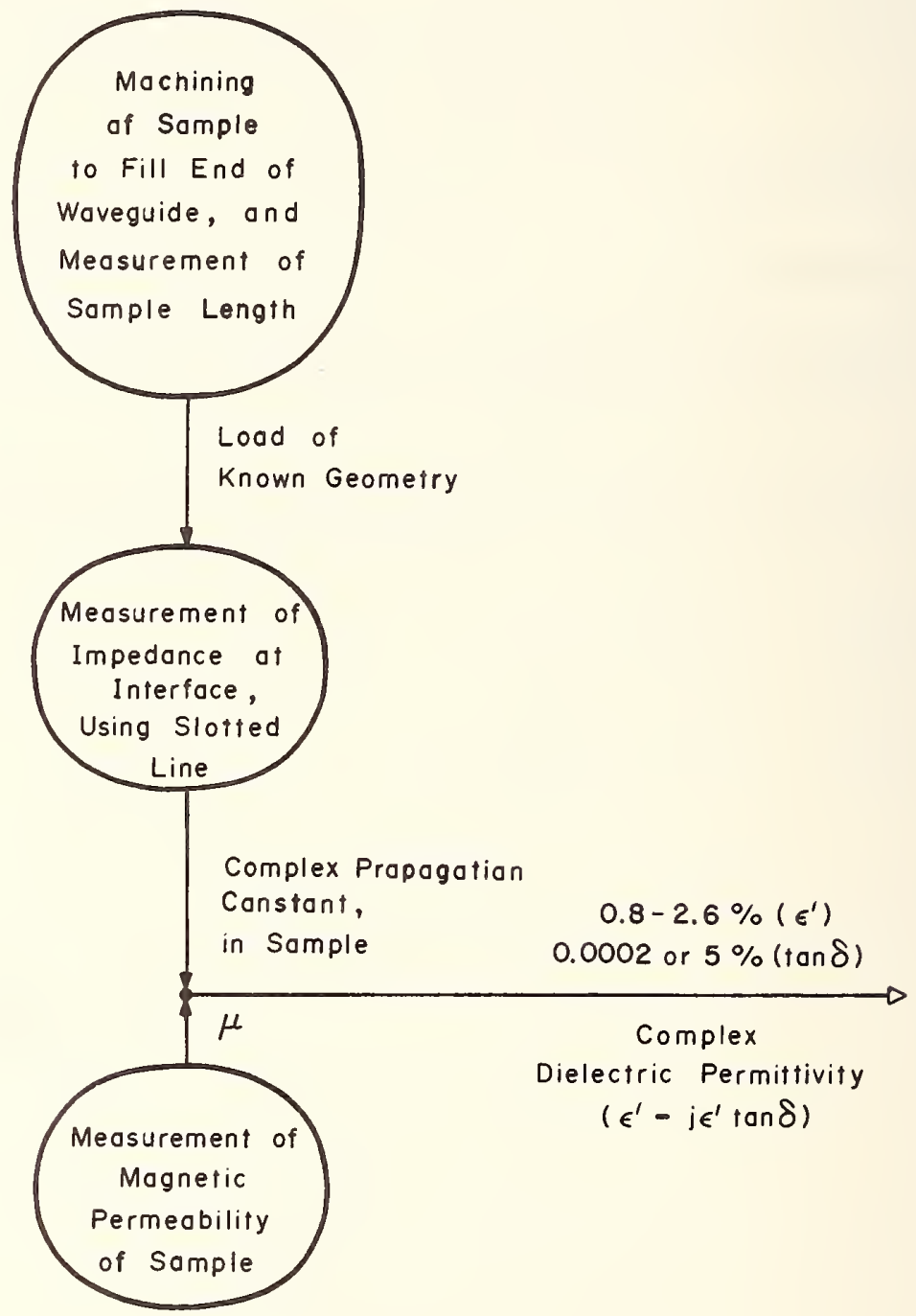


Mic rowave Complex Relative Dielectric Permittivity, Real Part, $\epsilon^{\prime}$

\section{DIELECTRIC LOADED TRANSMISSION LINES:}

Slotted line impedance measurements

$0.3-8.6 \mathrm{GHz}$

Bias Uncertainties

Sample dimensions

Gap errors around sample

Attenuation measurement

Probe position and wavelength measurements

Random Errors:

Total Uncertainty:
$0.5 \%$

0.2 to $2 \%$

negligible

$0.1 \%$

not reported

0.8 to $2.6 \%$

Uncertainty quoted customer: $0.8-2.6 \%$

Notes: The real and imaginary parts of the permittivity are determined together in this method, as shown by the diagram on page 36. However, the errors in the real and imaginary parts are not the same, and are therefore discussed separately on pages $36-1$ and $36-2$.

Reference: See page 34-1.

Personnel: H. E. Bussey 
Microwave Complex Relative Dielectric Permittivity, Loss Tangent

\section{DIELECTRIC LOADED TRANSMISSION LINES}

Slotted line impedance measurement

$0.3-8.6 \mathrm{GHz}$

Bias Uncertainties:

Contribution of magnetic permeability

0 to $1 \%$

Gap errors

0.2 to $2 \%$

"Law" of crystal

$2 \%$

Environment (see Notes)

$0.5 \%$

Random Errors:

not reported

Total Uncertainty:

3.5 to $5.5 \%$

Uncertainty of $\tan \delta$ quoted customer: 0.0002 or $5 \%$, whichever is larger.

Notes: Errors due to environment include foreign surface conductivity, temperature effects, etc.

Reference: See page 34-1

Personnel: H. E. Bussey 


\title{
MICROWAVE COMPLEX RELATIVE DIELECTRIC PERMITTIVITY \\ Transmission Cavities
}

\author{
$0.5,1,3,6,9$ and $30 \mathrm{GHz}$ \\ Range: $1-100$ (Real Part) \\ $10^{-4}-10^{-1}$ (Loss Tangent)
}

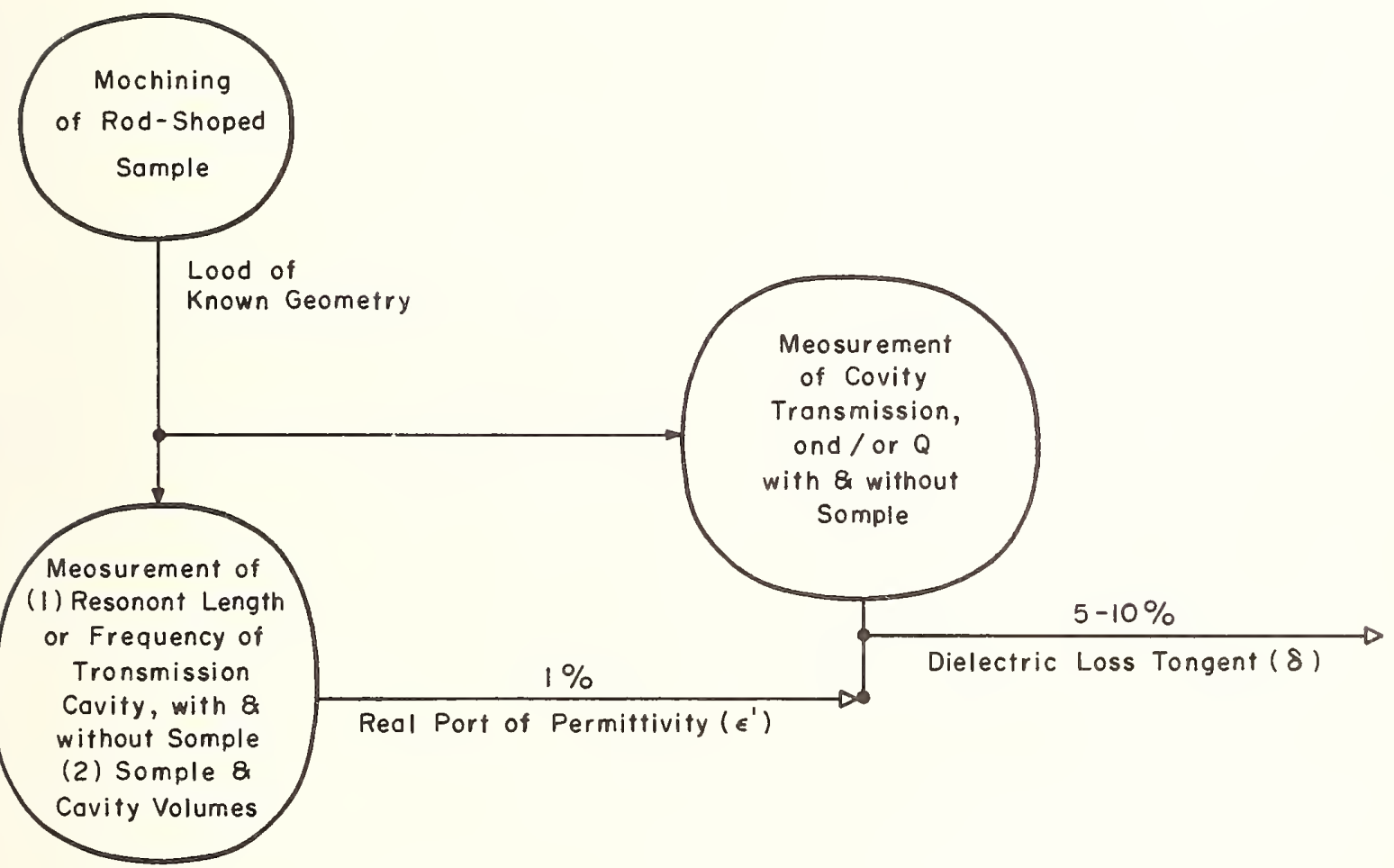


Microwave Complex Relative Dielectric Permittivity, Real Part, $\epsilon '$ TRANSMISSION CAVITIES:

$1<\epsilon^{\prime}<100$

$0.5,1,3,6,9$, and $30 \mathrm{GHz}$

Bias Uncertainties:

Volume measurements (sample volume and cavity volume)

Change in length or change in frequency

Misfit of sample in cavity

0.1 to $0.2 \%$

negligible

0.2 to $0.8 \%$

Random Errors:

not quoted

Total Uncertainty:

0.3 to $1 \%$

Uncertainty quoted customer: $\quad 0.3-1 \%$

Notes: $\mathrm{ATE}_{011}$ mode circular cavity resonator is used at 3,9 , and $30 \mathrm{GHz}$. Sample may be either a rod or a disk. At $0.5,1$, and $6 \mathrm{GHz}$ other modes are used, and the accuracy is lower than for the TE modes. Results are based on exact solutions for a rod and disk. 'Either a complex propagation constant may be used when the loss is high, or the real and imaginary parts may be calculated separately.

Reference: See page 34-1

Personnel: H. E. Bussey 
Microwave Complex Relative Dielectric Permittivity, Loss Tangent TRANSMISSION CAVITIES:

$10^{-4}-10^{-1}$

$0.5,1,3,6,9$ and $30 \mathrm{GHz}$

Bias Uncertainties:
Attenuation
$0.3 \%$
Q measurement, including attenuation errors
1 to $2 \%$
Gap errors
$1 \%$
Environment
Bias from unknown sources
see Notes
$\left[4 \times 10^{-3} / \tan \delta\right] \%$
not reported

Random Errors:

Total Uncertainty:

$\left[2.5\right.$ to $\left.3.5+4 \times 10^{-3} / \tan \delta\right] \%$

Uncertainty quoted customer: $5-10 \%$

Notes: Environmental errors include foreign surface conductivity, temperature effects, etc. Their magnitudes are not well known.

There are some bias errors from sources which have not yet been identified. Their total magnitude is determined by calibration against samples having known loss tangents.

The transmission coefficient of the cavity is often used to obtain the loss; see reference below.

Also, see Notes on page $37-1$.

Reference: H. E. Bussey, Cavity resonator dielectric measurements on rod samples, 1959 Annual Report, Conference on Electrical Insulation, National Academy of Sciences, Publication 756 of the National Research Council.

Personnel: H. E. Bussey 



\section{PERIODICALS}

JOURNAL OF RESEARCH reports National Bureau of Standards research and development in physics, mathematics, chemistry, and engineering. Comprehensive scientific papers give complete details of the work, including laboratory data, experimental procedures, and theoretical and mathematical analyses. Illustrated with photographs, drawings, and charts.

\section{Published in three sections, available separately:}

\section{- Physics and Chemistry}

Papers of interest primarily to scientists working in these fields. This section covers a broad range of physical and chemical research, with major emphasis on standards of physical measurement, fundamental constants, and properties of matter. Issued six times a year. Annual subscription: Domestic, $\$ 9.50$; foreign, $\$ 11.75^{*}$.

\section{Mathematical Sciences}

Studies and compilations designed mainly for the inathematician and theoretical physicist. Topics in mathenatical statistics, theory of experiment design, nunierical analysis, theoretical physics and chemistry, logical design and programming of computers and computer systems. Short numerical tables. Issued quarterly. Annual subscription: Domestic, $\$ 5.00$; foreign, $\$ 6.25 *$.

\section{Engineering and Instrumentation}

Reporting results of interest chiefly to the engineer and the applied scientist. This section includes many of the new developments in instrumentation resulting from the Bureau's work in physical measurement, data processing, and development of test methods. It will also cover some of the work in acoustics, applied mechanics, building research, and cryogenic engineering. Issued quarterly. Annual subscription: Domestic, $\$ 5.00$; foreign, $\$ 6.25^{*}$.

\section{TECHNICAL NEWS BULLETIN}

The best single source of information concerning the Bureau's research, developmental, cooperative and publication activities, this monthly publication is designed for the industry-oriented individual whose daily work involves intimate contact with science and technology-for engineers, chemists, physicists, research managers, product-development managers, and company executives. Annual subscription: Domestic, $\$ 3.00$; foreign, $\$ 4.00 \%$.

\section{NONPERIODICALS}

Applied Mathematics Series. Mathennatical tables, manuals, and studies.

Building Science Series. Research results, test methods, and perfornıance criteria of building materials, components, systems, and structures.

Handbooks. Recommended codes of engineering and industrial practice (including safety codes) developed in cooperation with interested industries, professional organizations, and regulatory bodies.

Special Publications. Proceedings of NBS conferences, bibliographies, annual reports, wall charts, pamphlets, etc.

Monographs. Major contributions to the technical literature on various subjects related to the Bureau's scientific and technical activities.

National Standard Reference Data Series. NSRDS provides quantitive data on the physical and chemical properties of materials, compiled from the world's literature and critically evaluated.

Product Standards. Provide requirements for sizes, types, quality and methods for testing various industrial products. These standards are developed cooperatively with interested Government and industry groups and provide the basis for common understanding of product characteristics for both buyers and sellers. Their use is voluntary.

Technical Notes. This series consists of communications and reports (covering both other agency and NBS-sponsored work) of limited or transitory interest.

Federal Information Processing Standards Publications. This series is the official publication within the Federal Government for information on standards adopted and promulgated under the Public Law 89-306, and Bureau of the Budget Circular A-86 entitled, Standardization of Data Elements and Codes in Data Systems.

\section{CLEARINGHOUSE}

The Clearinghouse for Federal Scientific and Technical Information, operated by NBS, supplies unclassified information related to Government-generated science and technology in defense, space, atomic energy, and other national programs. For further information on Clearinghouse services, write:

Clearinghouse

U.S. Department of Commerce

Springfield, Virginia 22151
Order NBS publications from:

Superintendent of Documents

Government Printing Office

Washington, D.C. 20402 
U.S. DEPARTMENT OF COMMERCE

WASHINGTON, D.C. 20230

OFFICIAL BUSINESS

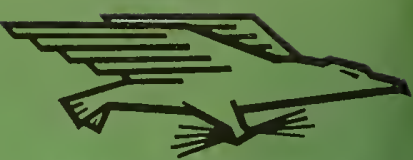

POSTAGE AND FEES PAID

U.S. DEPARTMENT OF COMMERCE 